ANA PAULA FRANCO DO AMARAL HVENEGAARD

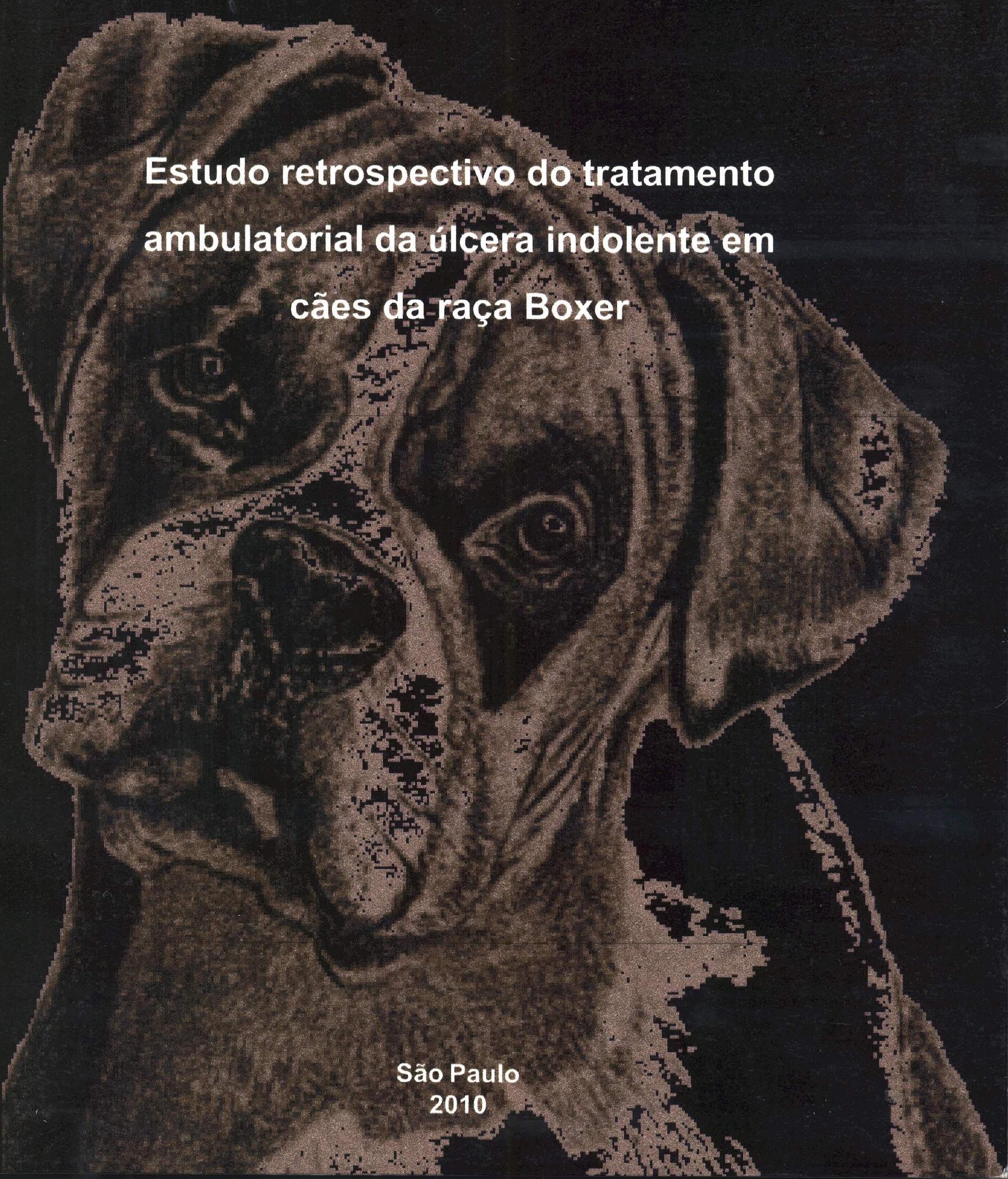




\section{Estudo retrospectivo do tratamento ambulatorial da úlcera indolente em cães da raça Boxer}

Dissertação apresentada ao Programa de Pós-Graduação em Clínica Cirúrgica Veterinária da Faculdade de Medicina Veterinária e Zootecnia da Universidade de São Paulo para obtenção do título de Mestre em Ciências

Departamento:

Cirurgia

Área de concentração:

Clínica Cirúrgica Veterinária

Orientador:

Prof. Dr. Paulo Sergio de Moraes Barros 
Autorizo a reprodução parcial ou total desta obra, para fins acadêmicos, desde que citada a fonte.

DADOS INTERNACIONAIS DE CATALOGAÇÃO-NA-PUBLICAÇÃO

(Biblioteca Virginie Buff D’Ápice da Faculdade de Medicina Veterinária e Zootecnia da Universidade de São Paulo)

Hvenegaard, Ana Paula Franco do Amaral

Estudo retrospectivo do tratamento ambulatorial da úlcera indolente em cães da raça Boxer / Ana Paula Franco do Amaral Hvenegaard. -- 2010.

99 f. : il.

Dissertação (Mestrado) - Universidade de São Paulo. Faculdade de Medicina Veterinária e Zootecnia. Departamento de Cirurgia, São Paulo, 2010.

Programa de Pós-Graduação: Clínica Cirúrgica Veterinária.

Área de concentração: Clínica Cirúrgica Veterinária.

Orientador: Prof. Dr. Paulo Sergio de Moraes Barros.

1. Úlcera indolente. 2. Boxer. 3. Tratamento. 4. Inibidores das proteinases. 5. Cães. I. Título. 


\section{UNIVERSIDADE DE SÃO PAULO}

\section{FACULDADE DE MEDICINA VETERINÁRIA E ZOOTECNIA}

Comissão de Etica no uso de animais

\section{CERTIFICADO}

Certificamos que o Projeto intitulado "Estudo retrospectivo dos casos de úlcera indolente em cães da raça Boxer", protocolado sob o n ${ }^{\circ}$ 1899/2010, utilizando número indeterminado de cães atendidos no HOVET/FMVZ/USP, sob a responsabilidade do Prof. Dr. Paulo Sérgio de Moraes Barros, está de acordo com os princípios éticos de experimentação animal da "Comissão de Ética no uso de animais" da Faculdade de Medicina Veterinária e Zootecnia da Universidade de São Paulo e foi aprovado em reunião de 07/04/ 2010.

We certify that the Research "Retrospective study of spontaneous chronic corneal epithelial defect in boxers", protocol number 1899/2010, under the responsibility Prof. Dr. Paulo Sérgio de Moraes Barros, agree with Ethical Principles in Animal Research adopted by "Ethic Committee in the use of animals" of the School of Veterinary Medicine and Animal Science of University of São Paulo and was approved in the meeting of day $04 / 07 / 2010$.

São Paulo, 08 de abril de 2010

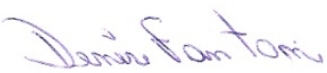

Profa. Dra. Denise Tabacchi Fantoni Presidente 
Nome: HVENEGAARD, Ana Paula Franco do Amaral

Título: Estudo retrospectivo do tratamento ambulatorial da úlcera indolente em cães da raça Boxer

Dissertação apresentada ao Programa de Pós-Graduação em Clínica Cirúrgica Veterinária da Faculdade de Medicina Veterinária e Zootecnia da Universidade de São Paulo para obtenção do título de Mestre em Ciências

Data:

\section{Banca Examinadora}

Prof. Dr.

Instituição:

Assinatura:

Julgamento:

Prof. Dr.

Instituição:

Assinatura:

Julgamento:

Prof. Dr. Instituição:

Assinatura: Julgamento: 
À minha família, Mãe, Pai, Ricardo e Carolina, que em nenhum momento mediram esforços para que conseguisse realizar todos os meus sonhos, que me guiaram pelos caminhos corretos, me ensinaram a fazer as melhores escolhas, me mostraram que a honestidade e o respeito são essenciais à vida e que devemos sempre lutar pelo que queremos. 
Aos demais familiares, em especial à Vó Aracy, de quem morro de saudades. 
Aos meus grandes amigos, Fernanda e Guilherme, Fernanda, Daniela, Fábio e Marta, pelas gargalhadas e principalmente pelo incentivo para alcançar todas as metas por mim estabelecidas. 
Ao meu orientador, Prof. Dr. Paulo Sergio de Moraes

Barros, por toda confiança. Obrigada por fazer do meu aprendizado um contentamento. Por me incentivar e guiar neste difícil caminho da pesquisa científica, auxiliando no que achava complicado e me ensinando a resolver da melhor forma. 
À Deus, acima de tudo, por me colocar neste caminho tão gratificante. Também por permitir que finalizasse mais uma etapa importante da minha vida. 


\section{AGRADECIMENTOS}

Acabo mais uma etapa da minha vida, o mestrado. Um sonho criado há apenas 4 anos, quando mergulhei com todo o meu coração no mundo da pesquisa científica e, desde então, dedico parte da minha vida.

Iniciarei os agradecimentos não por ordem de importância, mas na ordem em que as pessoas foram aparecendo na minha vida durante todo este período:

Agradeço primeiramente à Profa. Dra. Andréa Barbosa e a todos os professores do curso de Medicina Veterinária da Universidade de Santo Amaro, instituição em que me formei, adquiri a base do meu conhecimento e tive o primeiro contato com a oftalmologia veterinária.

Ao Dr. Luis Leon Cyon, pela paciência e ensinamentos no primeiro estágio realizado nesta área.

À Dra. Angélica M. V. Safatle, pela paciência desde o primeiro dia que a conheci e pelos ensinamentos e incentivos em inúmeros momentos da minha vida. Sou muito feliz por poder participar de parte de sua rotina profissional, o que me permitiu tornar a veterinária que sou hoje. Expresso aqui minha profunda admiração pela profissional que é.

Ao secretário do Departamento de Cirurgia, Belarmino Ney Pereira e agora, também à Alessandra Sousa, secretária do departamento e do programa de pósgraduação. Muito obrigada pela amizade, incentivo e por todo o auxílio na resolução das questões inerentes ao programa.

Ao amigo Luiz Felipe de Moraes Barros, por confiar e acreditar na minha capacidade e, desta forma, auxiliar no meu ingresso nesta difícil jornada.

À minhas amigas e "professoras", Adriana Cabral Lustoza, Márcia Pansera Galego, Milena Sefrin Helzel e Renata Squarzoni, que com paciência e dedicação, ensinaram grande parte da oftalmologia que sei hoje. Obrigada pelo carinho e amizade. 
Às queridas amigas Graziele Massae Shimamura e Daniela de Castro Leandro pelo convívio e amizade. Fico feliz por poder dividir com vocês momentos importantes da minha vida profissional e pessoal.

Ao amigo Eduardo Perlmann pela troca de experiência, pelas brincadeiras e pelo apoio mútuo.

À Dra. Andréa Antunes pelas broncas, ensinamentos, conselhos e ajuda. Também às suas alunas, Michelle Barbosa e Patrícia Jesler, pela amizade e incentivo.

Aos funcionários do Hospital Veterinário - USP, Cledson Lelis dos Santos, Jesus dos Anjos Vieira e Otávio Rodrigues dos Santos, por todo o apoio, auxílio e carinho. Agradeço principalmente ao Emerson A. C. de Oliveira, pelo auxílio no levantamento dos prontuários.

Ao Dr. Joaquim Edson Vieira, por muito gentilmente me auxiliar na realização da estatística e direcionamento da tese. Sempre muito prestativo e paciente, foi capaz de enaltecer meu projeto com suas indispensáveis colocações.

À Profa. Dra. Aline Bolzan, pelos ensinamentos e paciência. Obrigada também pelo carinho dedicado à nós, pós-graduandos, mesmo com tão pouco tempo de convívio.

Aos demais funcionários, médicos veterinários e residentes do Hospital Veterinário que, de alguma forma, participaram desta jornada.

À Faculdade de Medicina Veterinária e Zootecnia - USP, que me acolheu como aluna da pós-graduação e deu condições para a realização deste trabalho.

Ao Conselho Nacional de Desenvolvimento Científico e Tecnológico (CNPQ), pela bolsa concedida.

À todos os cães da raça Boxer, com sua alegria e inquietude e à seus cuidadosos proprietários, todo o meu carinho e respeito.

À todos que participaram, de alguma forma, desta etapa da minha vida. 


\section{RESUMO}

HVENEGAARD, A. P. F. A. Estudo retrospectivo do tratamento ambulatorial da úlcera indolente em cães da raça Boxer. [Retrospective study of clinical management of indolent ulcers in Boxer dogs]. 2010. 99 f. Dissertação (Mestrado em Ciências) - Faculdade de Medicina Veterinária e Zootecnia, Universidade de São Paulo, São Paulo, 2010.

Úlceras indolentes são úlceras corneais superficiais, espontâneas, que apresentam curso prolongado e que tendem a recidivar. Comumente observadas em cães de meia idade, da raça Boxer, provoca dor de início agudo e necessita de tratamento específico, já que este, quando não realizado de forma correta, pode prolongar o curso da lesão por semanas a meses. A doença é explicada por diversas alterações da superfície ocular. Com o objetivo de avaliar a eficácia dos tratamentos ambulatoriais preconizados no Serviço de Oftalmologia do Hospital Veterinário da Faculdade de Medicina Veterinária e Zootecnia da Universidade de São Paulo (HOVET-FMVZ-USP), e as principais considerações observadas no levantamento dos prontuários, realizou-se estudo retrospectivo dos casos atendidos entre os anos de 1997 e 2008. Segundo os resultados, observou-se que a maioria dos cães da raça Boxer apresentaram úlcera indolente, distrofia corneal e catarata; que as úlceras indolentes foram mais frequentemente observadas em fêmeas de meia idade e que a maioria dos proprietários demoraram mais de 15 dias para levar seus animais ao HOVET-FMVZ-USP; que as alterações oculares mais frequentemente referidas pelos proprietários foram o blefarospasmo, olho vermelho e a secreção; que as principais características das lesões observadas após o exame oftalmológico foram que a maioria das úlceras eram transparentes, apresentando epitélio não aderido ou com algum grau de vascularização; unilaterais, mais frequentemente observadas no olho direito; de aparecimento espontâneo e localizadas no centro da córnea. Quanto ao tratamento, observou-se que os inibidores das proteinases foram as medicações mais frequentemente prescritas e que sua administração não interferiu no tempo de cicatrização corneal ou na formação de granuloma. Vitamina C, apesar de ter prolongado de maneira significante o tempo de cicatrização corneal, reduziu a inflamação, consideração observada pela diminuição da presença de granuloma. Debridamento/cauterização corneal, além de não interferir na formação 
de granuloma, acelerou, significativamente, o processo de cicatrização. A antibioticoterapia e a administração de Atropina 1 \% não interferiu no tempo de cicatrização, mas se relacionaram diretamente, de forma estatisticamente significante, à presença de granuloma. O uso de anti-inflamatórios tópicos e sistêmicos também não interferiu no tempo de cicatrização, mas diminuíram, de maneira significante, a presença de granuloma nos cães em que foram administrados. Observou-se também que a não administração de atropina $1 \%$, antibióticos e anti-inflamatórios não interferiu no tempo de cicatrização, nem na formação de granuloma; que o tempo de alteração ocular, antes da primeira consulta e as características das lesões não interferiram, de maneira relevante, no tempo de cicatrização corneal. Portanto, conhecer os diversos tipos de tratamento se mostra fundamental para o sucesso da resolução da doença, já que este deve ser específico, realizado de forma cautelosa e por tempo indeterminado, cuidando para que a lesão não progrida e promovendo o retorno da transparência corneal.

Palavras-chave: Úlcera indolente. Boxer. Tratamento. Inibidores das proteinases. Cães. 


\section{ABSTRACT}

HVENEGAARD, A. P. F. A. Retrospective study of clinical management of indolent ulcers in Boxer dogs. [Estudo retrospectivo do tratamento ambulatorial da úlcera indolente em cães da raça Boxer]. 2010. 99 f. Dissertação (Mestrado em Ciências) - Faculdade de Medicina Veterinária e Zootecnia, Universidade de São Paulo, São Paulo, 2010.

Indolent ulcers are superficial corneal ulcers that occurs spontaneously, presents prolonged course and tend to relapse. Commonly observed in middle-aged Boxer dogs, causes pain of acute onset and requires appropriate treatment. The disease is explained by several changes on the corneal surface. Aiming to assess the effectiveness of clinical treatments, recommended by the Ophthalmology Service of the Veterinary Hospital, of the Veterinary College, of the University of São Paulo (HOVET-FMVZ-USP) and to evaluate major considerations registered on its medical records, a retrospective study was conducted (1997 - 2008). Results demonstrated that, during studied period: most Boxer dogs presented indolent ulcers, corneal dystrophy and cataracts; indolent ulcers were frequently observed in middle-aged female Boxers and most owners took more than 15 days to bring their animals to the hospital; blepharospasm, red eye and ocular discharge were the most owner's referred ocular alterations at the primary consultation; main features of examined lesions were transparent ulcers presenting non adherent epithelium and/or some degree of vascularization; unilateral, often observed at the right eye, of spontaneous onset and located at the center of the cornea. Regarding treatment, proteinase inhibitors were the most often prescribed medications; its administration did not affect corneal healing or granuloma formation. Vitamin C prolonged, significantly, the corneal healing time, although, its administration reduced its inflammation, observed by the decrement on the granuloma frequency. Corneal debridement / cauterization, did not interfere on granuloma formation and was capable to accelerate, significantly, the healing process. Antibiotics and $1 \%$ atropine did not affect the healing time, but were statistically related to the presence of granuloma. Topical and systemic antiinflammatories did not interfere at the healing time, but decreased, significantly, the presence of granuloma. Not to administer atropine 1\%, antibiotics and antiinflammatories, did not interfere at the corneal healing time nor the formation of 
granuloma. Duration period of ocular alterations before the first consultation and characteristics of the lesions did not interfere at the corneal healing time. Therefore, to know the various types of treatments seems to be fundamental to the resolution of the indolent ulcer, as treatment must be specific, performed cautiously and for indefinitely period, preventing the progression of the lesion, and promoting the return of corneal transparency.

Key words: Indolent ulcers. Boxer dogs. Treatment. Proteinase inhibitors. Dogs. 


\section{LISTA DE FIGURAS}

Figura 1 - Cão da raça Boxer, macho, 9 anos, com úlcera indolente no canto medial inferior do olho esquerdo. (A) Observar a descontinuação, não aderência do epitélio ao estroma e a opacidade corneal; (B) Observar a presença de neovascularização corneal. 51

Figura 2 - O mesmo cão da raça Boxer, macho, 9 anos, com úlcera indolente no canto medial inferior do olho esquerdo, após a administração do colírio de fluoresceína $1 \%$. Observar a delimitação da borda da úlcera e a presença de corante além das bordas, isto é, sob o epitélio, indicado pela seta branca. .51

Figura 3 - Representação da quantidade de úlceras segundo a localização na córnea. (TP) Terceira pálpebra - canto medial. 


\section{LISTA DE QUADROS}

Quadro 1 - Lista de oftalmopatias diagnosticadas no Serviço de Oftalmologia do HOVET-FMVZ-USP, em cães da raça Boxer, entre 1997 a 2008........58

Quadro 2 - Relação de medicamentos utilizados previamente ao atendimento no

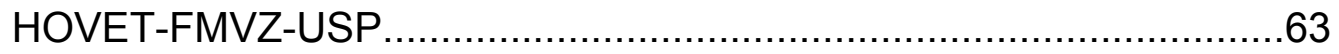




\section{LISTA DE GRÁFICOS}

Gráfico 1 - Representação gráfica da distribuição das úlceras segundo a idade dos animais, sendo (a) anos.

Gráfico 2 - Representação gráfica da distribuição do número de casos segundo o tempo de alteração ocular antes de serem atendidos no Serviço de Oftalmologia - HOVET-FMVZ-USP

Gráfico 3 - Representação gráfica da quantidade de úlceras diagnosticadas segundo a localização na córnea.

Gráfico 4 - Representação gráfica dos diferentes tratamentos ambulatoriais preconizados no Serviço de Oftalmologia do HOVET-FMVZ-USP no período estudado segundo o número de úlcera

Gráfico 5 - Representação gráfica dos tratamentos ambulatoriais preconizados segundo o tempo de cicatrização

Gráfico 6 - Representação gráfica das úlceras segundo a não utilização dos tratamentos referidos preconizados. .72

Gráfico 7 - Representação gráfica dos dias de alteração ocular referidos pelos proprietários na primeira consulta e os dias de cicatrização promovidos pelos tratamentos preconizados 


\section{LISTA DE TABELAS}

Tabela 1 - Distribuição das úlceras segundo a idade dos cães .59

Tabela 2 - Distribuição do número de casos segundo o tempo de alteração ocular antes de serem atendidos no Serviço de Oftalmologia - HOVET-FMVZUSP.

Tabela 3 - Manifestações oculares referidas pelos proprietários durante a primeira consulta.

Tabela 4 - Quantidade de úlceras diagnosticadas segundo sua localização na córnea. .66

Tabela 5 - Características das úlceras observadas durante exame da primeira consulta segundo o número de animais.

Tabela 6 - Tratamentos ambulatoriais preconizados no Serviço de Oftalmologia do HOVET-FMVZ-USP no período estudado segundo o número de úlceras. 69

Tabela 7 - Distribuição dos tratamentos ambulatoriais preconizados segundo o tempo de cicatrização.

Tabela 8 -Distribuição das úlceras que não tiveram os tratamentos referidos preconizados.

Tabela 9 - Distribuição da característica das úlceras segundo a média dos dias de cicatrização e dos dias de alteração ocular previamente à primeira consulta.

Tabela 10 - Correlação entre a utilização dos diferentes tratamentos ambulatoriais preconizados e a formação de granuloma. .75

Tabela 11 - Correlação entre a utilização dos diferentes tratamentos ambulatoriais preconizados e a cicatrização até 30 dias. 


\section{LISTA DE ABREVIATURAS E SIGLAS}

\begin{tabular}{|c|c|}
\hline Antibio & Antibiótico \\
\hline Antinfl & Anti-inflamatório não esteroidal \\
\hline Debrid/cauter & Debridamento/cauterização \\
\hline EDTA & Etilenodiaminotetracético \\
\hline FLPC & Filme lacrimal pré-corneal \\
\hline FMVZ & Faculdade de Medicina Veterinária e Zootecnia \\
\hline $\mathrm{h}$ & Hora \\
\hline HOVET & Hospital Veterinário \\
\hline Inib da colag & Inibidor da colagenase \\
\hline MB & Membrana basal \\
\hline MEC & Matriz extra-celular \\
\hline $\mathrm{mg} / \mathrm{ml}$ & Miligramas por mililitros \\
\hline $\mathrm{mm}$ & Milímetro \\
\hline MMP & Matriz metaloproteinase \\
\hline MMPs & Matriz metaloproteinases \\
\hline$\mu \mathrm{m}$ & Micrômetro \\
\hline (n) & Quantidade de animais ou úlceras \\
\hline $\mathrm{n}$ & Não \\
\hline NE & Neutrófilo elastase \\
\hline PVPI & Polivinil pirrolidona iodo (iodo povidine) \\
\hline SC & Solução de continuidade \\
\hline
\end{tabular}


USP

Universidade de São Paulo

VitC

Vitamina C (ácido ascórbico)

Sem

Sem antibiótico, atropina $1 \%$ ou anti-inflamatório 


\section{LISTA DE SÍMBOLOS}

a Alfa

$\% \quad$ Porcento

® $\quad$ Marca registrada

$\mu \quad$ Micron

$=$ Igual 


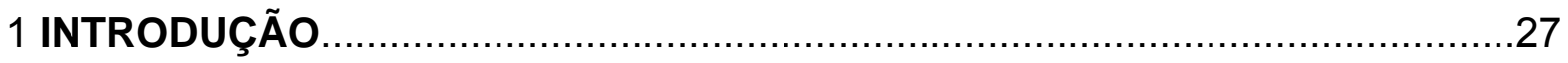

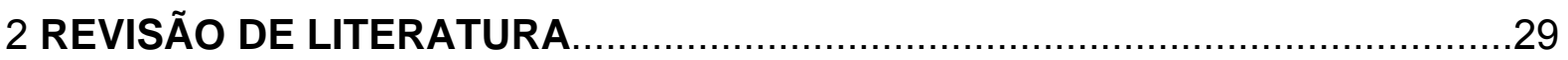

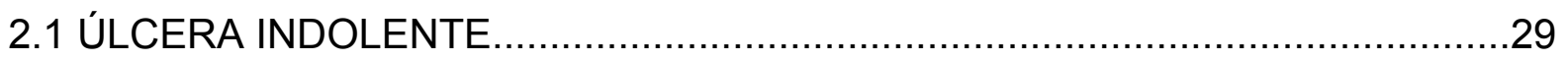

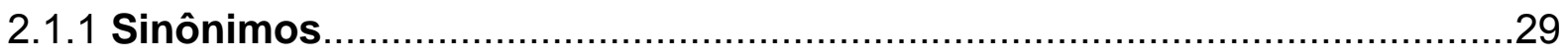

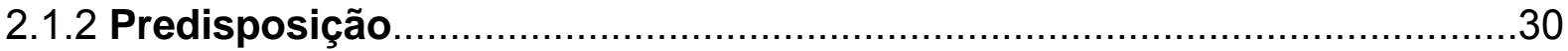

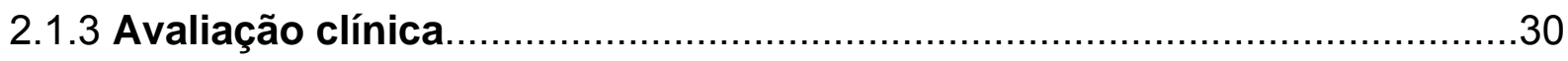

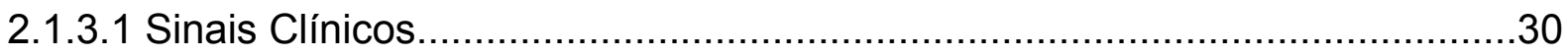

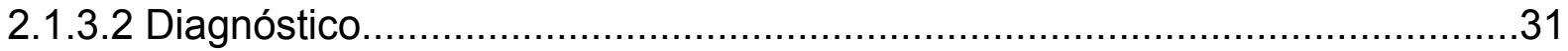

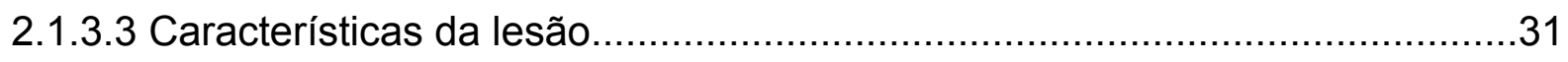

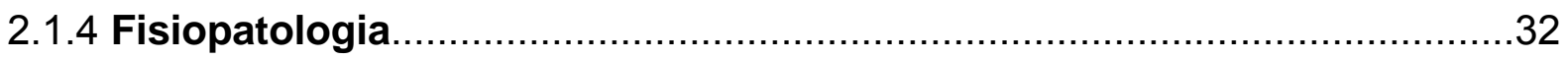

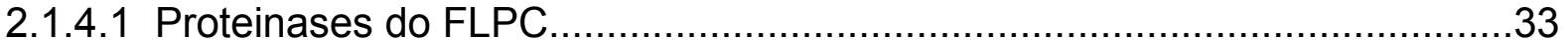

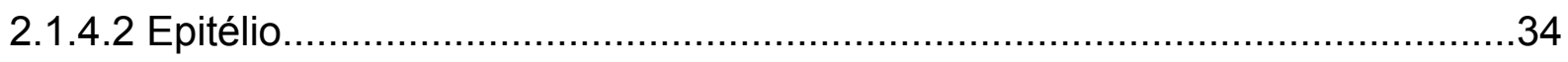

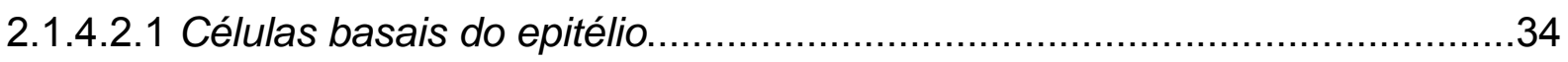

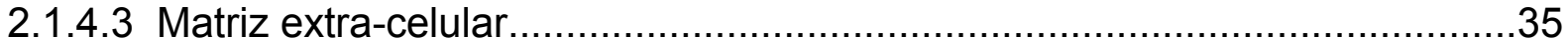

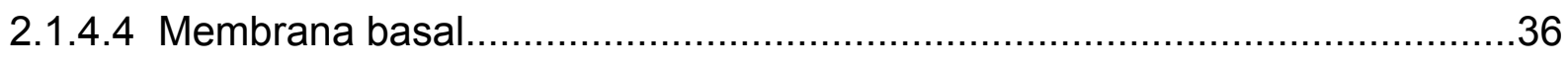

2.1.4.5 Estroma

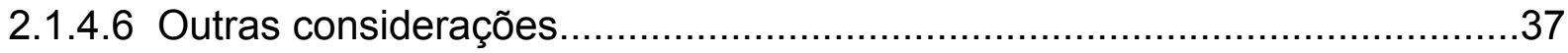

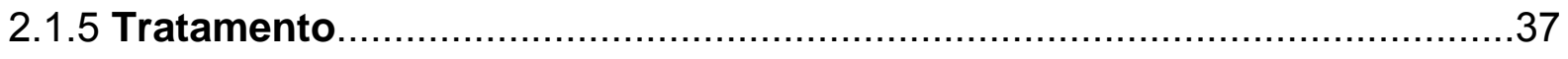

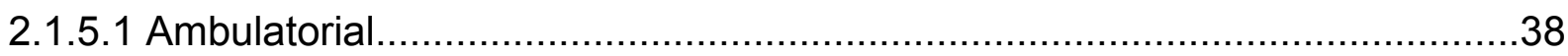

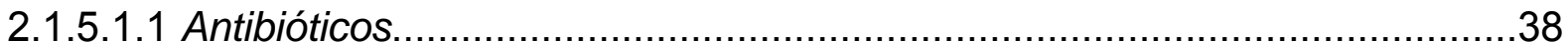

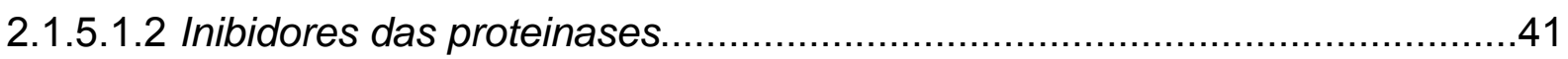




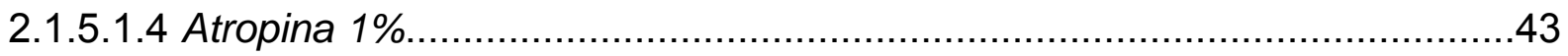

2.1.5.1.5 Debridamento/cauterização corneal.................................................43

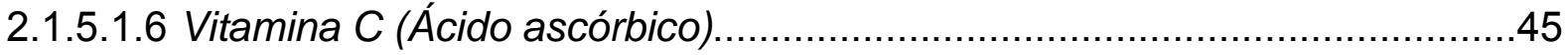

2.1.5.1.7 Preservativos oftalmológicos......................................................46

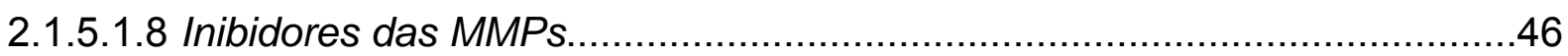

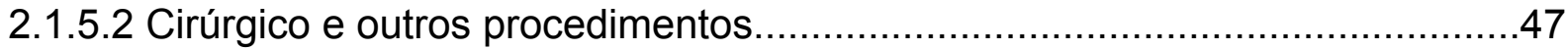

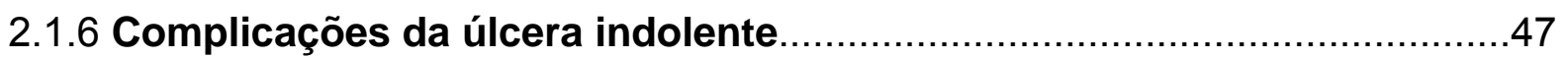

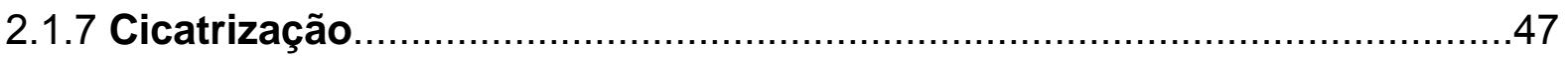

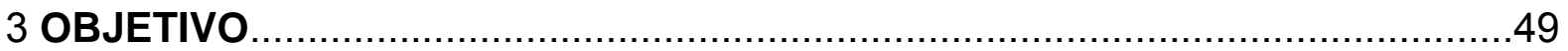

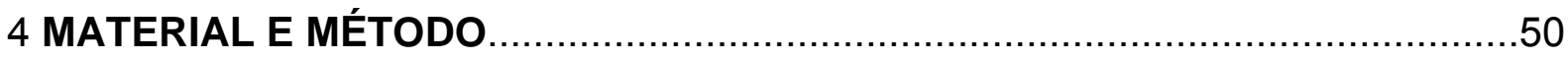

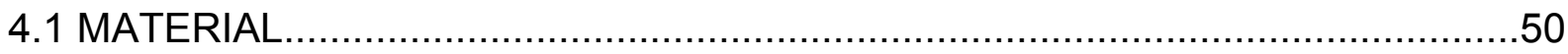

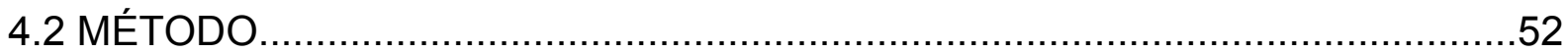

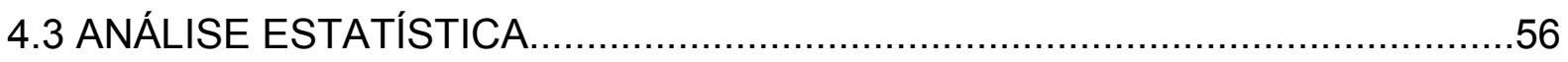

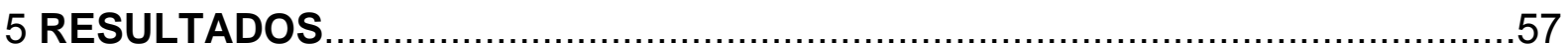

5.1 INCIDÊNCIA DA DOENÇA EM CÃES DA RAÇA BOXER $\ldots \ldots \ldots \ldots \ldots \ldots \ldots \ldots \ldots \ldots . \ldots 7$

5.1.1 Frequencia da raça Boxer no serviço de oftalmologia do HOVET-FMVZUSP e prevalência da doença nesta raça .........................................57

5.1.2 Doenças oculares diagnosticadas nesta raça durante o período do

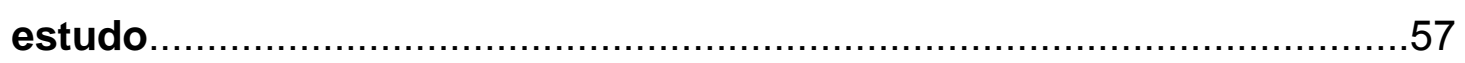

5.1 .30 sexo e a idade dos animais incluídos no estudo...............................59

5.1.4 Doenças sistêmicas que, além da úlcera, acometeram os animais

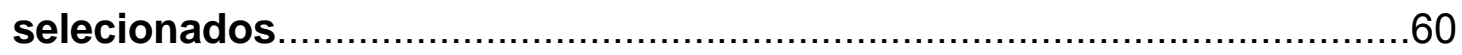

5.2 MANEJO AMBULATORIAL ANTES DA PRIMEIRA CONSULTA....................61 
5.2.2 Medicações utilizadas previamente à primeira consulta.

5.3.1 Manifestações oculares e sistêmicas referidas pelos proprietários durante anamnese da primeira consulta.

5.3.2 O olho mais frequentemente acometido

5.3.3 Localização das úlceras na córnea.

5.3.4 Características das úlceras ao exame oftalmológico na primeira consulta.

5.4 TRATAMENTO .68

5.4.1 Tratamentos ambulatoriais preconizados pelo Serviço de Oftalmologia do HOVET .68

5.4.2 Eficácia dos diferentes tratamentos ambulatoriais quanto a rapidez da resolução do quadro. .70

5.5 CICATRIZAÇÃO. .72

5.5.1 Interferência do tempo de alteração ocular antes da primeira consulta no tempo de cicatrização .73

5.5.2 Relação da característica das úlceras na primeira consulta, com o tempo de alteração antes da primeira consulta e o tempo de cicatrização 74

5.5.3 Correlação entre a utilização dos diferentes tratamentos ambulatoriais preconizados e a formação de granuloma. 74

5.5.4 Correlação entre a utilização dos diferentes tratamentos ambulatoriais preconizados e a cicatrização até 30 dias. 75

6 DISCUSSÃO .76

7 CONCLUSÕES. .85 


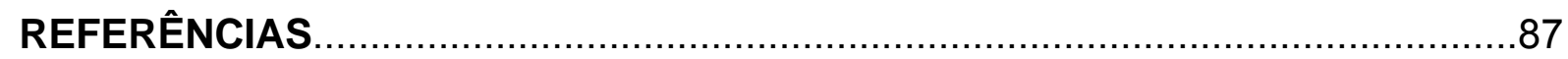

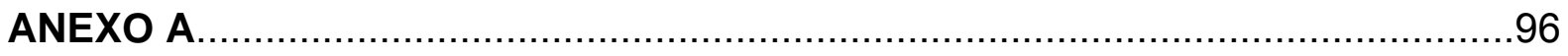




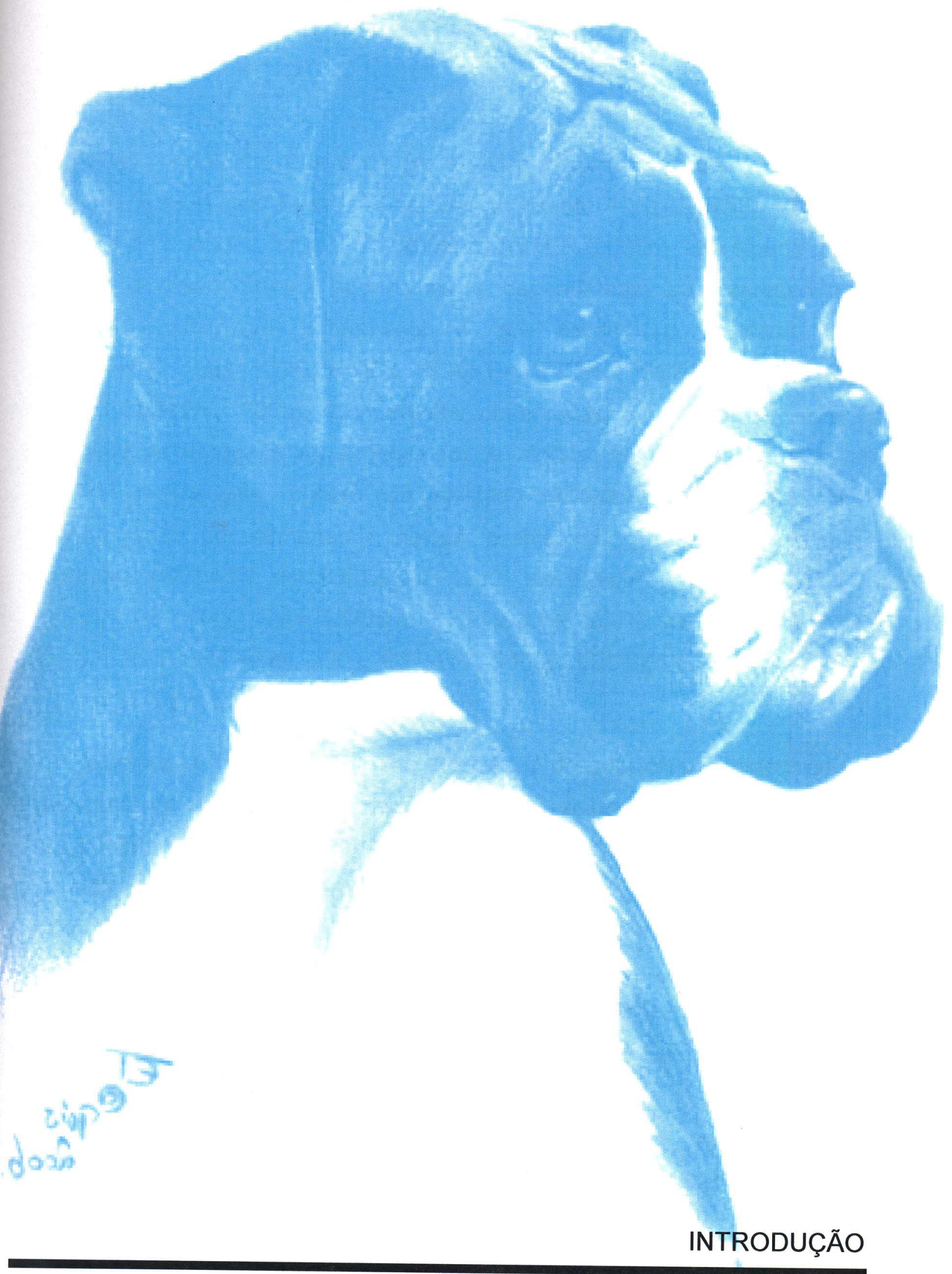




\section{INTRODUÇÃO}

Úlcera indolente, úlcera do Boxer, úlcera corneal refratária, úlcera corneal persistente e síndrome da erosão corneal recorrente (KIRSCHNER; NIYO; BETTS, 1989; GELATT, 2003b; BENTLEY, 2005; SLATTER, 2005b), são alguns dos nomes dados à úlceras corneais superficiais e espontâneas, que apresentam curso prolongado, cicatrizam pobremente e que tendem a recidivar (GELATT; SAMUELSON, 1982; KIRSCHNER, 1990; CAMPBELL; MURPHY, 1999; GELATT, 2003b; BENTLEY, 2005). Comumente observadas em cães de meia idade, principalmente da raça Boxer, provoca dor de início agudo e necessita de tratamento específico, já que este, quando não realizado de forma correta, pode prolongar o curso da lesão por semanas a meses, predispondo o animal à complicações importantes (GELATT; SAMUELSON, 1982; KIRSCHNER; NIYO; BETTS, 1989; MORGAN; ABRAMS, 1994; STANLEY; HARDMAN; JOHNSON, 1998; BENTLEY et al., 2001; MURPHY et al., 2001; GELATT, 2003b; LEDBETTER; MUNGER; RING, 2003b; BENTLEY, 2005; SLATTER, 2005b).

Segundo a literatura, diversas alterações da superfície ocular predispõe ao aparecimento e demora na cicatrização da lesão, como o aumento das proteinases do filme lacrimal pré-corneal (BROOKS et al., 2002; OLLIVIER et al., 2002; BROOKS et al., 2003; COUTURE et al., 2003; OLLIVIER et al., 2003), a degeneração do epitélio (GELATT; SAMUELSON, 1982; KIRSCHNER, 1990; BENTLEY et al., 2001), e de suas células basais (GELATT; SAMUELSON, 1982; KIRSCHNER; NIYO; BETTS, 1989; KIRSCHNER, 1990; SLATTER, 2005b), as alterações nos componentes da matriz extra-celular (NISHIDA, 1983; WILLEFORD et al. 1998; BENTLEY et al., 2001; BENTLEY et al., 2002), na conformação da membrana basal do epitélio (KIRSCHNER; NIYO; BETTS, 1989; BENTLEY, 2005) e a perda da arquitetura do estroma (KIM et al., 1999; BENTLEY et al., 2001; BENTLEY et al., 2002; BENTLEY, 2005; SLATTER, 2005b).

A maioria os tratamentos recomendados pela literatura são 0 debridamento/cauterização epitelial, a ceratotomia em pontos, em grade e a 
ceratectomia superficial. Apesar de frequentemente referidos, a maioria destes procedimentos são invasivos, além de necessitar anestesia geral. Os estudos em que se preconizou o tratamento ambulatorial, ou seja, administração de colírios, medicações sistêmicas e/ou debridamento/cauterização corneal, muitas vezes também realizaram outros procedimentos, o que dificultou o entendimento dos resultados alcançados (STANLEY; HARDMAN; JOHNSON, 1998; BENTLEY et al., 2001; LEDBETTER; MUNGER; RING, 2003a; LEDBETTER; MUNGER; RING, 2003b; BENTLEY, 2005).

Com o objetivo de relatar as principais considerações descritas nos prontuários dos cães da raça Boxer com úlcera indolente, submetidos apenas ao tratamento ambulatorial, ou seja, administração de colírios, medicações sistêmicas e/ou debridamento/cauterização corneal, preconizados pelo Serviço de Oftalmologia do Hospital Veterinário da Faculdade de Medicina Veterinária e Zootecnia da Universidade de São Paulo (HOVET-FMVZ-USP), realizou-se estudo retrospectivo dos casos atendidos entre os anos de 1997 e 2008. 


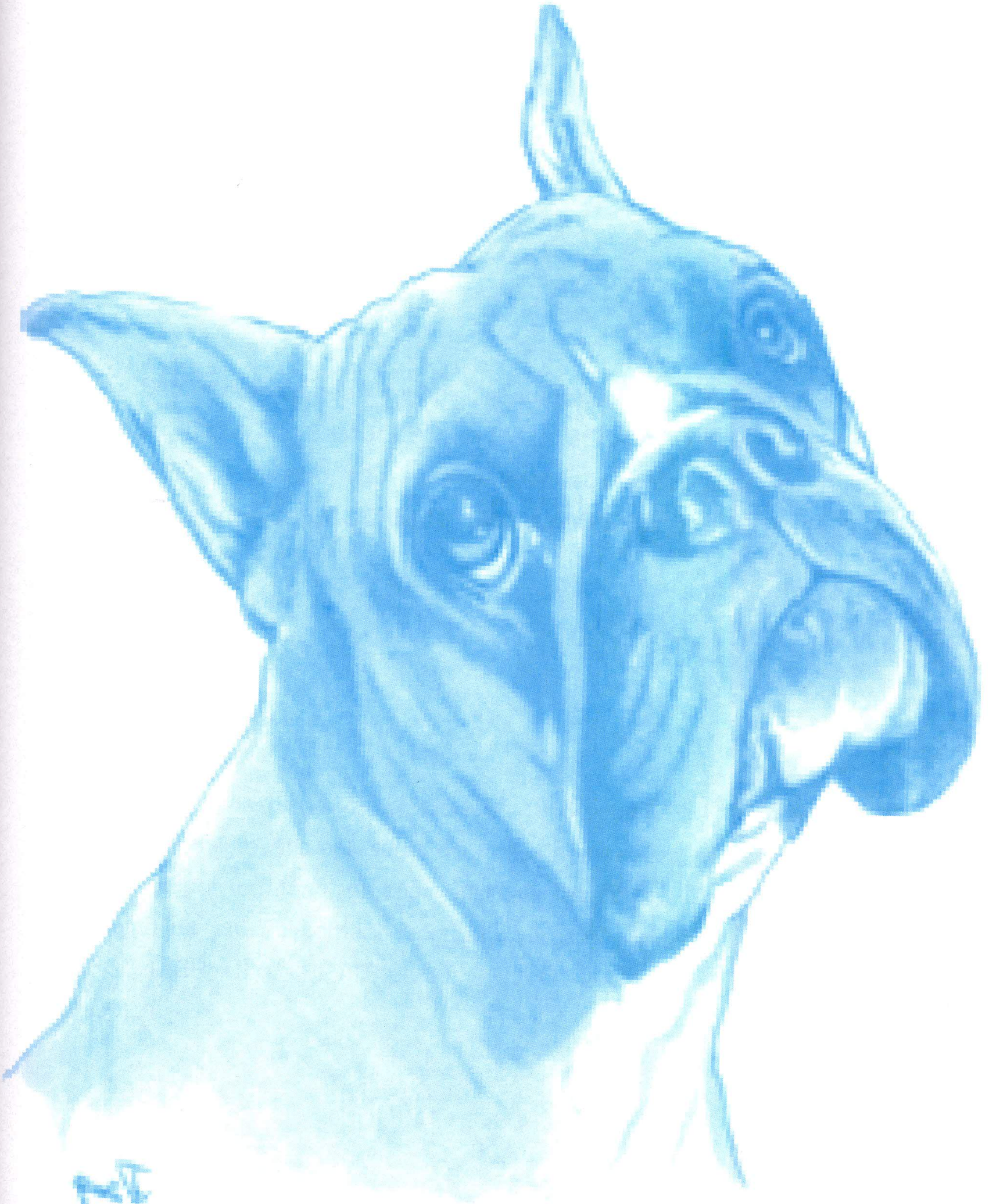

REVISÃO DE LITERATURA 


\section{REVISÃO DE LITERATURA}

A revisão de literatura foi dividida em tópicos relevantes descritos a seguir:

\section{1 ÚLCERA INDOLENTE}

São úlceras corneais superficiais que cicatrizam pobremente e que tendem a recidivar (GELATT; SAMUELSON, 1982; GELATT, 2003b). Apresentam curso prolongado e, quando não tratada adequadamente, pode se apresentar por semanas ou meses (KIRSCHNER, 1990; CAMPBELL; MURPHY, 1999; BENTLEY, 2005).

\subsubsection{Sinônimos}

Descrita desde 1954 (MAGRANE¹, 1956 apud GELATT; SAMUELSON, 1982, p. 3), esta oftalmopatia apresenta diferentes nomeações, tais com: úlcera do Boxer, úlcera corneal refratária, erosões epiteliais refratárias, úlcera corneal persistente, síndrome da erosão corneal recorrente, erosão recidivante ou úlcera de roedor (KIRSCHNER; NIYO; BETTS, 1989; GELATT, 2003b; BENTLEY, 2005; SLATTER, 2005b).

${ }^{1}$ MAGRANE, W. G. Keratitis in dogs. Veterinary Scopes, v. 1, p. 2-10, 1956. 


\subsubsection{Predisposição}

Cães de meia-idade (7 a 9 anos) ou idosos de diversas raças, sendo o Boxer a raça mais acometida (GELATT; SAMUELSON, 1982; KIRSCHNER; NIYO; BETTS, 1989; MORGAN; ABRAMS, 1994; STANLEY; HARDMAN; JOHNSON, 1998; BENTLEY et al., 2001; MURPHY et al., 2001; GELATT, 2003b; LEDBETTER; MUNGER; RING, 2003b; BENTLEY, 2005; SLATTER, 2005b). A úlcera indolente não apresenta predisposição sexual, mas estudos sugerem que sejam diagnosticadas mais frequentemente nos machos (GELATT; SAMUELSON, 1982; KIRSCHNER, 1990; STANLEY; HARDMAN; JOHNSON, 1998).

\subsubsection{Avaliação clínica}

A avaliação clínica foi dividida nos tópicos a seguir:

\subsubsection{Sinais Clínicos}

As úlceras indolentes ocorrem geralmente de forma espontânea, não havendo histórico de trauma (GELATT, 2003b; SLATTER, 2005b). Entretanto, alguns autores acreditam que pode ter havido trauma ou presença de corpo estranho semanas ou até meses antes do aparecimento da lesão (KIRSCHNER; NIYO; BETTS, 1989).

Os sinais clínicos geralmente se apresentam por mais de 2 semanas antes do primeiro atendimento (STANLEY; HARDMAN; JOHNSON, 1998; LEDBETTER; MUNGER; RING, 2003b; BENTLEY, 2005), como: blefarospasmo (comumente de início agudo), lacrimejamento e/ou secreção ocular, fotofobia e dor de grau variável, mas que diminui com a cronicidade da lesão. A presença de blefarospasmo e lacrimejamento pode variar entre os indivíduos (GELATT; SAMUELSON, 1982; KIRSCHNER; NIYO; BETTS, 1989; MORGAN; ABRAMS, 1994; STANLEY; 
HARDMAN; JOHNSON, 1998; BENTLEY et al., 2001; MURPHY et al., 2001; GELATT, 2003b; BENTLEY, 2005; SLATTER, 2005b).

\subsubsection{Diagnóstico}

Qualquer animal de meia idade, que apresente um defeito epitelial superficial espontâneo que dure mais do que 2 semanas, deve-se suspeitar da presença da doença (BENTLEY, 2005). Para tanto, a córnea deve ser examinada utilizando-se foco de luz e magnificação. A integridade corneal é melhor avaliada após instilação de colírio de fluoresceína $1 \%$, pois o corante é somente retido na superfície corneal quando há exposição do estroma, indicando a presença, sua delimitação e a presença e extensão do epitélio corneal não-aderido e degenerado (KIRSCHNER; NIYO; BETTS, 1989; KIRSCHNER, 1990; STANLEY; HARDMAN; JOHNSON, 1998; GELATT, 2003a,b; SLATTER, 2005b). Alguns estudos também referem o uso do corante rosa bengala $0,5 \%$ para melhor visibilização da região degenerada do epitélio (GELATT; SAMUELSON, 1982).

Exame cuidadoso para se eliminar qualquer causa de base, como infecção, anormalidades palpebrais e dos cílios, alterações no filme lacrimal pré-corneal (FLPC), lagoftamia ou mesmo presença de corpo estranho, ceratites imunomediadas ou queimaduras por álcalis, deve ser realizado antes de se confirmar a doença (KIRSCHNER, 1990; STANLEY; HARDMAN; JOHNSON, 1998; BENTLEY, 2005; SLATTER, 2005b,b). Dependendo do estágio da úlcera, testes diagnósticos auxiliares como cultura bacteriana, raspados de córnea e coloração Gram e Giemsa também podem ser realizados (GELATT; SAMUELSON, 1982; SLATTER, 2005a).

\subsubsection{Características da lesão}

As úlceras são usualmente unilaterais, não contaminadas, de aspecto acinzentado, apresentando aproximadamente 3 a $4 \mathrm{~mm}$ de diâmetro, contorno 
irregular e localizadas no eixo axial ou paraxial da córnea, podendo também estar localizada em sua periferia (GELATT; SAMUELSON, 1982; KIRSCHNER; NIYO; BETTS, 1989; KIRSCHNER, 1990; BENTLEY et al., 2001; HENDRIX; WARD; BARNHILL, 2001; GELATT, 2003b; LEDBETTER; MUNGER; RING, 2003a,b; SLATTER, 2005b). São caracterizadas por lesões superficiais, na qual observa-se a separação do epitélio com o estroma (KIRSCHNER; NIYO; BETTS, 1989; GELATT, 2003b; SLATTER, 2005b). A presença de vasos sanguíneos, pigmento e outras opacidades também podem estar presentes (GELATT, 2003b; SLATTER, 2005b).

Em estágios precoces, raramente há estimulo para vascularização, sendo esta uma característica diagnóstica útil. Esta reação corneal não auxilia a cicatrização, mas pode resultar em tecido de granulação significante e fibrose no tratamento tardio (BENTLEY, 2005; SLATTER, 2005b). No Boxer, a vascularização pode apresentar-se de forma rápida e marcada (ROBERTS ${ }^{1}$, 1966, apud GELATT; SAMUELSON, 1982, p. 111), mas crônica ou ausente nas demais raças (KIRSCHNER; NIYO; BETTS, 1989). Uma lesão central pode persistir por semanas ou meses sem qualquer resposta vascular, o que pode não acontecer nas lesões mais periféricas (BENTLEY, 2005). Lesões no Golden Retriever, por exemplo, são mais frequentemente diagnosticadas no limbo temporal e apresentam vascularização (SLATTER, 2005b).

\subsubsection{Fisiopatologia}

Clinicamente, a úlcera indolente é bastante similar à erosão corneal recorrente em humanos, pois além de se desenvolver espontaneamente e eventualmente afetar ambos os olhos, relaciona-se com uma distrofia da membrana basal do epitélio e/ou do estroma anterior (KIRSCHNER, 1990; AITKEN; BEIROUTY; LEE, 1995; HEYWORTH et al., 1998; GARRANA et al., 1999; REIDY; PAULUS; GONA, 2000; GELATT, 2003b). Bentley (2005) não concorda com tal comparação e acredita que esta doença seja apenas idade-dependente, pois cães de diferentes

${ }^{1}$ ROBERTS, S. R. Superficial indolent ulcer of the córnea in Boxer dogs. Journal of the Small Animal Practice, v. 6, p. 111-115, 1966. 
raças podem desenvolver a doença, mas a maioria dos afetados são de meia idade ou idosos.

Microscopias de luz e eletrônica e análise imunohistoquímica já foram utilizadas para estudar as características morfológicas que podem contribuir com a causa de base da fisiopatologia da doença (GELATT; SAMUELSON, 1982; KIRSCHNER; NIYO; BETTS, 1989; KIRSCHNER, 1990; BENTLEY et al., 2001; BENTLEY, 2005). As principais alterações observadas nestes estudos estão descritas a seguir:

\subsubsection{Proteinases do FLPC}

Proteinases encontradas no FLPC são enzimas produzidas pelas células epiteliais da córnea, fibroblastos estromais, plasmina, leucócitos e agentes patogênicos da microbiota, como Pseudomonas aeruginosa e Aspergillus spp. Quando em níveis aumentados, podem levar à rápida degradação do colágeno estromal e da matriz extra-celular (MEC). Em equinos, as principais proteinases responsáveis por esta alteração são as matriz metaloproteinases 2 e 9 (MMP-2 e MMP-9) e as proteinases do soro, como a neutrófilo elastase (NE). Estas enzimas normalmente se encontram no FLPC em quantidades equilibradas com seus inibidores, mas durante a doença (BROOKS et al., 2002; OLLIVIER et al., 2002; BROOKS et al., 2003; COUTURE et al., 2003; OLLIVIER et al., 2003):

- Apresentam-se em quantidades aumentadas, mas no decorrer do processo de cicatrização voltam à se estabilizar em níveis basais (OLLIVIER et al., 2003).

- Exercem o dobro da atividade proteolítica sobre a córnea (WILLEFORD et al.,1998).

Autores sugerem que esta alteração prejudique a adesão das células epiteliais às fibronectinas, auxiliando na fisiopatologia da doença (WILLEFORD et al.,1998). 


\subsubsection{Epitélio}

O epitélio corneal é simples, escamoso e não queratinizado, de espessura variável, composto por um padrão básico de membrana basal, células epiteliais basais, células aladas e células superficiais escamosas (SLATTER, 2005b). Na presença de úlcera indolente, o epitélio apresenta-se:

- Mais fino, com aproximadamente metade das camadas do epitélio sadio (GELATT; SAMUELSON, 1982).

- Degenerado, com ausência da arquitetura normal (BENTLEY et al., 2001).

- Não aderido à matriz extra-celular (BENTLEY et al., 2001).

- Edematoso e enrolado na borda da lesão (KIRSCHNER, 1990).

\subsection{Células basais do epitélio}

As células basais do epitélio são responsáveis pela produção da membrana basal e por parte da adesão do epitélio ao estroma, realizada por hemidesmossomos presentes em sua membrana celular (GELATT; SAMUELSON, 1982; KIRSCHNER; NIYO; BETTS, 1989; KIRSCHNER, 1990; SLATTER, 2005b). Na presença de úlcera indolente, estas células apresentam-se:

- Achatadas e alongadas (GELATT; SAMUELSON, 1982; KIRSCHNER; NIYO; BETTS, 1989).

- Com núcleo picnótico (GELATT; SAMUELSON, 1982).

- Com vacúolos em seu citoplasma e na região intercelular (KIRSCHNER; NIYO; BETTS, 1989).

Tais alterações levam à produção de uma membrana basal anormal, com ausência ou presença de poucos hemidesmossomos (GELATT; SAMUELSON, 1982; KIRSCHNER; NIYO; BETTS, 1989). Além disso, Slatter (2005b) refere que 
alguns hemidesmossomos, quando presentes, podem apresentar-se defeituosos e incapazes de realizar sua função.

\subsubsection{Matriz extra-celular}

A matriz extra-celular (MEC) é composta por proteínas como a fibronectina, fibrina, laminina e colágeno. Estas, funcionam como estruturas de "suporte" no processo de migração e aderência das células epiteliais durante a cicatrização corneal (NISHIDA, 1983; WILLEFORD et al., 1998; BENTLEY et al., 2001; BENTLEY et al., 2002). Durante o processo de cicatrização:

- Fibronectina e fibrina estimulam a produção de ativador de plasminogênio pela célula epitelial (NISHIDA, 1983; WILLEFORD et al., 1998).

- O plasminogênio é convertido em plasmina, substância capaz de estimular e promover adesão celular aos componentes da matriz (NISHIDA, 1983; WILLEFORD et al., 1998).

- Fibronectina apresenta-se em grande quantidade na região ulcerada e em pouca quantidade na periferia da lesão e no estroma, quantidades similares às encontradas em córneas sadias (BENTLEY et al., 2001; BENTLEY et al., 2002).

Estes processos auxiliam na cicatrização corneal, mas estudo no qual se realizou análise imunohistoquímica dos componentes da MEC, observou:

- Ausência de laminina e colágeno tipo IV e VII na superfície da lesão ou, quando presentes, em pouca quantidade e em segmentos descontínuos. (BENTLEY et al., 2001; BENTLEY et al., 2002).

Bentley et al. (2001) sugerem que tais alterações nos componentes da MEC e a baixa quantidade de hemidesmossomos alteram a estrutura e função da membrana basal (MB). 


\subsubsection{Membrana basal}

A membrana basal (MB) é responsável pela orientação e organização das células epiteliais, agindo também como filtro seletivo da superfície corneal. Ultraestruturalmente é dividida entre lamina densa e lamina rara que, biomecanicamente são diferenciadas pela quantidade de laminina, sulfato de proteoglicanos e colágeno tipo IV. Alguns autores referem que a perda desta membrana é uma das principais causas da doença (KIRSCHNER; NIYO; BETTS, 1989; BENTLEY, 2005). Estudos observaram que, durante a doença:

- MB está presente, mas descontínua, irregular e com espessura alterada (GELATT; SAMUELSON, 1982; KIRSCHNER; NIYO; BETTS, 1989).

- Encontra-se posicionada sobre um material fibrogranular com debris celulares (BENTLEY et al., 2001).

As alterações biomecânicas da MB, prejudicam ainda mais a força de adesão entre o epitélio e o estroma (GELATT; SAMUELSON, 1982; KIRSCHNER; NIYO; BETTS, 1989).

\subsubsection{Estroma}

O estroma constitui $90 \%$ da espessura corneal. Composto por fibrócitos, ceratócitos, colágeno e substância fundamental (glicosaminoglicanos e glicoproteínas), é responsável pelo suporte da estrutura corneal (SLATTER, 2005b). Em animais com úlcera indolente:

- A superfície estromal anterior apresenta-se composta por fibrilas colágenas entremeadas por material amorfo fibrilar, caracterizando uma área acelular hialinizada, medindo aproximadamente 4,4 $\mu \mathrm{m}$ de espessura (KIM et al., 1999; BENTLEY et al., 2001; BENTLEY et al., 2002; BENTLEY, 2005). Apesar de todas as alterações descritas anteriormente, alguns autores sugerem que esta área seja a principal responsável pela 
demora na cicatrização da ferida (BENTLEY et al., 2001; BENTLEY, 2005).

- Slatter (2005b) refere que esta área seja capaz de se proliferar e, como a estrutura é alterada, ocasionar edema corneal difuso.

No estroma, linfócitos, macrófagos e neutrófilos são normalmente encontrados entremeados às lamelas paralelas formadas pelas fibrilas colágenas (SLATTER, 2005b). Linfócitos e, principalmente neutrófilos, foram observados na úlcera indolente em infiltrados moderados ou raros, podendo também apresentar-se ocasionalmente em infiltrados linfocítico-plasmocítico de graus variáveis (BENTLEY et al., 2001).

\subsubsection{Outras considerações}

Alterações na inervação corneal, observadas pela quantidade de substância "p", um polipeptídeo encontrado na inervação sensorial e de calcitonina genedependente, também foram observadas durante estudo realizado em cães com úlcera indolente submetidos a debridamentos semanais. A quantidade de substância "p" observada estava aumentada nas células epiteliais, mas em níveis normais no FLPC (MURPHY et al., 2001). Além disso, estudo realizado em cães observou que o epitélio com úlcera indolente é incapaz de expressar seus fatores de crescimento adequadamente, o que dificulta ainda mais a migração e a adesão epitelial (BENTLEY, 2005).

\subsubsection{Tratamento}

O tratamento da úlcera indolente pode levar semanas a meses e a recidiva não é incomum (GELATT; SAMUELSON, 1982; KIRSCHNER; NIYO; BETTS, 1989; GELATT, 2003b). Explicando ao proprietário sobre a progressão, o tempo esperado 
para a cicatrização, a possível recidiva e as complicações, sua insatisfação será menor e colaborará para resultados melhores. Proprietários menos informados tornam-se frustrados e concordam pobremente com a terapia recomendada (GELATT, 2003b).

Diversas modalidades de tratamento tem sido recomendada (BENTLEY, 2005), entretanto, deve-se primeiro confirmar o diagnóstico, pois se for secundária, remover a causa e então iniciar o tratamento. Depois, criar um ambiente ideal para a reparação da lesão e prevenir sua progressão (SLATTER, 2005b).

\subsubsection{Ambulatorial}

Considerar-se-á neste segmento, os tratamentos preconizados durante o atendimento ambulatorial do animal, ou seja, a administração tópica de colírios, de medicações por via sistêmica e a realização do debridamento/cauterização corneal:

\subsection{Antibióticos}

Vários fatores devem ser considerados na seleção de um antibiótico: a identificação do organismo ofensor e sua sensibilidade; a localização do organismo; a penetração do fármaco, suas propriedades farmacológicas, farmacêuticas e tóxicas; além do espectro de ação dos fármacos disponíveis. Muitas vezes, a identificação do organismo responsável e sua sensibilidade pode não se justificar, tanto pelos custos envolvidos como pela necessidade de se instituir o tratamento antes desses resultados estarem disponíveis. Entretanto, faz-se necessário o conhecimento dos organismos mais comumente encontrados na microbiota do saco conjuntival, principalmente em casos de infecções graves ou recorrentes (GELATT, 2003b; SLATTER, 2005a,b).

Aeróbios gram-positivos são as bactérias mais comumente cultivadas do saco conjuntival de cães sadios, sendo Staphylococcus sp., Bacillus sp. e 
Corinebacterium $s p$. as predominantes. Bactérias gram-negativas são encontradas em apenas $7 \%$ a $15 \%$ dos cães sadios. Streptococcus alpha e gama-hemoliticos e Proteus sp. são ocasionalmente encontrados (TEIXEIRA et al., 2002; GELATT, 2003b). Alguns autores referem que a microbiota normal também pode variar com a estação climática e a raça do animal (GELATT, 2003b).

Combinações de fármacos bactericidas, são comumente utilizadas por promover maior espectro de atividade e reduzir as chances de resistência ao antibiótico (SLATTER, 2005a). Gelatt (2003b) refere que alguns são levemente epiteliotóxicos, sendo importante ressaltar que, por definição, este tipo de lesão não é contaminada, indicando que seu uso pode não ser necessário e prejudicar a rápida resolução da ferida (BENTLEY et al., 2001; HENDRIX; WARD; BARNHILL, 2001). Por conta disso, Bentley (2005) sugere que a antibioticoterapia deva ser preconizada apenas profilaticamente, a cada 8 ou $12 \mathrm{~h}$ e permanecer até a resolução da lesão.

Diversos estudos foram realizados para se identificar a atuação de diferentes antibióticos na cicatrização corneal e observaram que:

- Bacitracina aumenta o tempo de cicatrização (PETROUTSOS et al., 1983).

- Cloranfenicol, quando utilizado em baixa dose, não retarda a epitelização corneal (PETROUTSOS et al., 1983), além de provocar menores alterações morfológicas em células epiteliais do que as fluorquinolonas (NELSON et al., 1990; HENDRIX; WARD; BARNHILL, 2001).

- Sulfato de gentamicina aumenta o tempo de cicatrização (PETROUTSOS et al., 1983).

- Sulfato de neomicina aumenta o tempo de cicatrização (PETROUTSOS et al., 1983), mas associado a polimixina B e gramicidina, é menos prejudicial para a reepitelização corneal do que outros antibióticos (sulfato de gentamicina, tobramicina e cloranfenicol) (STERN et al., 1983).

- Tobramicina, apesar de ser mais prejudicial para a reepitelização corneal do que outros antibióticos, ocasionam menores alterações 
morfológicas e efeito citopatológico do que as fluorquinolonas (NELSON et al., 1990; HENDRIX; WARD; BARNHILL, 2001).

- Colírio veterinário de sulfato de condroitina $100 \mathrm{mg} / \mathrm{ml}$ e tobramicina 3 $\mathrm{mg} / \mathrm{ml}$ (Tobramax®, Labyes S.A., Buenos Aires, Argentina), cicatrizam $78,85 \%$ das úlceras indolentes de cães em até 4 semanas (LEDBETTER; MUNGER; RING, 2003a).

- Colírio veterinário de sulfato de condroitina $200 \mathrm{mg} / \mathrm{ml}$ e ciprofloxacina $3 \mathrm{mg} / \mathrm{ml}$ (Ciprovet $\circledast$, Labyes S.A., Buenos Aires, Argentina), apresenta mesmo tempo de cicatrização que o Tobramax® em cães com úlcera indolente (LEDBETTER; MUNGER; RING, 2003b).

- Ciprofloxacina 0,3\% em dose recomendada, cicatriza a córnea em até 15 dias (JENSEN et al., 2005), mas pode promover cicatrização desorganizada (MOREIRA et al., 1997, MARINO et al., 2005).

- Gatifloxacina 0,3\% em baixa frequência é capaz de cicatrizar úlceras de córnea em até 15 dias (JENSEN et al., 2005).

- Ofloxacina pode ocasionar edema estromal, infiltrado polimorfonuclear conjuntival e cicatrização demorada e desorganizada (MOREIRA et al., 1997, MARINO et al., 2005).

Stern et al. (1983) acreditam que parte destas alterações esteja também relacionada com a presença de preservativos oftalmológicos nas soluções.

Doxiciclina, administrada na forma sistêmica, é atualmente um dos tratamentos mais recomendados na Mediciana Humana para o tratamento de úlceras corneais recidivantes, pois são capazes de diminuir a neovascularização, inibir a atuação das MMPs e acelerar a reepitelização corneal (PERRY et al., 1993; DURSUN et al., 2001; WANG; TSANG; CORONEO, 2007; DAN et al., 2008). 


\subsection{Inibidores das proteinases}

As proteinases são enzimas produzidas pelo epitélio corneal lesionado, ceratócitos ativados e células inflamatórias que migram para a região da ferida, como macrófagos e polimorfonucleares. $O$ uso de substâncias inibidoras das proteinases, tais como a acetilcisteína, ácido etilenodiaminotetracético (EDTA) ou soro sanguíneo ( $\alpha-2$ macroglobulina), mostra-se necessário no processo de cicatrização corneal, pois promovem a estabilidade e o suporte do tecido na reestruturação corneal, além da inibição de MMPs e NE (BARMAN, 1975; BROOKS et al., 2002; ALDAVOOD et al., 2003).

Acetilcisteína, um dos mais rotineiramente utilizados, além de inibir proteinases e MMPs (BURNS et al., 1989; BROOKS et al., 2002), também apresenta propriedade mucolítica (FRAUNFELDER; WRIGHT; TRIPATHI, 1977). Estudos observaram que:

- EDTA 0,2 \% e acetilcisteína $10 \%$ reduzem a atividade proteolítica do FLPC em eqüinos em mais de 90 \% (OLLIVIER et al., 2002).

- Acetilcisteína $3 \%$ pode acelerar o processo de reepitelização (ALDAVOOD et al., 2003).

- Acetilcisteína, na concentração de 10 e $20 \%$ não retardam a cicatrização corneal (PETROUTSOS et al., 1982; ALDAVOOD et al., 2003).

- Em doses mais elevadas, a acetilcisteína pode ser tóxica ao epitélio e ocasionar inflamação corneal (THERMS; MOLON-NOBLOR; GROVE, 1991).

\subsection{Anti-inflamatórios}

Alguns anti-inflamatórios inibem a regeneração epitelial, infiltração de células inflamatórias, atividade fibroblástica e regeneração endotelial. Corticosteróides, por 
exemplo, diminuem a resistência da ferida, potencializam as colagenases em até 15 vezes e aumentam amplamente o risco de infecção; por outro lado, este potente anti-inflamatório é capaz de limitar a opacificação cicatricial pela inibição da fibroplasia, diminuir a vascularização e reduzir a pigmentação, o que auxilia no retorno da transparência corneal. Corticosteróides tópicos, como dexametasona $0,1 \%$ ou prednisolona $1 \%$, são indicados após cirurgia intra-ocular, ceratoplastias, certos tipos de ceratectomias, na formação do tecido de granulação ou para limitação da formação cicatricial, desde que a infecção tenha sido controlada, a cobertura epitelial tenha sido restabelecida e a integridade estrutural da córnea não esteja comprometida. Medicações anti-inflamatórias devem ser utilizadas com moderação em cães idosos, nos quais a cicatrização pode ser prolongada para além de 7 a 10 dias (SLATTER, 2005a).

Estudos realizados com diferentes anti-inflamatórios, observaram que:

- Anti-inflamatórios não esteroidais (AINE), como polissulfato glicosaminoglicano, quando administrados em doses elevadas, podem provocar o encolhimento e a perda da característica celular em culturas de células corneais de cães (HENDRIX; WARD; BARNHILL, 2002).

- Suprofeno (AINE), quando administrado em doses elevadas, também pode provocar o encolhimento e a perda da característica celular em culturas de células de cães. Em doses recomendadas, não influencia na taxa de migração epitelial (HENDRIX; WARD; BARNHILL, 2002).

- Diclofenaco sódico não apresenta influência no tempo de cicatrização e na taxa de migração epitelial em córneas de coelhos (LOYA et al., 1994).

- Cetorolaco de trometamina e nepafenac não apresentam influência no tempo de cicatrização corneal. Entretanto, nepafenac parece ser mais eficiente no controle da dor pós cirúrgica da ceratectomia refrativa em humanos (DONNENFELD, 2007; DURRIE; KENNARD; BOGHOSSIAN, 2007).

- Em cães, cetorolaco de trometamina, administrado na forma sistêmica, é mais eficiente no controle da dor pós operatória (em laparotomias ou artrotomias), do que flunixin-meglumine e butorfanol (MATHEWS et al., 1996). 
- Hidrocortisona pode provocar o encolhimento e a perda da característica celular em células de cães (HENDRIX; WARD; BARNHILL, 2002).

- Dexametasona, quando administrada em doses elevadas, também pode provocar o encolhimento e a perda da característica celular em culturas de células de cães. Em doses recomendadas não influencia na taxa de migração epitelial (HENDRIX; WARD; BARNHILL, 2002).

- Dexametasona, quando comparada a hidrocortisona e a prednisolona, é o corticosteróide menos prejudicial para a cicatrização corneal em cães (HENDRIX; WARD; BARNHILL, 2002).

\subsection{Atropina $1 \%$}

É utilizada para aliviar o espasmo do músculo ciliar (e consequente dor), decorrente da uveíte anterior secundária à úlcera e diminuir a formação de sinéquia posterior quando houver pupila miótica. Sua atuação pode durar $24 \mathrm{~h}$ ou mais (até 5 dias em alguns cães), mas é contra-indicada nas raças susceptíveis ao glaucoma e em animais diagnosticados com luxação lenticular ou ceratoconjuntivite seca (SLATTER, 2005a). Hollingsworth et al. (1992), observaram que a administração tópica de atropina pode diminuir a produção de FLPC em cães por até 5 semanas. Como a qualidade e quantidade de FLPC são fundamentais para promover ambiente adequado para a reepitelização corneal, seu uso deve ser realizado com cautela (KIRSCHNER, 1990; BENTLEY, 2005; SLATTER, 2005a).

\subsection{Debridamento/cauterização corneal}

Neste procedimento ambulatorial, o epitélio corneal não aderido é removido sob anestesia tópica, com movimentos radiais em direção ao centro da lesão, realizados com cureta corneal (espátula para remoção de corpo estranho), aplicadores com ponta de algodão secos, espátula opaca (como de Kimura ou de 
íris) ou uma pinça de dente fino (STANLEY; HARDMAN; JOHNSON, 1998; LEDBETTER; MUNGER; RING, 2003a; SLATTER, 2005b). Geralmente remove-se epitélio de até 1 a $2 \mathrm{~mm}$ da margem da retenção de fluoresceína. Por isso, não é incomum ter uma área extensa de epitélio anormal e grande aumento do tamanho da úlcera após o debridamento. Remoção ou alteração do estroma exposto parece ser também uma parte necessária no processo de cicatrização. Este procedimento pode necessitar ser repetido a cada 3 a 14 dias, mas a quantidade de epitélio solto deve diminuir a cada remoção, conforme a úlcera cicatriza (STANLEY; HARDMAN; JOHNSON, 1998; GELATT, 2003b).

Stanley, Hardman e Johnson (1998), referiram sucesso de 63 \% na resolução da doença em cães que apresentavam úlcera indolente, tratados com debridamento por haste estéril com ponta de algodão seco. Entretanto, apesar desta técnica apresentar a vantagem de não necessitar anestesia geral, apresenta cicatrização mais demorada, além de necessitar repetidos debridamentos, quando comparado às técnicas de ceratectomia superficial e ceratotomia em grade.

O debridamento também pode ser realizado utilizando-se agentes químicos, como ácido tricloracético, fenol líquido, tintura de iodo ou iodo povidine diluído (GELATT, 2003b; SLATTER, 2005b). Polivinil pirrolidona iodo (iodo povidine ou PVPI), medicação antimicrobiana rotineiramente utilizada na antissepsia précirúrgica oftalmológica, é também frequentemente utilizado como cauterizante no debridamento corneal de cães. Estudos observaram que PVPI:

- Na concentração de 0,33 \%, pode apresentar mesmo tempo de cicatrização corneal do que na administração de gentamicina (YORK et al., 1988; JIANG; WU; SHEN, 2009).

- Em concentrações menores do que 0,5 \%, não apresentam toxicidade significante para a superfície ocular (YORK et al., 1988).

- Em concentrações maiores, como 0,5 \%, pode retardar a cicatrização em mais 1 dia (YORK et al., 1988).

- Não provocam alterações significantes na espessura corneal após a realização de repetidos debridamentos/cauterizações (BENTLEY et al., 2002). 
Autores como Slatter (2005a), não recomendam a utilização de agentes cauterizantes, pois acreditam que resultados similares com menor fibrose podem ser alcançados com debridamento cirúrgico cuidadoso, uso de antibióticos e/ou recobrimento físico da lesão.

\subsection{Vitamina C (Ácido ascórbico)}

Pirie $^{1}$ (1946 apud BRUBAKER et al., 2000, p. 96) relatou há mais de 50 anos, a presença do ácido ascórbico no epitélio corneal. Este, proveniente da circulação sistêmica, adentra o bulbo do olho junto com o humor aquoso e se difunde pelo endotélio até alcançar o epitélio corneal (BRUBAKER et al., 2000). Quanto maior for a concentração desta vitamina na circulação, maior será sua concentração na superfície corneal (REIM; SEIDL; BRUCKER, 1978).

A vitamina $C$ é capaz de estimular e regular a síntese de colágeno na córnea (SAIKA et al., 1992; GROSS, 2000) e de funcionar como importante filtro de raios ultra-violeta; por conta disso, encontra-se presente em maior quantidade nas espécies de vida diurna, do que nas de vida noturna (RINGVOLD et al., 1998). Estudos observaram que a vitamina $\mathrm{C}$ :

- Diminui seu nível fisiológico após lesão corneal (BILGIHAN et al., 2001) e na presença de catarata diabética (BARROS et al., 2002).

- $\mathrm{Na}$ administração tópica pode diminuir, significativamente, a degeneração corneal por radicais oxidativos, além de reduzir, de forma eficiente, a reação inflamatória da região (KASETSUWAN et al., 1999).

- Na administração sistêmica, pode promover melhores resultados na cicatrização corneal em humanos submetidos a cirurgias refrativas (STOJANOVIC; RINGVOLD; NITTER, 2003) e após queimaduras corneais por álcalis (SAIKA et al., 1993).

- Em culturas de ceratócitos humanos, pode estimular a síntese de fibroblastos e componentes da matriz extra-celular, remodelando e

\footnotetext{
${ }^{1}$ PIRIE A. Ascorbic acid content of cornea. Biochemical Journal, v. 40, p: 96-100,
} 1946. 
orientando as fibrilas colágenas que compõe a região (GUO et al., 2007).

\subsection{Preservativos oftalmológicos}

Diversas preparações oftalmológicas apresentam preservativos em sua composição, tais como: timerosal, sorbatos, cloridrato de benzalcônio, lauril sulfato de sódio, digluconato de clorexidine e EDTA (COLLIN; GRABSCH, 1982).

EDTA, , não apresenta nenhum efeito sobre a cicatrização corneal ou taxa de migração celular em coelhos quando utilizado na concentração de 0,1 \%, 4 vezes ao dia (COLLIN; GRABSCH, 1982). A perda da morfologia, o encolhimento das células e a inibição da migração celular foi observada em culturas corneais de cães após administração de cloridrato de benzalcônio e timerosal (HENDRIX; WARD; BARNHILL, 2002). Green et al. (1989) observaram que o uso de lauril sulfato de sódio é prejudicial para a cicatrização corneal. Simmons et al. (1988), observaram que timerosal e sorbatos reduzem em taxas significativas a replicação de células epiteliais em culturas de córneas de coelhos.

\subsection{Inibidores das MMPs}

Atualmente, uma nova abordagem de tratamento sugere a utilização de inibidores das MMPs. Alguns autores sugerem que a-2 macroglobulina, substância encontrada no soro sanguíneo, é um dos agentes mais potentes para esta função (BROOKS et al., 2002). Doxiciclina também apresenta capacidade de inibir as MMPs em culturas de células epiteliais da córnea humana (DURSUN et al., 2001) e no FLPC de equinos (BROOKS et al., 2002; OLLIVIER et al., 2002). Observado em diferentes estudos realizados em equinos e cães, EDTA e acetilcisteína também podem apresentar tal capacidade (BROOKS et al., 2002; OLLIVIER et al., 2002; COUTURE et al., 2003). Ciclosporina e ciprofloxacina apresentam inibição 
importante das MMPs no FLPC de cães. Por outro lado, tetraciclinas, prednisolona e polissulfato glicosaminoglicano tópicos e flunixin meglumine sistêmico não apresentam a mesma atuação (COUTURE et al., 2003; RAINBOW et al., 2003).

\subsubsection{Cirúrgico e outros procedimentos}

Para lesões mais crônicas, vascularizadas e refratárias, alguns autores referem que o tratamento de escolha deva ser a realização de ceratotomia em grade e/ou em pontos, ou a ceratectomia superficial, por terem observado taxas de sucesso bastante satisfatórias em seus estudos (STANLEY; HARDMAN; JOHNSON, 1998; LEDBETTER; MUNGER; RING, 2003a,b; SLATTER, 2005b).

\subsubsection{Complicações da úlcera indolente}

O epitélio corneal é, normalmente, uma barreira efetiva contra bactérias invasoras. Contudo, como observado anteriormente, proteinases produzidas durante o processo de cicatrização de úlceras crônicas podem complicar o quadro da doença e disseminar sua progressão, além de promover uveíte secundária, hipópio ou até ruptura corneal e prolapso de íris (SLATTER, 2005b).

\subsubsection{Cicatrização}

O epitélio corneal apresenta grande capacidade de regeneração (4 a 7 dias); já o estroma, pode apresentar cicatrização avascular em feridas estromais descomplicadas ou vascularizada em lesões infectadas e destrutivas (SLATTER, 2005b).

Diferentemente da cicatrização transparente do epitélio, durante a cicatrização avascular, as fibras colágenas se assentam de forma irregular por todo 
o estroma em regeneração formando cicatrizes (nébula, mácula ou leucoma), que interferem na transmissão de luz e diminuem a transparência corneal. Quanto mais profunda for a lesão inicial, mais densa e permanente é a cicatriz. Em animais jovens, dependendo da lesão, as cicatrizes tendem à clarear opticamente. Pigmentação e deposição de lipídeos também pode ocorrer próximo à área lesionada (SLATTER, 2005b).

No processo de cicatrização vascular, ocorre infiltração celular mais extensa e invasão de vasos sanguíneos do plexo límbico sobre a ferida. Eventualmente, os vasos sanguíneos colapsam mas não desaparecem, permanecendo visíveis por biomicroscopia com lâmpada de fenda. Tecido de granulação também pode se formar e ocasionar cicatrização densa (SLATTER, 2005b). 


\section{OBJETIVO}

Objetivou-se, em estudo retrospectivo, relatar as principais considerações descritas nos prontuários dos cães da raça Boxer com úlcera indolente, submetidos apenas ao tratamento ambulatorial, ou seja, administração de colírios, medicações sistêmicas e/ou debridamento/cauterização corneal, preconizados pelo Serviço de Oftalmologia do Hospital Veterinário da Faculdade de Medicina Veterinária e Zootecnia da Universidade de São Paulo (HOVET-FMVZ-USP) entre os anos de 1997 e 2008. 


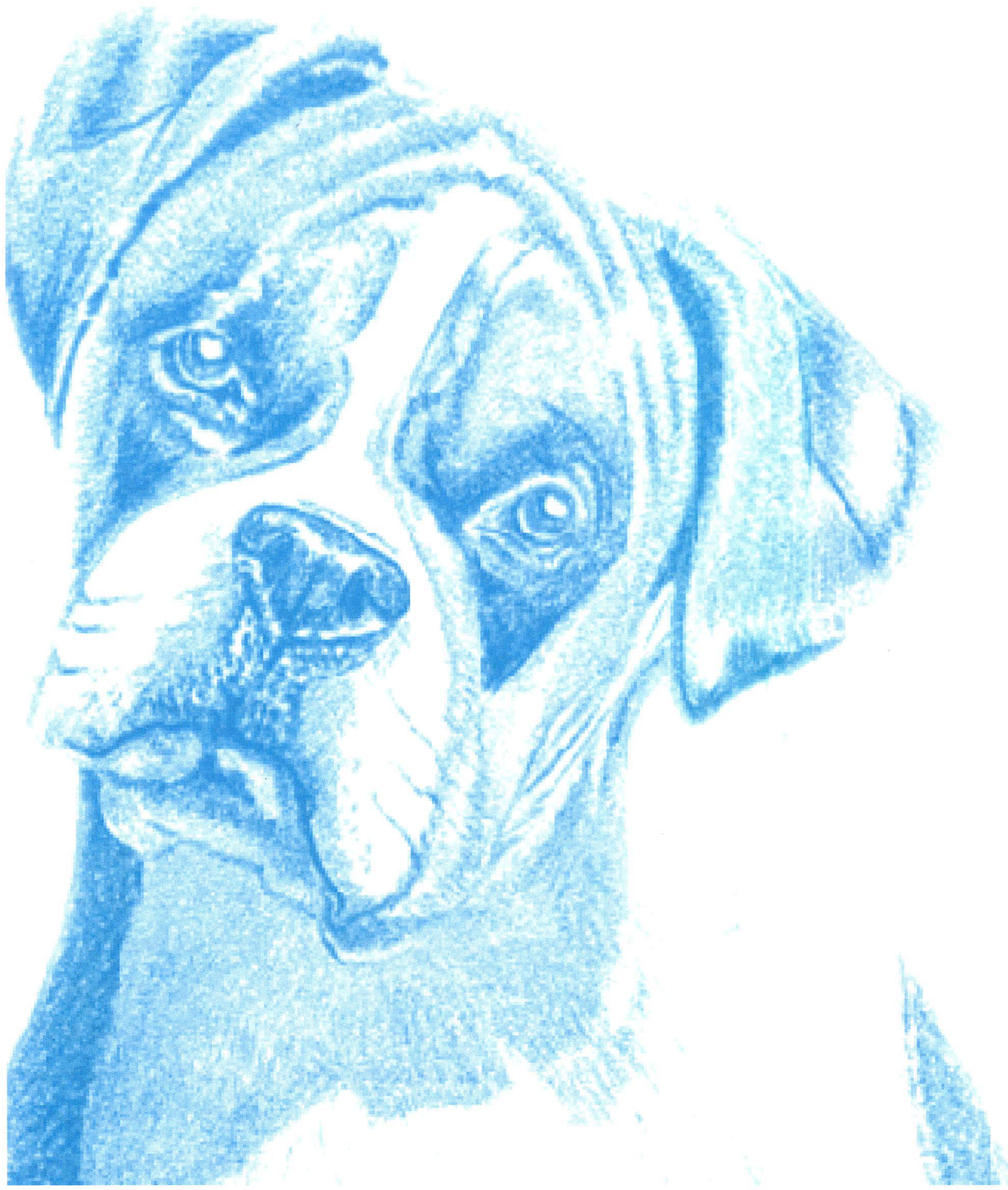

MATERIAL E MÉTODO 


\section{MATERIAL E MÉTODO}

O Material e método foi divido nos tópicos a seguir:

\subsection{MATERIAL}

Os prontuários dos cães da raça Boxer atendidos entre os anos de 1997 e 2008 no Serviço de Oftalmologia do Hospital Veterinário da Faculdade de Medicina Veterinária e Zootecnia da USP (HOVET-FMVZ-USP) foram revisados. Os animais que, após realização de exame oftalmológico completo incluindo teste de fluoresceína (Colírio de fluoresceína $1 \% ®$, Ophthalmos Indústria Farmacêutica, São Paulo, Brasil), tonometria de aplanação (Tono-pen XL, Mentor, Califórnia, EUA) e biomicroscopia com lâmpada de fenda (SL-14, Kowa Optimed Incorporation, Torrance, EUA), foram diagnosticados com úlcera indolente (Figuras 1 e 2), foram selecionados.

Como critérios de exclusão, definiu-se que os animais estudados não poderiam apresentar úlcera indolente secundárias a alterações palpebrais, ceratoconjuntivite seca ou outra oftalmopatia que justificasse seu desenvolvimento; não apresentar doenças sistêmicas concomitantes que necessitassem de qualquer medicação por qualquer via de administração que pudessem interferir no tempo de cicatrização corneal e na formação de granuloma; além de terem sido submetidos apenas ao tratamento ambulatorial, ou seja, administração de colírios, medicações sistêmicas e debridamento/cauterização corneal. Os prontuários que não estivessem corretamente preenchidos, desde o diagnóstico até o dia da alta, também não seriam incluídos no estudo. 


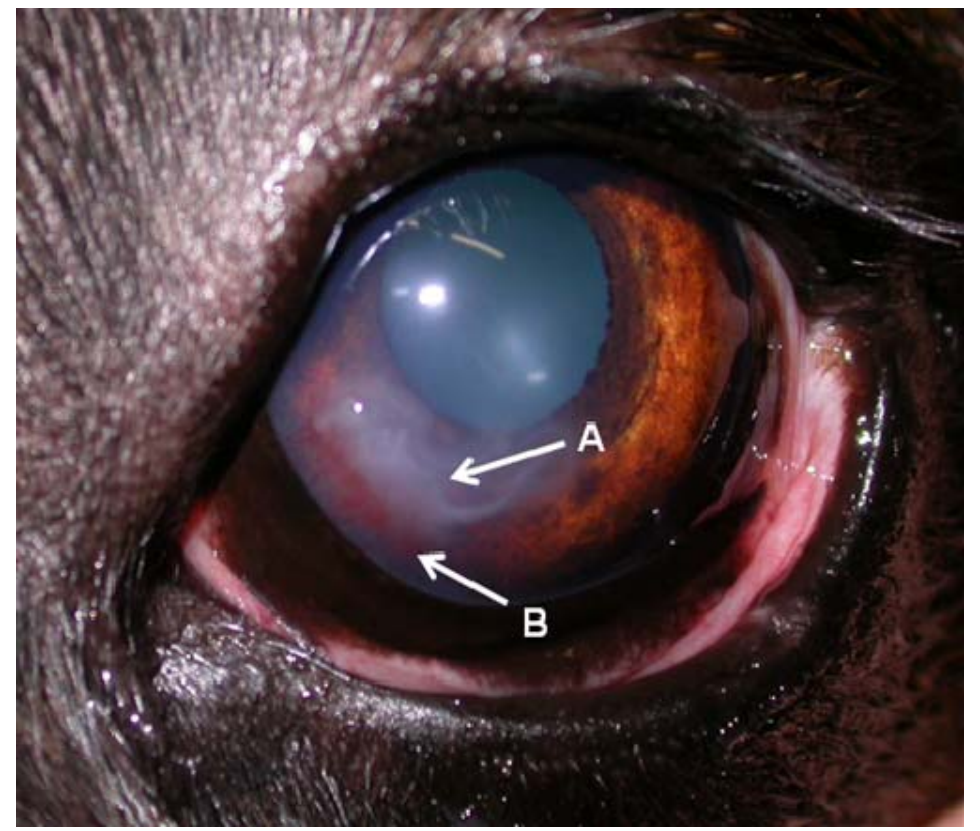

Fonte: Serviço de Oftalmologia - HOVET-FMVZ-USP

Figura 1 - Cão da raça Boxer, macho, 9 anos, com úlcera indolente no canto medial inferior do olho esquerdo. (A) Observar a descontinuação, não aderência do epitélio ao estroma e a opacidade corneal; (B) Observar a presença de neovascularização corneal

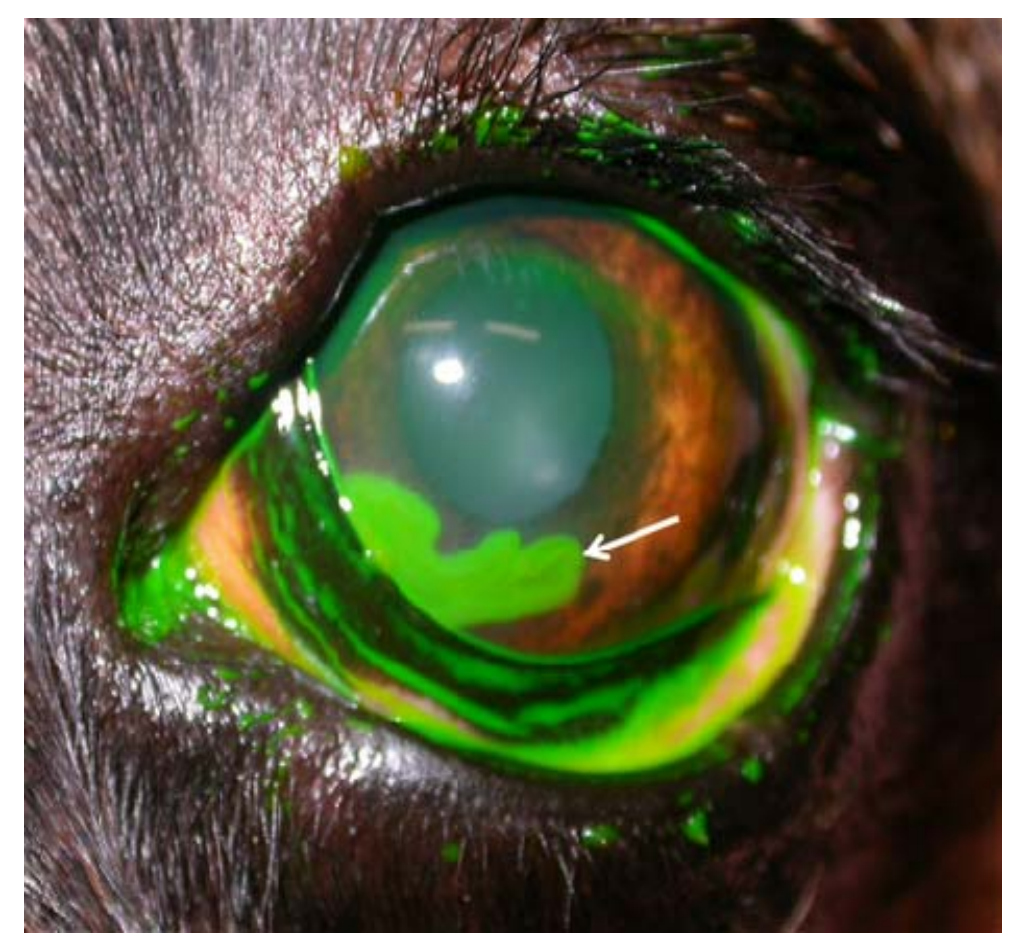

Fonte: Serviço de Oftalmologia - HOVET-FMVZ-USP

Figura 2 - O mesmo cão da raça Boxer, macho, 9 anos, com úlcera indolente no canto medial inferior do olho esquerdo, após a administração do colírio de fluoresceína $1 \%$. Observar a delimitação da borda da úlcera e a presença de corante além das bordas, isto é, sob o epitélio, indicado pela seta branca 


\subsection{MÉTODO}

As informações colhidas dos prontuário revisados e avaliadas para o estudo foram:

- Prevalência da doença em cães da raça Boxer

- Frequência da raça Boxer no Serviço de Oftalmologia do HOVET-FMVZ-USP e prevalência da doença nesta raça.

- Doenças oculares diagnosticadas nesta raça durante o período do estudo.

○ O sexo e a idade dos animais incluídos no estudo.

- Doenças sistêmicas que, além da úlcera, acometeram os animais selecionados.

- Manejo ambulatorial antes da primeira consulta

○ O tempo de alteração ocular antes da primeira consulta.

- As medicações utilizadas previamente à primeira consulta.

- Avaliação clínica

- As manifestações oculares e sistêmicas referidas pelos proprietários durante anamnese da primeira consulta.

○ O olho mais frequentemente acometido.

○ A localização das úlceras na córnea.

o As características das úlceras ao exame oftalmológico da primeira consulta. 
- Tratamento

o Primeiramente, realizou-se a identificação de todos os tratamentos ambulatoriais preconizados pelo Serviço de Oftalmologia do HOVET-FMVZ-USP durante o período estudado. Depois, identificou-se o dia de cicatrização de cada caso. Os dados foram então organizados na forma de tabela, contendo os 142 casos estudados e seus respectivos dias de alta, com os tratamentos ambulatoriais preconizados (Anexo A). Para facilitar o estudo, as medicações foram organizadas em grupos de tratamentos, da seguinte maneira:

- Todas as medicações prescritas com o intuito de inibir as proteinases formaram o grupo dos inibidores das proteinases.

- Os casos em que se prescreveu vitamina C por via oral, o grupo Vitamina $\mathbf{C}$.

- Os casos em que se realizou debridamento/cauterização corneal, formou o grupo debridamento/cauterização.

- Os casos em que foi prescrito antibióticos, administrados tanto por via tópica, quanto sistêmica, formaram o grupo antibióticos.

- Criou-se também o grupo Sem, ou seja, o grupo dos animais que não receberam antibiótico, atropina $1 \%$ ou anti-inflamatório, pois segundo a literatura, algumas destas medicações poderiam prejudicar e/ou retardar a cicatrização das úlceras.

- Atropina 1 \% tópica formou outro grupo.

- Os casos em que foi prescrito anti-inflamatórios tópicos ou sistêmicos, esteroidais e não esteroidais, o grupo antiinflamatório. 
- Para a avaliação da eficácia dos diferentes grupos de tratamentos:

- Analisou-se a velocidade de cicatrização para cada grupo de tratamento. Para tanto, comparou-se por teste estatístico (Mann-Whitney, utilizando-se o teste de Kolmogorov-Smirnov = K-S para justificá-lo), o tempo de cicatrização de todos os animais que utilizaram o grupo de tratamento avaliado, com o tempo de cicatrização de todos os animais que não o utilizaram. Desta forma, se observou se a utilização do grupo de tratamento foi mais eficiente na resolução do quadro, ou se sua não utilização seria mais interessante para um menor tempo de cicatrização. Os valores de "p", calculados por Kruskal-Wallis que resultaram em $p<0,05$, foram considerados estatisticamente significantes.

- Cicatrização

- Correlacionou-se, na forma de gráfico (correlação de Pearson), a interferência do tempo de alteração ocular antes da primeira consulta, com o tempo de cicatrização para, desta forma, avaliar se o tempo de alteração ocular antes da primeira consulta influencia no tempo de cicatrização.

- Relacionou-se, na forma de tabela, a característica das úlceras na primeira consulta, com o tempo de alteração antes da primeira consulta e o tempo de cicatrização. Desta forma, se observou se as alterações corneais observadas na primeira consulta se relacionam com o tempo de alteração, ou seja, se a resposta corneal é mais evidente (neovasos, opacidade e granuloma) nos casos que apresentavam maior tempo de alteração sem tratamento eficiente; além de observar se tais alterações corneais influenciam no tempo de cicatrização. 
- Analisou-se a correlação entre a utilização dos diferentes grupos de tratamentos ambulatoriais preconizados e a formação de granuloma. Para tanto, comparou-se por teste estatístico (teste exato de Fisher), os casos que apresentaram granuloma durante ou após a cicatrização, segundo o grupo de tratamento que utilizaram, ou não utilizaram e os casos que não apresentaram granuloma durante ou após a cicatrização, segundo o grupo de tratamento que utilizaram, ou não utilizaram. Desta forma, se observou se a utilização do grupo de tratamento é capaz ou não de proporcionar a transparência corneal durante e após o processo de cicatrização. Os valores de "p", calculados por Kruskal-Wallis, que resultaram em $p<0,05$ foram considerados estatisticamente significantes.

- Analisou-se também a eficácia de cada grupo de tratamento em cicatrizar as úlceras em até $\mathbf{3 0}$ dias, ou seja, sua capacidade em acelerar o processo de cicatrização. Para tanto, comparou-se também por teste exato de Fisher os casos que apresentaram tempo de cicatrização de até 30 dias, segundo o grupo de tratamento que utilizaram, ou não utilizaram, e os casos que apresentaram tempo de cicatrização maior do que 30 dias, segundo o grupo de tratamento que utilizaram, ou não utilizaram. Desta forma, se observou se a utilização ou não de cada grupo de tratamento é capaz ou não de acelerar o processo de cicatrização. Os valores de " $p$ ", calculados por Kruskal-Wallis, que resultaram em $p<0,05$ foram considerados estatisticamente significantes. 


\subsection{ANÁLISE ESTATÍSTICA}

As variáveis classificatórias foram apresentadas em tabelas de contingência descritivas, contendo freqüências absolutas ( $n$ ) e relativas (\%).

As variáveis foram apresentadas em tabelas contendo média, desvio padrão, mediana e valores mínimos e máximos. As variáveis quantitativas segundo o tempo de cicatrização foram comparadas pelo teste de Mann-Whitney, utilizando-se o teste de Kolmogorov-Smirnov = K-S para justificá-lo. As variáveis quantitativas segundo a presença ou não de granuloma e a cicatrização até 30 dias foram avaliadas pelo teste exato de Fisher. A interferência do tempo de alteração ocular antes da primeira consulta no tempo de cicatrização foi avaliada pelo teste de correlação de Pearson.

Os gráficos, em "boxplot" ou diagrama em caixas, representam a distribuição dos dados. A linha horizontal dentro da caixa é o valor da mediana e os limites inferior e superior da caixa mostram, respectivamente, o percentil 25 e o percentil 75. Os limites inferior e superior, simbolizado pelas linhas verticais, representam os valores mínimo e máximo. Valores "outliers" são os pontos localizados fora do intervalo formado pelo percentil 75 mais $1,5 \mathrm{vez}$ o intervalo interquartilítico e pelo percentil 25 menos 1,5 vez o intervalo interquartilítico. Valores "outliers" acima de 3 vezes o intervalo interquartilítico foram chamados de valores extremos.

Os valores de "p" foram calculados por Kruskal-Wallis e os que resultaram em $p<0,05$ foram considerados estatisticamente significantes. 


\section{RESULTADOS}

Para melhor entendimento das diversas variáveis analisadas, dividiu-se os resultados segundo os tópicos citados no material e método:

\subsection{PREVALÊNCIA DA DOENÇA EM CÃES DA RAÇA BOXER}

A prevalência da doença será discutida nos tópicos a seguir:

5.1.1 Frequência da raça Boxer no serviço de oftalmologia do HOVET-FMVZUSP e prevalência da doença nesta raça

Foram atendidos 25046 animais no Serviço de Oftalmologia do HOVETFMVZ-USP entre os anos de 1997 e 2008. Destes, 324 (1,29 \%) eram cães da raça Boxer, com 189 (58,33 \%) diagnósticos de úlcera indolente.

5.1.2 Doenças oculares diagnosticadas nesta raça durante o período do estudo

Todas as oftalmopatias diagnosticadas nesta raça durante o período estudado estão apresentadas no quadro 1. 
Quadro 1 - Lista de oftalmopatias diagnosticadas no Serviço de Oftalmologia do HOVET-FMVZ-USP, em cães da raça Boxer, entre 1997 a 2008

\begin{tabular}{|c|c|c|c|}
\hline Oftalmopatia & $\mathrm{n}$ & Oftalmopatia & $\mathrm{n}$ \\
\hline Úlcera indolente & 189 & Coriorretinite & 2 \\
\hline Distrofia/degeneração corneal & 22 & Descemetocele & 2 \\
\hline Neoformação em pálpebra $/ 3^{a}$ palpebra & 20 & Descolamento de retina & 2 \\
\hline Uveíte & 16 & Formação intraocular & 2 \\
\hline Conjuntivite & 13 & Neurite óptica & 2 \\
\hline Ceratoconjuntivite seca & 11 & Panuveíte & 2 \\
\hline Leucoma & 10 & Paralisia facial & 2 \\
\hline Catarata madura & 9 & Uveíte facogênica & 2 \\
\hline Blefarite & 8 & Amaurose & 1 \\
\hline Despigmentação da $3^{a}$ pálpebra & 8 & Anisocoria & 1 \\
\hline Florida spots & 8 & Ceratocone & 1 \\
\hline Catarata hipermadura & 6 & Ceratoconjuntivite & 1 \\
\hline Catarata imatura & 6 & Ceratouveíte & 1 \\
\hline Glaucoma & 6 & Corpo estranho & 1 \\
\hline Esclerose do cristalino & 5 & Ectrópio & 1 \\
\hline Nada digno de nota & 5 & Esclerite & 1 \\
\hline Prolapso de íris & 5 & Exoftalmia & 1 \\
\hline Blefaroconjuntivite & 4 & Hemangiossarcoma & 1 \\
\hline Cílio ectópico & 4 & Hifema & 1 \\
\hline Distiquíase & 4 & Laceração da $3^{a}$ pálpebra & 1 \\
\hline Hiperplasia da glândula da $3^{a}$ pálpebra & 4 & Midríase à esclarecer & 1 \\
\hline Atrofia progressiva de retina & 3 & Neuropatia & 1 \\
\hline Buftalmia & 3 & Nevus em íris & 1 \\
\hline Catarata incipiente & 3 & Obstrução do ductonasolacrimal & 1 \\
\hline Degeneração retiniana & 3 & Ruptura de bulbo & 1 \\
\hline Formação em conjuntiva bulbar & 3 & Subluxação do cristalino & 1 \\
\hline Formação orbitária & 3 & Trauma & 1 \\
\hline Phthisis bulbi & 3 & Tumor venéreo transmissível & 1 \\
\hline Síndrome de Horner & 3 & Úlcera neurogênica & 1 \\
\hline Ceratomalácea & 2 & & \\
\hline
\end{tabular}

(n) quantidade de animais 


\subsubsection{O sexo e a idade dos animais incluídos no estudo}

Dos 189 diagnósticos de úlceras indolente, 47 animais se incluíam nos critérios de exclusão deste estudo, portanto, 142 casos em 120 prontuários (cães) foram estudados. Destes, 53 (44,17\%) eram machos e 67 (55,83 \%) fêmeas, com idades variando de 1 a 12 anos (média 7,71 anos). A distribuição da presença de úlcera segundo a idade está representada na tabela 1 e gráfico 1 , onde observa-se 0 acometimento mais frequente em cães de meia idade (7 e 8 anos).

Tabela 1 - Distribuição das úlceras segundo a idade dos cães

\begin{tabular}{ccc}
\hline Idade (anos) & Úlceras & $\%$ \\
\hline 1 & 1 & 0,70 \\
2 & 0 & 0 \\
3 & 0 & 0 \\
4 & 2 & 1,41 \\
5 & 5 & 3,52 \\
6 & 17 & 11,97 \\
7 & 40 & 28,17 \\
8 & 36 & 25,35 \\
9 & 23 & 16,20 \\
10 & 15 & 10,56 \\
11 & 2 & 1,41 \\
12 & 1 & 0,70 \\
\hline Total & 142 & \\
\hline
\end{tabular}




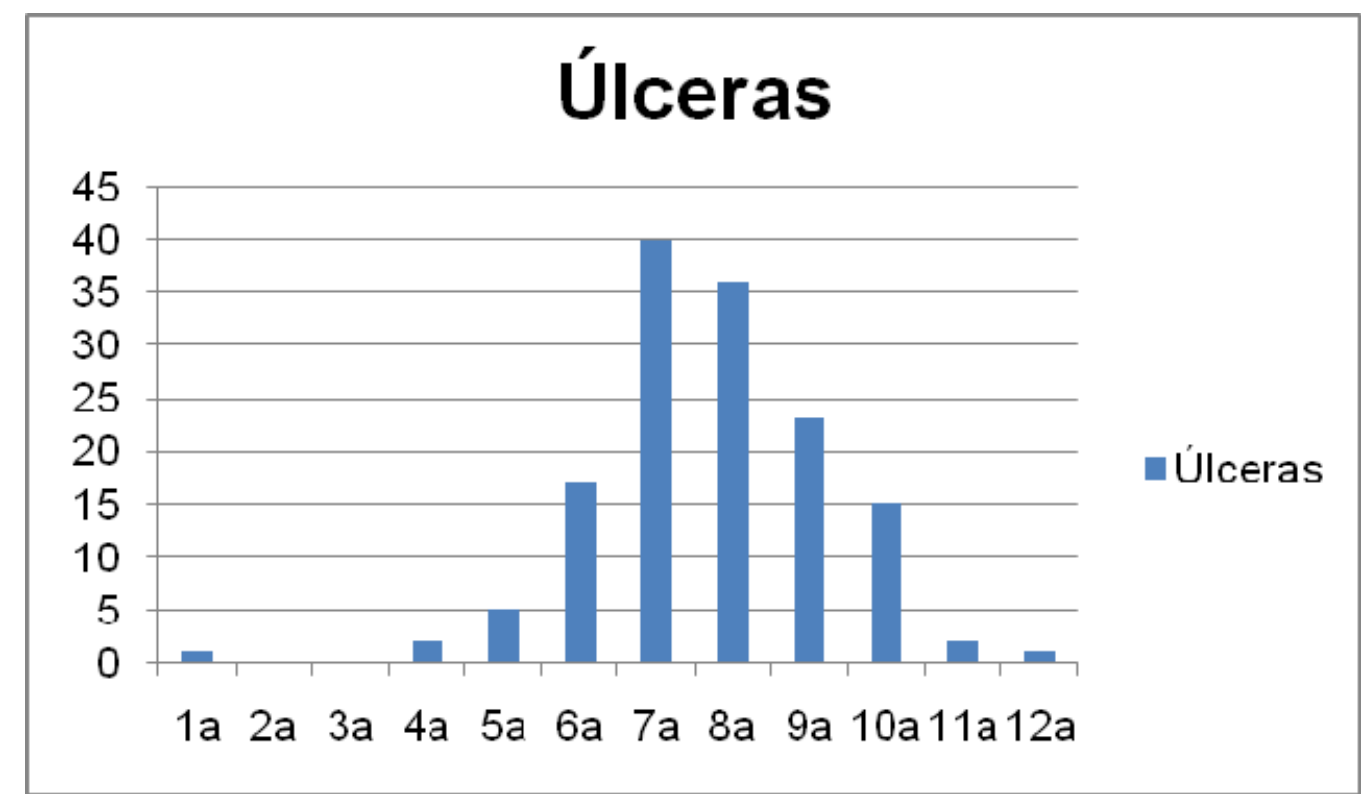

Gráfico 1 - Representação gráfica da distribuição das úlceras segundo a idade dos animais, sendo (a) anos

5.1.4 Doenças sistêmicas que, além da úlcera, acometeram os animais selecionados

Alguns animais apresentavam alterações sistêmicas concomitantes à lesão, como algum grau de cardiopatia (7), artrite (2) ou insuficiência renal crônica (1). Mastocitoma (12) e adenocarcinoma de glândula hepatóide (1) também foram observados. Como estes animais não estavam sob tratamentos que pudessem interferir neste estudo, tais como administração de soro fisiológico intra-venoso, protetores articulares ou hepáticos, foram incluídos nos 142 casos estudados. 


\subsection{MANEJO AMBULATORIAL ANTES DA PRIMEIRA CONSULTA}

O manejo ambulatorial antes da primeira consulta foi dividido nos seguintes tópicos:

\subsubsection{Tempo de alteração ocular antes da primeira consulta}

Durante anamnese, se observou que a maioria dos cães já havia sido atendida por outro médico veterinário e estava utilizando medicação tópica e/ou sistêmica, por mais de 15 dias sem resolução do quadro, motivo pela qual seus proprietários buscaram o serviço do HOVET-FMVZ-USP. O tempo de alteração ocular referido pelos proprietários em 126 dos 142 casos, está representado na tabela 2 e gráfico 2 :

Tabela 2 - Distribuição do número de casos segundo o tempo de alteração ocular antes de serem atendidos no Serviço de Oftalmologia - HOVET-FMVZ-USP

\begin{tabular}{lccc}
\hline Tempo de alteração & Dias & Casos & $(\%)$ \\
\hline 1 semana & 1 a 7 & 28 & 22,22 \\
2 semanas & 8 a 14 & 10 & 7,94 \\
3 semanas & 15 a 21 & 27 & 21,43 \\
4 semanas & 22 a 28 & 29 & 23,01 \\
5 semanas & 29 a 35 & 1 & 0,79 \\
6 semanas & 36 a 42 & 7 & 5,55 \\
7 semanas & 43 a 49 & 1 & 0,79 \\
8 semanas & 50 a 56 & 10 & 7,94 \\
10 semanas & 64 a 70 & 2 & 1,59 \\
13 semanas & 85 a 91 & 3 & 2,38 \\
18 semanas & 120 a 126 & 2 & 1,59 \\
6 meses & 162 a 168 & 3 & 2,38 \\
1 ano & 330 a 336 & 3 & 2,38 \\
\hline \multicolumn{1}{c}{ Total } & 126 \\
\hline
\end{tabular}




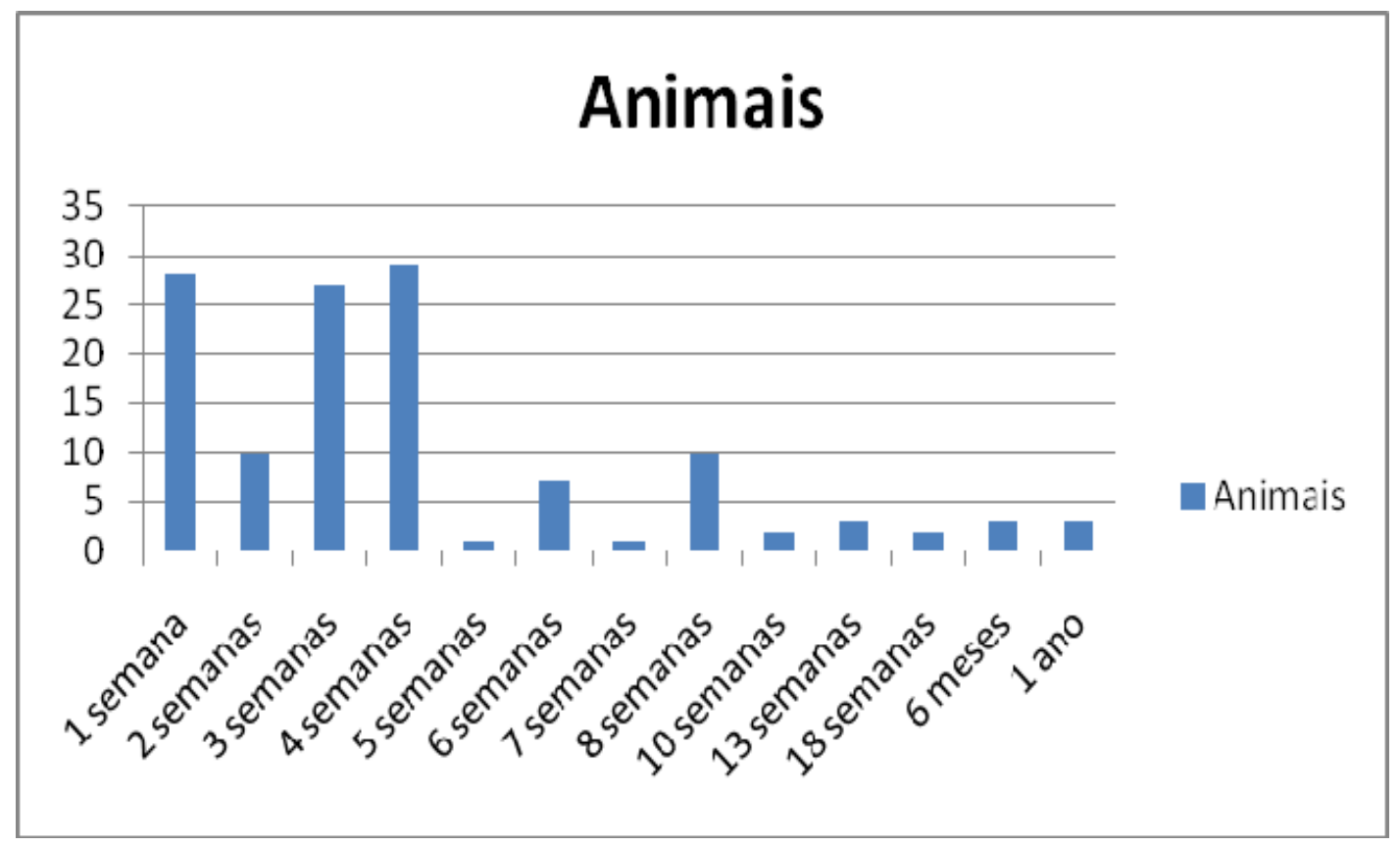

Gráfico 2 -Representação gráfica da distribuição do número de casos segundo o tempo de alteração ocular antes de serem atendidos no Serviço de Oftalmologia - HOVET-FMVZ-USP

\subsubsection{Medicações utilizadas previamente à primeira consulta}

As medicações referidas estão apresentadas no quadro 2: 
Quadro 2 - Relação de medicamentos utilizados previamente ao atendimento no HOVET-FMVZ-USP

\begin{tabular}{|c|c|c|c|}
\hline Medicamento & Animais & Medicamento & Animais \\
\hline Epitezan® & 34 & Argirol $\circledast$ & 2 \\
\hline Tobrex® & 25 & Chá de camomila & 2 \\
\hline Acetilcisteína & 17 & Decadron $®$ & 2 \\
\hline Cloranfenicolß & 14 & Garasone $®$ & 2 \\
\hline Ciprovet ${ }^{\circledR}$ & 13 & Gentamicina $®$ & 2 \\
\hline Atropina $1 \% ®$ & 10 & Ocufen $®$ & 2 \\
\hline Agua Boricada & 9 & 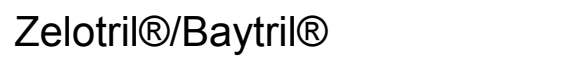 & 2 \\
\hline Still $\circledast$ & 9 & Arovit ( & 2 \\
\hline Lácrima plus ${ }^{\circledR}$ & 8 & Neodexa ${ }^{\circledR}$ & 2 \\
\hline Cewin $®$ & 6 & Nistatina & 2 \\
\hline Dunason® & 6 & $\begin{array}{l}\text { Antinflamatório não esteroidal } \\
\text { subcutâneo }\end{array}$ & 1 \\
\hline Soro Fisiológico & 6 & Cetrolac $®$ & 1 \\
\hline Keravit $尺$ & 5 & Compressa com água morna & 1 \\
\hline Tobradex® & 5 & Difen $\circledast$ & 1 \\
\hline Agua Filtrada & 4 & Epitegel $\circledast$ & 1 \\
\hline Biamotil $\circledast$ & 4 & Gentacort $尺$ & 1 \\
\hline Meticorten $®$ & 4 & Ivermectina & 1 \\
\hline Clarvisol ${ }^{\circledR}$ & 3 & Keflex® & 1 \\
\hline Dexafenicol® & 3 & Terramicina $®$ & 1 \\
\hline EDTA & 3 & Tylenol $\circledR$ & 1 \\
\hline Fluimucilß & 3 & Vitamina A & 1 \\
\hline 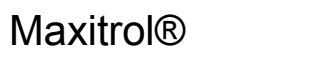 & 3 & Glicose & 1 \\
\hline Moura Brasil $\circledast$ & 3 & Cinerária Marítima ${ }^{\circledR}$ & 1 \\
\hline 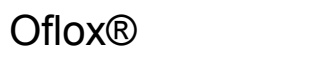 & 3 & 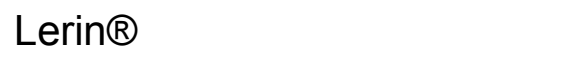 & 1 \\
\hline
\end{tabular}




\subsection{AVALIAÇÃO CLÍNICA}

A avaliação clínica será discutida nos tópicos a seguir:

\subsubsection{Manifestações oculares e sistêmicas referidas pelos proprietários durante anamnese da primeira consulta}

Observou-se que a principal queixa dos proprietários era o blefarospasmo, o olho vermelho (congestão e/ou hiperemia conjuntival) e a secreção (aquosa/lacrimejamento, mucosa ou purulenta). Além destes, alguns proprietários referiram a apatia (2) e a disorexia (1) de seus cães. Outros, tentaram o diagnóstico oftalmológico, sugerindo que seus animais apresentavam glaucoma (3), catarata (2) ou conjuntivite (1). Em 10 casos, os proprietários referiram que a causa da úlcera teria sido um trauma, mesmo não o havendo presenciado. A tabela 3 mostra as principais manifestações oculares referidas pelos proprietários durante anamnese da primeira consulta. 
Tabela 3 - Manifestações oculares referidas pelos proprietários durante a primeira consulta

\begin{tabular}{lcc}
\hline Manifestação ocular & Proprietários & $(\%)$ \\
\hline Blefarospasmo & 99 & 69,72 \\
Olho vermelho & 98 & 69,01 \\
Secreção & 92 & 64,79 \\
Prurido & 64 & 45,07 \\
Opacidade corneal & 11 & 7,75 \\
Aumento do bulbo & 5 & 3,52 \\
Baixa de visão & 5 & 3,52 \\
Dor & 5 & 3,52 \\
Protrusão da 3a pálpebra & 4 & 2,82 \\
Fotofobia & 2 & 1,41 \\
\hline Total & 142 & \\
\hline
\end{tabular}

\subsubsection{O olho mais frequentemente acometido}

Observou-se que as úlceras se apresentaram mais frequentemente na forma unilateral (130 cães), entretanto, 6 animais apresentaram a alteração em ambos os olhos ao mesmo tempo. Observou-se a recorrência da alteração após certo período de tempo no olho contralateral (10 cães) ou no olho previamente acometido (4 cães). As úlceras foram mais frequentemente observadas no olho direito (77 casos, $54,23 \%$ ), do que no esquerdo ( 65 casos, $45,77 \%$ ). 


\subsubsection{Localização das úlceras na córnea}

As úlceras se mostraram principalmente localizadas no centro da córnea, assim representado na tabela 4 , gráfico 3 e figura 3.

Tabela 4 - Quantidade de úlceras diagnosticadas segundo sua localização na córnea

\begin{tabular}{lcc}
\hline Região da córnea & Úlceras & $(\%)$ \\
\hline Central & 57 & 40,14 \\
Medial superior & 7 & 4,83 \\
Medial central & 14 & 9,86 \\
Medial inferior & 12 & 8,45 \\
Temporal & 28 & 19,72 \\
Temporal superior & 7 & 4,83 \\
Temporal inferior & 17 & 11,97 \\
\hline \multicolumn{2}{c}{ Total } & 142 \\
\hline
\end{tabular}

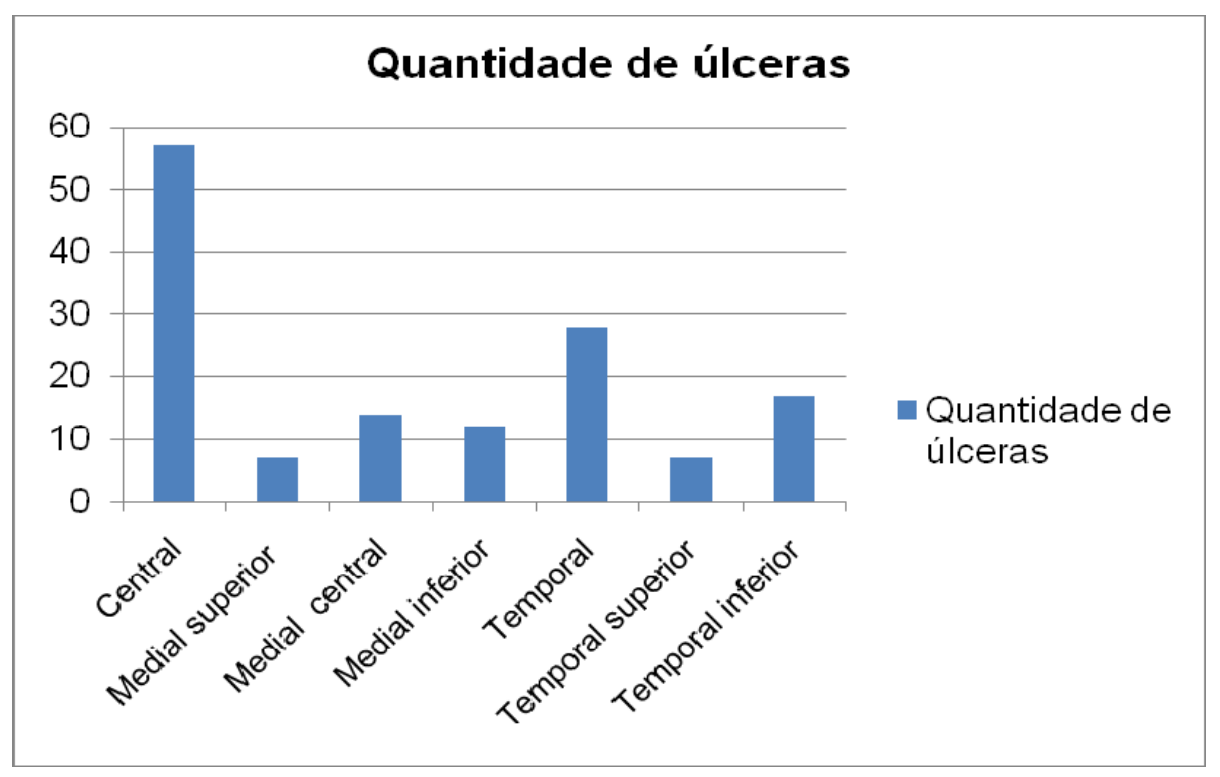

Gráfico 3 - Representação gráfica da quantidade de úlceras diagnosticadas segundo a localização na córnea 


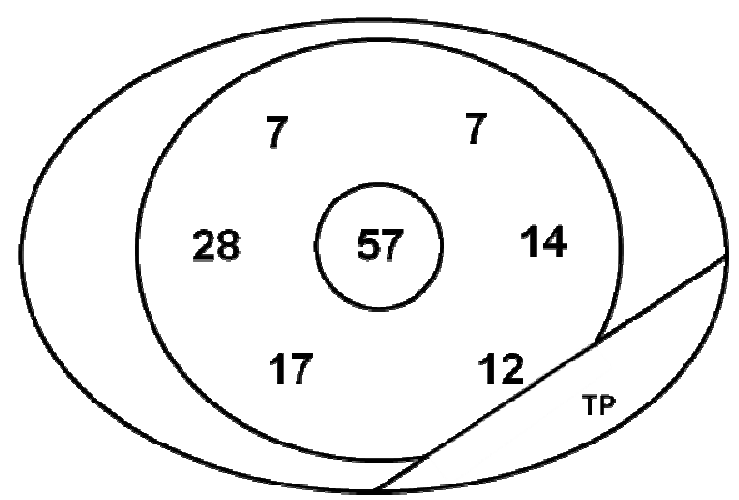

Figura 3 - Representação da quantidade de úlceras segundo a localização na córnea. (TP) Terceira pálpebra - canto medial

\subsubsection{Características das úlceras ao exame oftalmológico na primeira consulta}

Ao exame oftalmológico da primeira consulta, as úlceras apresentavam diferentes características que estão descritas na tabela 5. Observou-se que a maioria das lesões eram caracterizadas pela descontinuação do epitélio e/ou com algum grau de neovascularização.

Tabela 5 - Características das úlceras observadas durante exame da primeira consulta segundo o número de animais

\begin{tabular}{lcc}
\hline Tipo de úlcera & Animais & (\%) \\
\hline Solução de continuidade (SC) & 49 & 34,51 \\
SC com neovascularização & 34 & 23,94 \\
SC com granuloma & 17 & 11,97 \\
SC com neovascularização e opacidade & 14 & 9,86 \\
SC com neovascularização e granuloma & 13 & 9,15 \\
SC com opacidade & 6 & 4,23 \\
SC com opacidade e granuloma & 6 & 4,23 \\
SC com opacidade, granuloma e & 3 & 2,11 \\
neovascularização & &
\end{tabular}

Total 142

(SC) Solução de continuidade - descontinuação do epitélio 


\subsection{TRATAMENTO}

O tratamento foi discutidos nos tópicos a seguir:

\subsubsection{Tratamentos ambulatoriais preconizados pelo Serviço de Oftalmologia do HOVET}

No que se refere ao tratamento tópico, observou-se que, para a maior parte dos casos prescreveu-se inibidores das proteinases associados a outras medicações (129 olhos - 90,68 \%), sendo 1 gota no olho acometido, 4 vezes ao dia, até a resolução do quadro. Acetilcisteína $10 \%$ foi prescrita para 121 casos, acetilcisteína $5 \%$ e EDTA $0,35 \%$ para 4 casos cada. Os demais tratamentos tópicos incluíram antibiótico (tobramicina, ofloxacina, ciprofloxacina, gatifloxacina e pomada de cloranfenicol), anti-inflamatório esteroidal (dexametasona e fluocinolona) e não esteroidal (diclofenaco sódico e cetorolaco de trometamina), estes prescritos também na dose de 1 gota no olho acometido, 4 vezes ao dia, por um período que variou de 10 dias até a resolução do quadro. Atropina $1 \%$ foi prescrita ocasionalmente, de 2 a 3 vezes ao dia, por períodos que variaram de 3 a 15 dias. Por via oral, prescreveu-se $500 \mathrm{mg}$ de Vitamina $\mathrm{C}$ a cada 12 horas e, em alguns casos, antibiótico (enrofloxacina) e anti-inflamatório não esteroidal (flunixinmeglumine e meloxicam) nas doses recomendadas em bula para cães. O debridamento/cauterização com iodo povidine diluído a 0,2 \% (em água destilada), após anestesia tópica (Cloridrato de Proximetacaína 0,5 \%, Alcon Labs., São Paulo, Brasil), foi realizado em 87 casos com o auxílio de uma pinça hemostática e um pouco de algodão. Todos os grupos de tratamentos com suas respectivas quantidade de úlceras por eles tratadas estão descritos na tabela 6 e gráfico 4 : 
Tabela 6 - Tratamentos ambulatoriais preconizados no Serviço de Oftalmologia do HOVET-FMVZUSP no período estudado segundo o número de úlceras

\begin{tabular}{lcc}
\hline \multicolumn{1}{c}{ Medicações } & Úlceras & $\%$ \\
\hline Inibidores das proteinases & 129 & 90,68 \\
Vitamina C & 110 & 77,46 \\
Debridamento/cauterização & 87 & 61,28 \\
Antibiótico & 81 & 57,04 \\
Sem antibiótico, atropina 1 \% ou anti-inflamatório & 54 & 38,03 \\
Atropina 1 \% & 25 & 17,61 \\
Anti-inflamatório & 20 & 14,08 \\
\hline Total & 142 & \\
\hline
\end{tabular}

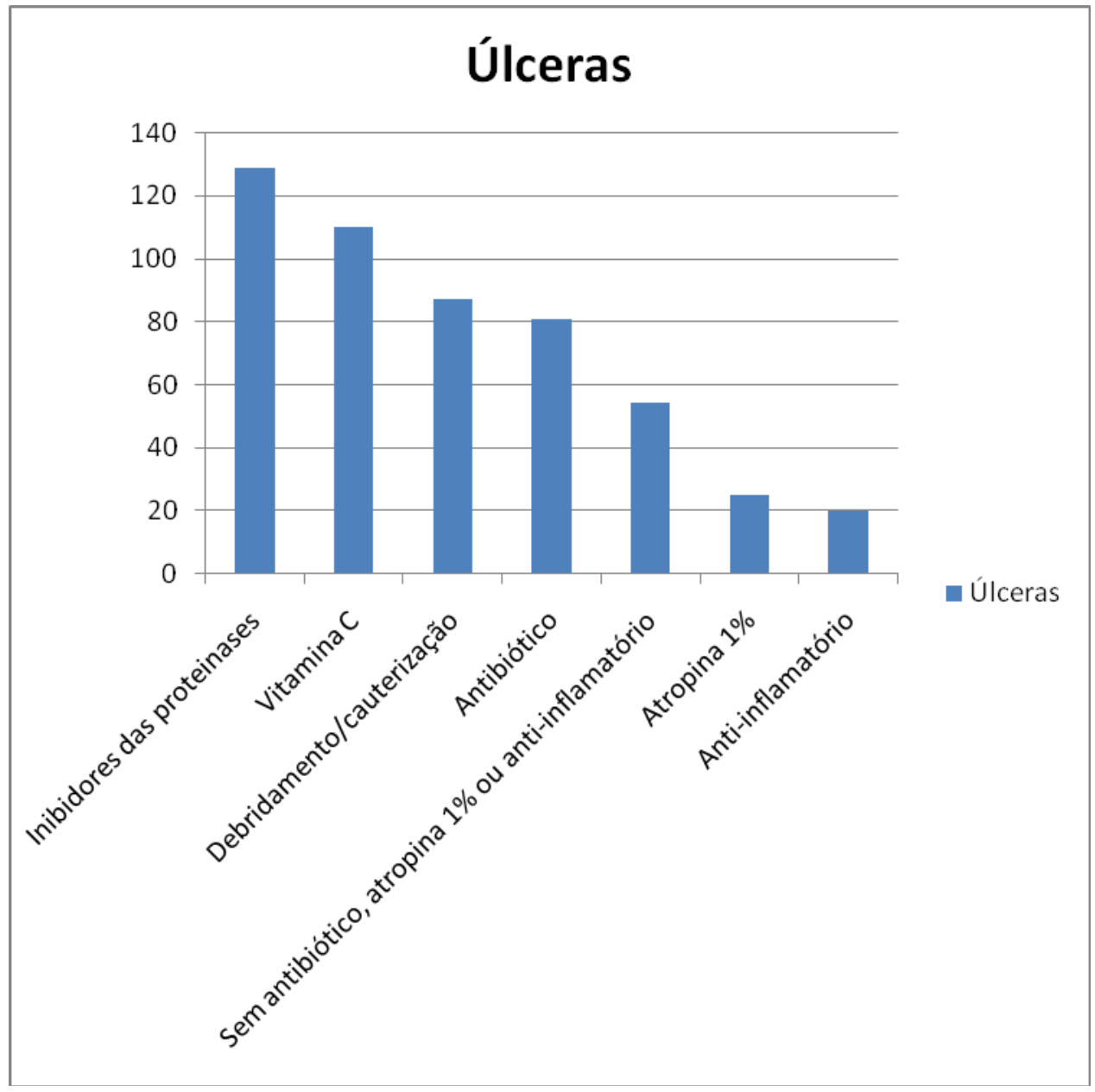

Gráfico 4 - Representação gráfica dos diferentes tratamentos ambulatoriais preconizados no Serviço de Oftalmologia do HOVET-FMVZ-USP no período estudado, segundo o número de úlceras 


\subsubsection{Eficácia dos diferentes tratamentos ambulatoriais quanto a rapidez da resolução do quadro}

Comparou-se os tipos de tratamentos preconizados com o tempo de cicatrização. Para tanto, as úlceras foram primeiramente numeradas de 1 a $142 \mathrm{e}$ depois distribuídas na forma de tabela (Anexo $A$ ), com o dia em que o animal recebeu alta do serviço e segundo a utilização ou não dos diversos grupos de tratamento preconizados.

Observou-se que a utilização de Vitamina $C$ e a realização do debridamento/cauterização interferiram, significativamente, na cicatrização corneal, pois o tempo de cicatrização foi menor nos animais que tiveram suas feridas debridadas/cauterizadas (Tabela 7 e Gráfico 5) e nos que não receberam vitamina $C$ por via sistêmica (Tabela 8 e Gráfico 6). Estipulou-se como valores estatisticamente significantes, aqueles em que $p<0,05$.

Tabela 7 - Distribuição dos tratamentos ambulatoriais preconizados segundo o tempo de cicatrização

\begin{tabular}{lccccccc}
\hline Medicação & Úlceras & Média & $\begin{array}{c}\text { Desvio } \\
\text { padrão }\end{array}$ & Mediana & Mínimo & Máximo & $\mathrm{p}$ \\
\hline Inibid das protei & 129 & 30,95 & 19,56 & 25 & 27,54 & 34,36 & 0,648 \\
Vitamina C & 110 & 32,69 & 20,81 & 27,5 & 28,76 & 36,62 & 0,023 \\
Debrid/cauter & 87 & 26,64 & 15,52 & 21 & 23,34 & 29,95 & $\mathrm{p}<0,0001$ \\
Antibiótico & 81 & 31,99 & 21,96 & 27 & 27,13 & 36,84 & 0,593 \\
Sem & 54 & 28,89 & 14,75 & 24 & 24,86 & 32,91 & 0,638 \\
Atropina 1 \% & 25 & 39,24 & 33,43 & 28 & 25,44 & 53,04 & 0,672 \\
Anti-inflamatório & 20 & 41,55 & 35,17 & 29 & 25,09 & 58,01 & 0,420 \\
\hline
\end{tabular}

Inibid das protei (Inibidores das proteinases); Debrid/cauter (Debridamento/cauterização); Sem (Sem antibiótico, atropina $1 \%$ ou anti-inflamatório) 


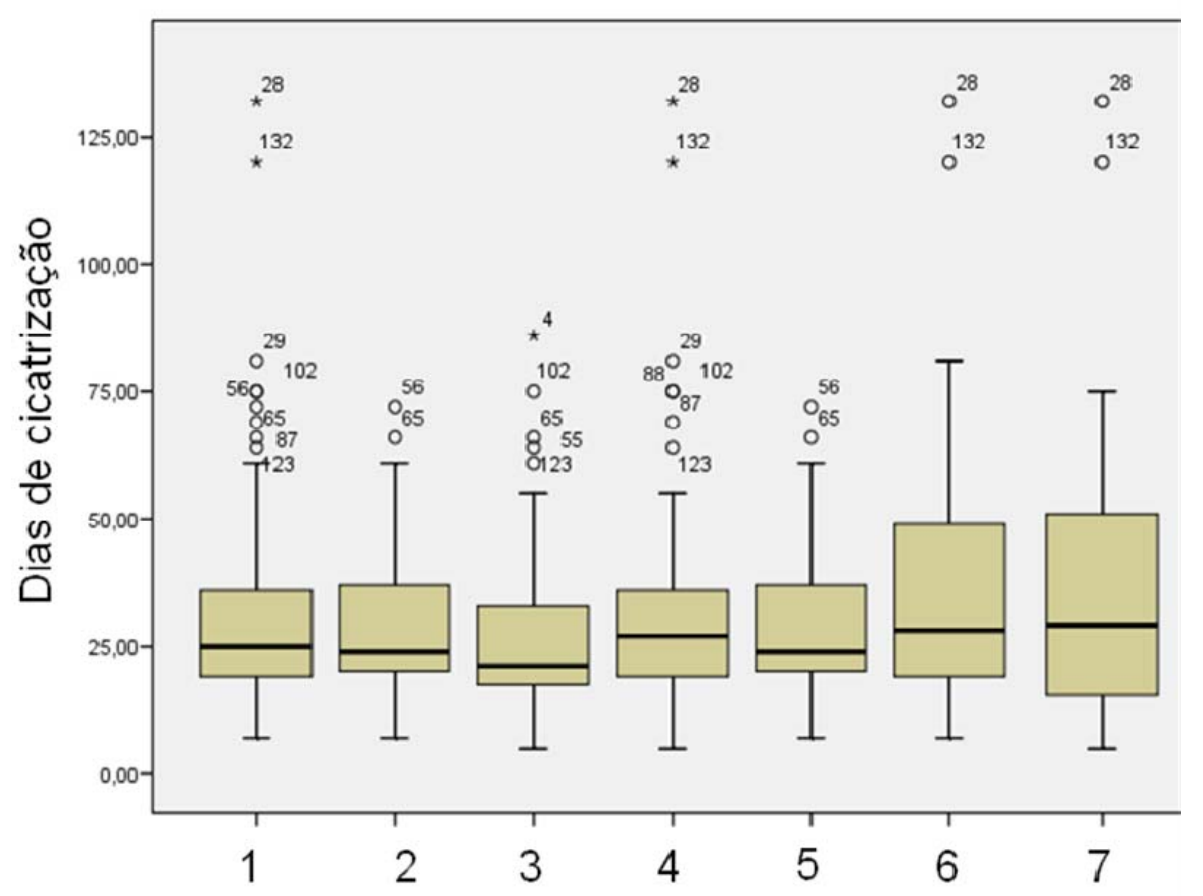

1 - Inibidores das proteinases; 2 - Vitamina C; 3 - Debridamento/cauterização; 4 - Antibiótico; 5 - Sem antibiótico, atropina $1 \%$ ou anti-inflamatório; 6- Atropina $1 \%$ 7- Anti-inflamatório

Gráfico 5 - Representação gráfica dos tratamentos ambulatoriais preconizados segundo o tempo de cicatrização

Tabela 8 - Distribuição das úlceras que não tiveram os tratamentos referidos preconizados

\begin{tabular}{lccccccc}
\hline Medicação & Úlceras & Média & $\begin{array}{c}\text { Desvio } \\
\text { padrão }\end{array}$ & Mediana & Mínimo & Máximo & p \\
& & & & & & \\
\hline Inibid das protei & 13 & 30,38 & 21,63 & 21 & 17,3 & 43,45 & 0,648 \\
Vitamina C & 32 & 24,75 & 13,71 & 19,5 & 19,81 & 29,69 & 0,023 \\
Debrid/cauter & 55 & 37,64 & 23,5 & 29 & 31,28 & 43,99 & $\mathrm{p}<0,0001$ \\
Antibiótico & 61 & 29,46 & 16,23 & 24 & 25,30 & 33,61 & 0,593 \\
Sem & 88 & 32,14 & 22,16 & 26 & 27,44 & 36,83 & 0,638 \\
Atropina 1 \% & 117 & 29,12 & 14,88 & 25 & 26,39 & 31,84 & 0,672 \\
Antinflamatório & 122 & 29,15 & 15,34 & 25 & 26,41 & 31,9 & 0,420 \\
\hline
\end{tabular}

Inibid das protei (Inibidores das proteinases); Debrid/cauter (Debridamento/cauterização); Sem (Sem antibiótico, atropina $1 \%$ ou anti-inflamatório) 


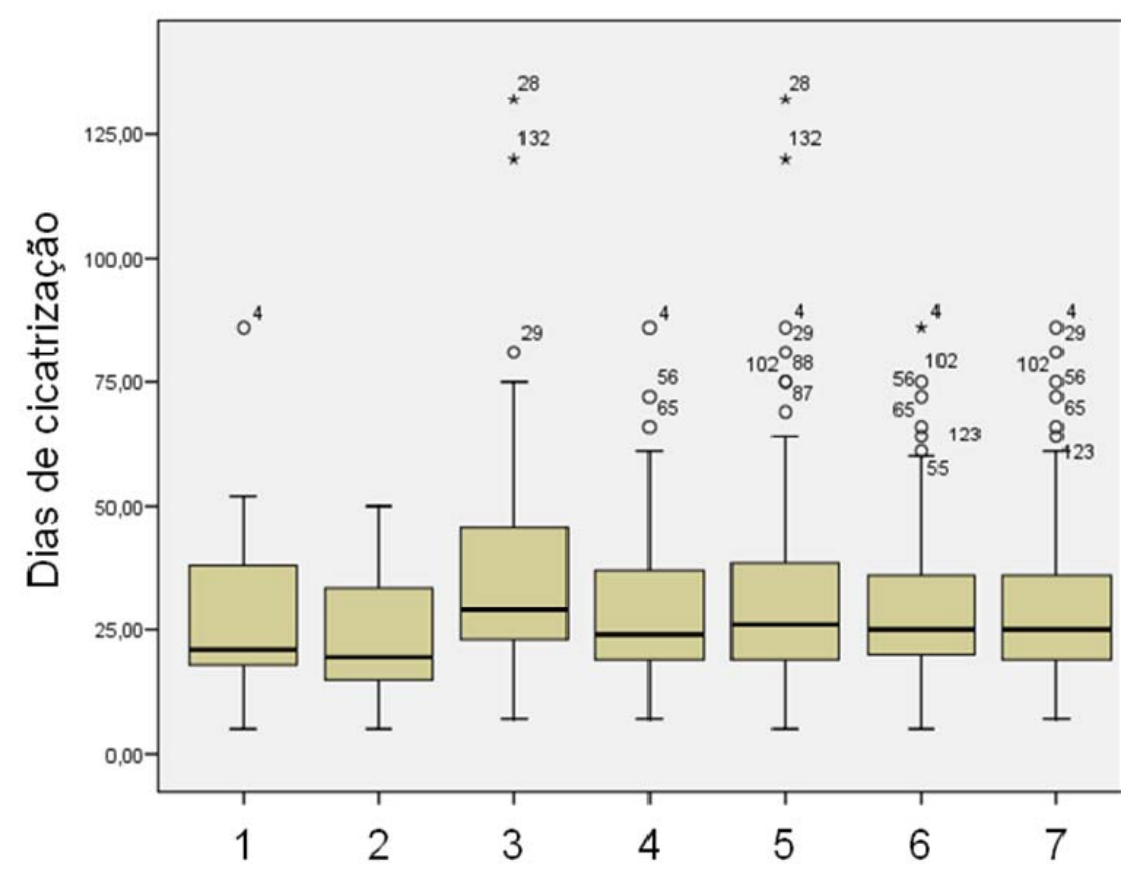

1 - Inibidores das proteinases; 2 - Vitamina C; 3 - Debridamento/cauterização; 4 - Antibiótico; 5 - Sem antibiótico, atropina $1 \%$ ou anti-inflamatório; 6- Atropina $1 \%$ 7- Anti-inflamatório

\begin{abstract}
Gráfico 6 - Representação gráfica das úlceras segundo a não utilização dos tratamentos referidos preconizados
\end{abstract}

\title{
5.5 CICATRIZAÇÃO
}

A cicatrização será discutida nos seguintes tópicos: 


\subsubsection{Interferência do tempo de alteração ocular antes da primeira consulta no} tempo de cicatrização

Não se observou correlação entre os dias de alteração referidos pelos proprietários na primeira consulta e os dias de cicatrização promovidos pelos tratamentos preconizados $(\mathrm{p}=0,781)$ (Gráfico 7 ).

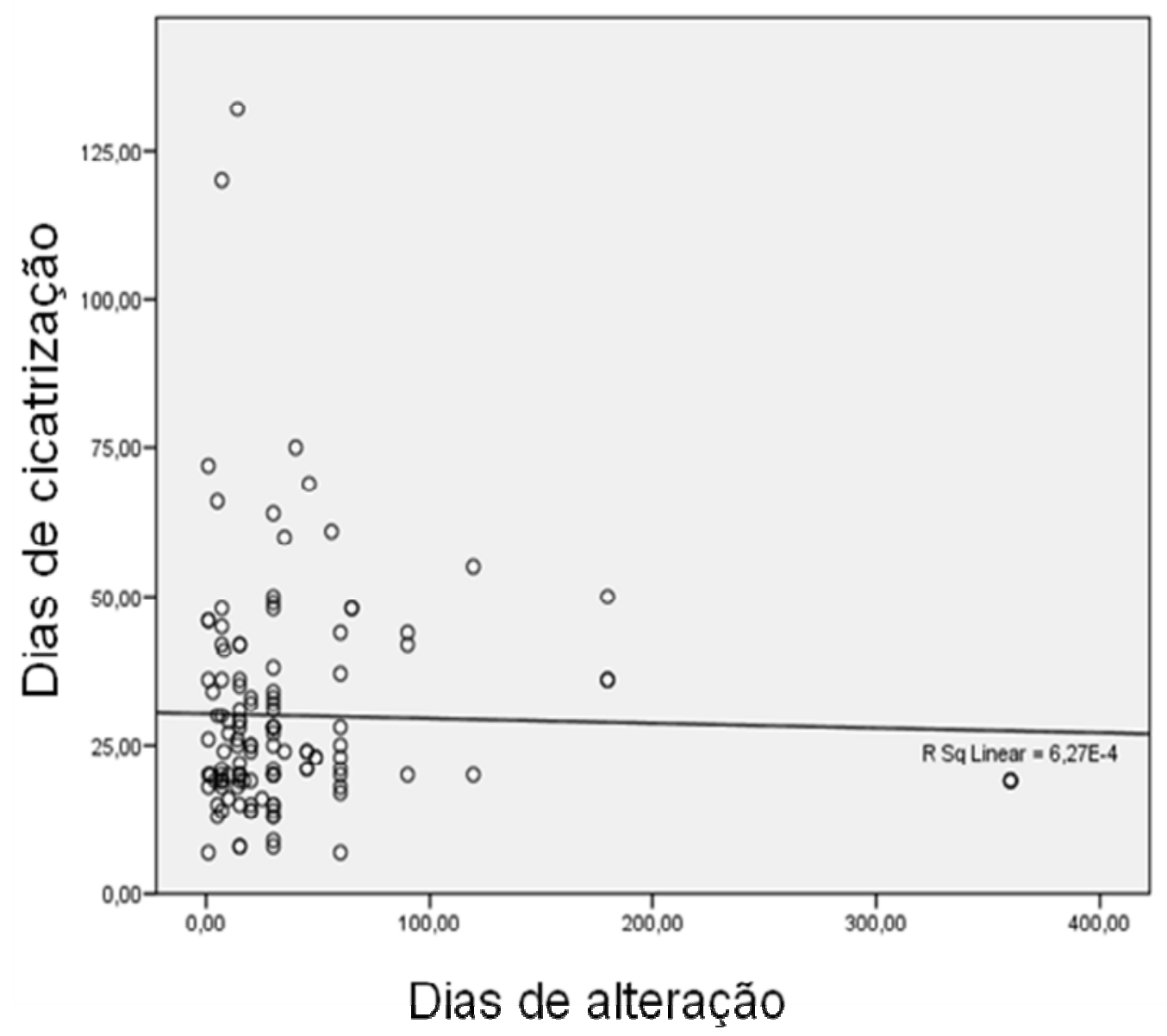

Gráfico 7 - Representação gráfica dos dias de alteração ocular referidos pelos proprietários na primeira consulta e os dias de cicatrização promovidos pelos tratamentos preconizados 


\subsubsection{Relação da característica das úlceras na primeira consulta, com o tempo de alteração antes da primeira consulta e o tempo de cicatrização}

Observou-se que a característica da úlcera variou segundo a média dos dias de cicatrização e dos dias de alteração ocular previamente à primeira consulta (Tabela 9).

Tabela 9 - Distribuição da característica das úlceras segundo a média dos dias de cicatrização e dos dias de alteração ocular previamente à primeira consulta

\begin{tabular}{lccc}
\hline Tipo de úlcera & Animais & $\begin{array}{c}\text { Média dos } \\
\text { dias de } \\
\text { cicatrização }\end{array}$ & $\begin{array}{c}\text { Média dos dias } \\
\text { de alteração }\end{array}$ \\
\hline SC com opacidade, granuloma e & 2 & 12 & 20 \\
neovascularização & 6 & 18,33 & 13,2 \\
SC com opacidade e granuloma & 11 & 20,45 & 35,91 \\
SC com neovascularização e opacidade & 13 & 24,46 & 10,9 \\
SC com neovascularização e granuloma & 32 & 30,62 & 26,56 \\
SC com neovascularização & 42 & 32,17 & 19,5 \\
Solução de continuidade (SC) & 5 & 37,2 & 53,8 \\
SC com opacidade & 15 & 38,4 & 65,27 \\
SC com granuloma & 126 & &
\end{tabular}

(SC) Solução de continuidade. Destacado em amarelo, observa-se as menores e maiores médias dos dias de cicatrização e alteração antes da primeira consulta.

\subsubsection{Correlação entre a utilização dos diferentes tratamentos ambulatoriais preconizados e a formação de granuloma}

Observou-se que o uso de vitamina $C$ e anti-inflamatório diminuem; e que antibiótico e atropina $1 \%$ aumentam, de forma estatisticamente significante, a probabilidade de formação do granuloma (Tabela 10). 
Tabela 10 - Correlação entre a utilização dos diferentes tratamentos clínicos preconizados e a formação de granuloma

\begin{tabular}{lccccc}
\hline & \multicolumn{2}{c}{ Utilizou } & \multicolumn{2}{c}{ Não utilizou } & \multirow{2}{*}{ Sem } \\
\cline { 2 - 5 } & Granuloma & $\begin{array}{c}\text { Sem } \\
\text { granuloma }\end{array}$ & Granuloma & granuloma & \\
\hline Inib das proteinases & 56 & 73 & 7 & 6 & 0,563 \\
Vitamina C & 43 & 67 & 20 & 12 & 0,026 \\
Debrid/cauter & 33 & 54 & 30 & 25 & 0,058 \\
Antibiótico & 43 & 38 & 20 & 41 & 0,018 \\
Atropina 1 \% & 18 & 7 & 45 & 72 & 0,003 \\
Anti-inflamatório & 19 & 44 & 1 & 78 & p<0,0001 \\
\hline Inib das proteinases (Inibidores das proteinases); Debrid/cauter (Debridamento/cauterização)
\end{tabular}

\subsubsection{Correlação entre a utilização dos diferentes tratamentos ambulatoriais preconizados e a cicatrização até 30 dias}

Observou-se que a realização de debridamento/cauterização pode, provavelmente, acelerar o processo de cicatrização da úlcera indolente, pois " $p$ ", apesar de ter valor muito próximo do limite, ainda assim foi menor que 0,05 (Tabela 11).

Tabela 11 - Correlação entre a utilização dos diferentes tratamentos ambulatoriais preconizados e a cicatrização até 30 dias

\begin{tabular}{lccccc}
\hline & \multicolumn{2}{c}{ Utilizou } & \multicolumn{2}{c}{ Não utilizou } & \\
\cline { 2 - 5 } & Até 30 dias & $\begin{array}{c}\text { Mais do } \\
\text { que 30 dias }\end{array}$ & Até 30 dias & $\begin{array}{c}\text { Mais do } \\
\text { que 30 } \\
\text { dias }\end{array}$ & $\mathrm{p}$ \\
\hline Inib das protein & 81 & 48 & 9 & 4 & 0,768 \\
Vitamina C & 67 & 43 & 23 & 9 & 0,302 \\
Debrid/cauter & 61 & 26 & 29 & 26 & 0,049 \\
Antibiótico & 48 & 33 & 42 & 19 & 0,292 \\
Atropina 1 \% & 14 & 11 & 76 & 41 & 0,493 \\
Anti-inflamatório & 10 & 80 & 10 & 42 & 0,214 \\
\hline
\end{tabular}

Inib das protein (Inibidores das proteinases); Debrid/cauter (Debridamento/cauterização) 


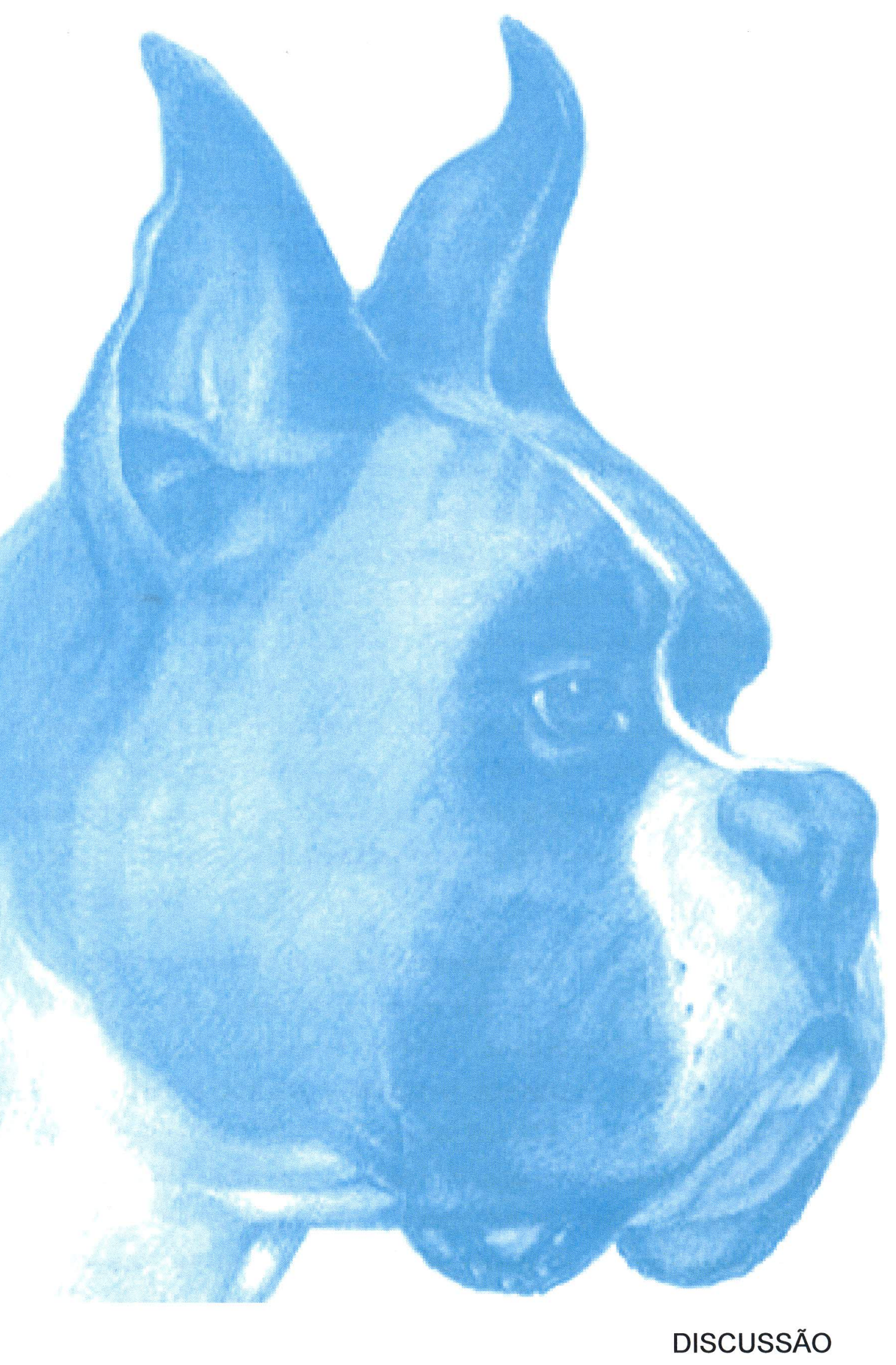




\section{DISCUSSÃO}

Muitos autores concordam que o Boxer seja a raça mais predisposta a apresentar úlcera indolente (GELATT; SAMUELSON, 1982; KIRSCHNER; NIYO; BETTS, 1989; MORGAN; ABRAMS, 1994; STANLEY; HARDMAN; JOHNSON, 1998; BENTLEY et al., 2001; MURPHY et al., 2001; GELATT, 2003b; LEDBETTER; MUNGER; RING, 2003b; BENTLEY, 2005; SLATTER, 2005b) e que, além da úlcera, frequentemente apresentam catarata, degeneração retiniana progressiva, distiquíase, glaucoma, distrofia corneal, estromal e endotelial (SLATTER, 2005). Apesar desta raça não ter sido frequentemente observada na rotina oftalmológica veterinária do Serviço de Oftalmologia do HOVET-USP, a úlcera indolente foi a oftalmopatia que mais acometeu estes cães durante o período do estudo. Observouse que a distrofia corneal e a catarata em diferentes estágios de evolução, também foram frequentemente observadas, mas glaucoma, distiquíase e a degeneração retiniana foram apenas eventualmente diagnosticadas. Alguns cães estudados apresentavam mastocitoma ou algum grau de cardiopatia concomitantes à oftalmopatia, alterações as quais Welle et al. (2008) e Oyama et al. (2008) referem o Boxer também apresentar predisposição racial e, por isso, serem frequentemente observadas nesta raça.

Neste estudo, a maioria dos cães diagnosticados com úlcera indolente foram as fêmeas de meia idade. Apesar de muitos autores concordarem que os cães de meia idade são os mais acometidos (GELATT; SAMUELSON, 1982; KIRSCHNER; NIYO; BETTS, 1989; STANLEY; HARDMAN; JOHNSON, 1998; BENTLEY et al., 2001; MURPHY et al., 2001; GELATT, 2003b; BENTLEY, 2005; SLATTER, 2005b), alguns estudos observaram ser o macho o mais predisposto a desenvolver a alteração (GELATT; SAMUELSON, 1982; KIRSCHNER, 1990; STANLEY; HARDMAN; JOHNSON, 1998; BENTLEY et al., 2001). Apesar de não avaliado neste estudo, autores referem não haver diferença quanto à prevalência da doença entre fêmeas castradas, inteiras, ou segundo a fase do cio (GELATT; SAMUELSON, 1982). 
Corroborando com diversos estudos realizados em cães com úlcera indolente, observou-se que a maioria dos cães apresentavam a alteração ocular até 1 semana, ou há mais de 15 dias antes do primeiro atendimento (GELATT; SAMUELSON, 1982; KIRSCHNER; NIYO; BETTS, 1989; STANLEY; HARDMAN; JOHNSON, 1998; MURPHY et al., 2001; LEDBETTER; MUNGER; RING, 2003b; BENTLEY, 2005), além de haver alguns animais que apresentavam a doença há mais de 6 meses e outros, há mais de 1 ano. Acredita-se que muitos destes cães tenham sido tratados anteriormente havendo recorrência intermitente da doença, ou não tenham realizado o tratamento de forma adequada. Sabe-se que a realização de tratamento adequado é fundamental para o sucesso da cicatrização (KIRSCHNER, 1990; CAMPBELL; MURPHY, 1999; BENTLEY, 2005) e que a recidiva da lesão não é incomum (GELATT; SAMUELSON, 1982; KIRSCHNER; NIYO; BETTS, 1989; GELATT, 2003b). Estudo realizado por Gelatt e Samuelson (1982), observou a recorrência da doença em 50 \% dos Boxers estudados. Estudo realizado em cães "não Boxers" apresentou a recorrência em $22 \%$ dos animais no período de até 1 ano (KIRSCHNER; NIYO; BETTS, 1989). Neste estudo, apenas 14 (9,86\%), dos 142 casos recidivaram, tanto no mesmo olho, quanto no olho contralateral. Além disso, observou-se que 6 animais apresentavam a alteração em ambos os olhos ao mesmo tempo, fato também ocasionalmente observado por Gelatt e Samuelson (1982) e Kirschner, Niyo e Betts (1989) em estudos anteriores.

Durante a anamnese da primeira consulta, blefarospasmo, olho vermelho e secreção foram os sintomas mais frequentemente referidos pelos proprietários. Todos estes, apesar de inespecíficos para o diagnóstico da úlcera indolente, foram frequentemente observados por diversos autores em estudos anteriores (GELATT; SAMUELSON, 1982; KIRSCHNER; NIYO; BETTS, 1989; MORGAN; ABRAMS, 1994; STANLEY; HARDMAN; JOHNSON, 1998; BENTLEY et al., 2001; MURPHY et al., 2001; GELATT, 2003a,b; BENTLEY, 2005; SLATTER, 2005b). Além destes, opacidade corneal, aumento do bulbo do olho, baixa de visão, dor, fotofobia e protrusão da $3^{a}$ pálpebra também foram referidos. A opacidade pode ser considerada um dos sinais clínicos da lesão, principalmente se houver alteração da arquitetura estromal. Já a dor, fotofobia, protrusão da $3^{a}$ pálpebra e a baixa de visão, associadas à apatia e à disorexia, são sintomas que poderiam estar relacionados ao desconforto ocular. Ao exame oftalmológico, a dor ocasionada pela lesão é 
diagnosticada pelo blefarospasmo, fotofobia, retração do bulbo e protrusão da $3^{\text {a }}$ pálpebra, os quais, junto com o lacrimejamento (aumento da produção do FLPC), justificariam a baixa de visão referida nos cães acometidos (MURPHY et al., 2001; SLATTER, 2005b).

O aumento do bulbo do olho, referido na anamnese, poderia ser explicado pela quemose da conjuntiva bulbar, geralmente observada quando o animal apresenta inflamação concomitante à lesão e prurido associado aos sintomas citados anteriormente (SLATTER, 2005b). Observou-se que os diagnósticos de glaucoma, catarata e conjuntivite, apesar de citados pelos proprietários, foram descartados após exame oftalmológico completo realizado pelo Serviço de Oftalmologia (HOVET-USP), que diagnosticou apenas a presença da úlcera indolente primária nos olhos dos cães incluídos neste estudo.

Dez proprietários referiram o trauma ocular como causa da lesão, mesmo sem o haverem presenciado. Alguns autores sugerem que há a possibilidade de ter realmente ocorrido um trauma semanas ou até meses antes do aparecimento da lesão (KIRSCHNER; NIYO; BETTS, 1989). Contudo, estudos observaram que a maioria das úlceras indolentes ocorrem de forma espontânea, sendo esta uma de suas principais características diagnósticas (GELATT, 2003b; BENTLEY, 2005; SLATTER, 2005b).

Após o exame, observou-se que as feridas apresentaram-se mais frequentemente na forma unilateral, no olho direito e localizadas no centro da córnea. Diversos autores corroboram com o fato de que a forma unilateral da úlcera indolente e sua localização centralizada na córnea sejam as mais rotineiramente diagnosticadas, mas que, apesar de poder haver uma discreta diferença entre a ocorrência no olho direito e esquerdo, esta dificilmente seja estatisticamente significante (GELATT; SAMUELSON, 1982; KIRSCHNER; NIYO; BETTS, 1989; KIRSCHNER, 1990; BENTLEY et al., 2001; HENDRIX; WARD; BARNHILL, 2001; GELATT, 2003b; LEDBETTER; MUNGER; RING, 2003a,b; SLATTER, 2005b). A localização das lesões no centro da córnea, também foi observada por Gelatt e Samuelson (1982), em $70 \%$ das úlceras que estudaram, o que foi observado em aproximadamente $40 \%$ dos Boxers deste estudo. Alguns autores observaram, pela estesiometria, que há um aumento na quantidade de substancia " $p$ " nas células 
epiteliais de cães com úlcera indolente, mas que, apesar disso, não há diferença entre a inervação destas córneas com córneas sadias (MARFURT; MURPHY; FLORCZAK, 2001; MURPHY et al., 2001). Sugere-se que a inervação não seja, portanto, a explicação para a maior ocorrência da lesão no centro da córnea. Até a presente data, se desconhece a causa de tal consideração.

As principais característica das lesões foram úlceras transparentes, apresentando apenas a descontinuação do epitélio ou com presença de neovascularização, observações que corroboram com diversos estudos realizados anteriormente (KIRSCHNER; NIYO; BETTS, 1989; GELATT, 2003b; SLATTER, 2005b). Segundo a literatura, as úlceras apresentando apenas a descontinuidade do epitélio (solução de continuidade) e localizadas no centro da córnea são mais frequentemente observadas nos seus estágios mais precoces (MURPHY et al., 2001; BENTLEY, 2005; SLATTER, 2005b), o que corrobora com os resultados obtidos neste estudo, já que, a maioria das úlceras diagnosticadas com estas características também foram as que apresentavam o menor tempo de alteração ocular. Estudo realizado por Gelatt e Samuelson (1982), observou vascularização em $40 \%$ das úlceras que estudaram; Murphy et al. (2001), observaram a presença de neovasos em $56 \%$ de seus casos, sendo que $80 \%$ deles estavam localizados na periferia corneal. Neste estudo, $45 \%$ dos casos apresentaram neovascularização, mas não se correlacionou a localização da úlcera com a presença dos vasos.

Opacidade corneal e granuloma foram ocasionalmente diagnosticados. Autores referem que o granuloma pode ser frequentemente observado em cães da raça Boxer, já que, quando apresentam vascularização, esta se dá de forma rápida e marcada (ROBERTS ${ }^{1}, 1966$, apud GELATT; SAMUELSON, 1982, p. 111; BENTLEY, 2005; SLATTER, 2005b). Gelatt e Samuelson (1982) observaram a presença de granuloma em $32 \%$ de seus casos, valor aproximado ao encontrado neste estudo, no qual se observou granuloma em $27,46 \%$ dos casos (39 de 142). A opacidade esteve presente em $20 \%$ dos casos. Apesar de ser referida pela literatura, a pigmentação e a lipidose corneal não foram observadas neste estudo (GELATT; SAMUELSON, 1982; GELATT, 2003b; SLATTER, 2005b).

\footnotetext{
${ }^{1}$ ROBERTS, S. R. Superficial indolent ulcer of the córnea in Boxer dogs. Journal of the Small Animal Practice, v. 6, p. 111-115, 1966.
} 
Segundo a literatura, os tratamentos mais comumente realizados nos casos de úlcera indolente são o debridamento epitelial, a ceratotomia em pontos, em grade e a ceratectomia superficial. A maioria dos estudos que utilizaram medicação tópica, muitas vezes também realizaram outros procedimentos, o que dificultou o entendimento dos resultados alcançados (STANLEY; HARDMAN; JOHNSON, 1998; BENTLEY et al., 2001; LEDBETTER; MUNGER; RING, 2003a,b; BENTLEY, 2005).

Diversas medicações foram prescritas previamente à primeira consulta numa primeira tentativa de resolução do quadro. Após o atendimento no HOVET-USP, algumas das medicações foram mantidas, outras, interrompidas por não serem consideradas tratamentos recomendados ou eficazes para a úlcera indolente de cães (GELATT; SAMUELSON, 1982; KIRSCHNER, 1990; CAMPBELL; MURPHY, 1999; GELATT, 2003b; BENTLEY, 2005; SLATTER, 2005a).

Inibidores das proteinases foram uma das medicações mais frequentemente prescritas, tanto previamente à primeira consulta, quanto após o atendimento. Com o objetivo de promover a estabilidade e o suporte do tecido na reestruturação corneal, inibir as MMPs, a NE e a atividade proteolítica, além de auxiliar na diminuição da secreção ocular (BARMAN, 1975; FRAUNFELDER; WRIGHT; TRIPATHI, 1977; BROOKS et al., 2002; OLLIVIER et al., 2002; ALDAVOOD et al., 2003), a acetilcisteína $10 \%, 5 \%$ e EDTA 0,35\% foram prescritos para quase 90 $\%$ dos casos estudados. A média do tempo de cicatrização das úlceras em que foram administrados foi de aproximadamente 30 dias (7 a 132 dias). Segundo a análise estatística, sua administração não interferiu na formação de granuloma e no tempo de cicatrização corneal, o que já foi observado em estudos anteriores (PETROUTSOS et al., 1982; ALDAVOOD et al., 2003).

A vitamina C (ácido ascórbico) foi a segunda medicação mais rotineiramente prescrita no HOVET-USP e ocasionalmente prescrita antes do primeiro atendimento. Com o objetivo de estimular e regular a síntese de colágeno, fibroblastos, componentes da matriz extra-celular na córnea (SAIKA et al., 1992; GROSS, 2000; GUO et al., 2007) e reduzir a reação inflamatória da região (KASETSUWAN et al., 1999; BENTLEY et al., 2001), prescreveu-se vitamina $C$ até a resolução do quadro. Observou-se que, de forma estatisticamente significante, apesar de ter prolongado 0 tempo de cicatrização quando comparado aos cães cuja vitamina não foi 
administrada (média de aproximadamente 32 dias, 7 a 132 dias), reduziu a reação inflamatória da córnea, diminuindo a frequência de granuloma nas úlceras dos cães com ela tratados.

Debridamento/cauterização corneal, realizado após anestesia tópica com pinça hemostática e algodão umedecido com PVPI 0,2 \% foi o terceiro tratamento mais realizado no serviço. Apesar de citado em diversos estudos como um procedimento menos eficiente do que a ceratotomia em pontos, em grade ou a ceratectomia superficial (GELATT; SAMUELSON, 1982; KIRSCHNER; NIYO; BETTS, 1989; KIRSCHNER, 1990; STANLEY; HARDMAN; JOHNSON, 1998; BENTLEY et al., 2001; GELATT, 2003b; SLATTER, 2005a,b), escolheu-se estudar apenas este procedimento pela segurança, praticidade durante sua realização e por ser considerado um procedimento não invasivo (ambulatorial).

A remoção de epitélio além da margem da úlcera e a repetição do procedimento foram frequentemente realizados por diversos autores (KIRSCHNER; NIYO; BETTS, 1989; STANLEY; HARDMAN; JOHNSON, 1998; GELATT, 2003b). Corroborando com a literatura, na maioria dos casos avaliados neste estudo, realizou-se a remoção de grande parte do epitélio não aderido e, ocasionalmente, removeu-se todo o epitélio corneal; o procedimento foi repetido após 20 dias em 5 casos e, novamente após mais 20 dias (40 dias), em 1 caso. Stanley, Hardman e Johnson (1998), referiram sucesso em $84 \%$ dos cães que apresentavam úlcera indolente tratados com debridamento por haste estéril com ponta de algodão seco em até 40 dias. Gelatt e Samuelson (1982), após realizarem o procedimento com iodo, observaram sucesso em $80 \%$ dos casos. Neste estudo, utilizou-se PVPI 0,2 \% em 87 dos 142 casos estudados (61,28 \%), obtendo-se sucesso na resolução do quadro em todas feridas. Quando comparado aos demais tratamentos, não induziu a formação do granuloma e apresentou tempo de cicatrização estatisticamente menor do que as que não sofreram o procedimento (média de 26 dias, 7 a 132 dias), sugerindo-se até que este procedimento pode, provavelmente, acelerar o processo de cicatrização corneal $(p<0,05)$.

As medicações mais rotineiramente referidas pelos proprietários durante a primeira consulta foram os antibióticos. Entretanto, este tipo de medicação foi apenas a quarta mais frequentemente prescrita no HOVET. Prescreveu-se colírio de 
tobramicina $0,3 \%$ para 60 (42\%), dos 142 casos estudados, a ofloxacina para 12 casos, ciprofloxacina para 6 casos, gatifloxacina para 1 caso e a pomada de cloranfenicol para 1 caso. Sulfato de condroitina associado à tobramicina incluiu 6 dos 60 casos e, associado à ciprofloxacina em 4 dos 6 casos. Enrofloxacina foi prescrita na forma sistêmica para 1 caso. Segundo a literatura, este tipo de úlcera não apresenta contaminação (BENTLEY et al., 2001; HENDRIX; WARD; BARNHILL, 2001) e, por conta disso, antibioticoterapia profilática foi recomendada (BENTLEY; 2005) principalmente nos casos em que se realizou o debridamento/cauterização, procedimento capaz de aumentar a vulnerabilidade corneal a infecções pela perda da MB do epitélio (KIRSCHNER, 1990). A análise estatística deste tipo de tratamento não foi realizada segundo cada grupo de antibióticos e sim, a avaliação segundo sua administração. No geral, observou-se que a antibioticoterapia não interferiu no tempo de cicatrização das úlceras (média de 32 dias, 5 a 132 dias), mas esteve diretamente relacionada, de forma estatisticamente significante, com a presença de granuloma. Sugere-se que a formação do granuloma seja justificado pelo aumento da inflamação da superfície ocular ocasionada pela toxicidade tanto de alguns antibióticos (tobramicina, ciprofloxacina e ofloxacina) (PETROUTSOS et al., 1983; NELSON et al., 1990; MOREIRA et al., 1997; HENDRIX; WARD; BARNHILL, 2001; JENSEN et al., 2005; MARINO et al., 2005), quanto de alguns preservativos oftalmológicos (como o cloridrato de benzalcônio, encontrado nos colírios de Tobrex ${ }^{\circledR}$, Ciloxan ${ }^{\circledR}$, Oflox ${ }^{\circledR}$ e Zymar ${ }^{\circledR}$ ) (STERN et al.,1983; HENDRIX; WARD; BARNHILL, 2002). Doxiciclina sistêmica, apesar de sugerida por diversos autores, não foi prescrita para nenhum dos casos estudados (PERRY et al., 1993, DURSUN et al., 2001; WANG; TSANG; CORONEO, 2007; DAN et al., 2008).

Colírio de atropina $1 \%$ foi prescrito pelo serviço para 25 casos (17\%), e antes do atendimento, para 10 casos. Apesar de ser recomendado para o tratamento de úlceras por aliviar a dor decorrente do espasmo da musculatura ciliar (GELATT, 2003b; SLATTER, 2005a), também pode diminuir a produção do FLPC (HOLLINGSWORTH et al., 1992) e prejudicar o processo de cicatrização (KIRSCHNER, 1990; BENTLEY, 2005; SLATTER, 2005a,b). Observou-se que o uso da atropina, apesar de ter prolongado o tempo de cicatrização (média de 39 dias, 7 a 132 dias), não apresentou relevância estatística significante. Entretanto, observou-se que sua utilização predispôs, significativamente, à formação do granuloma. Apesar 
de teste de lágrima de Schirmer não ter sido realizado, sugere-se que a presença do granuloma esteja relacionada à estimulação da inflamação da superfície ocular decorrente da diminuição da produção do FLPC (HOLLINGSWORTH et al., 1992; SLATTER, 2005a).

Anti-inflamatórios tópicos e sistêmicos foram ocasionalmente prescritos. Slatter (2005a) refere que, apesar deste tipo de medicação ser capaz de promover o retorno da transparência corneal nos casos de feridas opacificadas e vascularizadas, deveriam ser somente administrados após o restabelecimento da epitelização corneal, pois alguns anti-inflamatórios podem inibir sua regeneração e diminuir a resistência da ferida, potencializando as colagenases em até 15 vezes, aumentando assim o risco de infecção. Colírios anti-inflamatórios não esteroidais foram os mais frequentemente administrados. Diclofenaco sódico, por exemplo, foi prescrito para 11 casos e cetorolaco de trometamina para 3. Por via sistêmica, prescreveu-se meloxicam para 1 caso e flunixin-meglumine para 1 caso. Os anti-inflamatórios esteroidais prescritos foram fluocinolona e dexametasona. Dois casos de úlcera, um utilizando meloxicam e outro diclofenaco sódico, evoluíram para a malácea corneal. Nos demais, observou-se que, segundo análise estatística, sua administração foi capaz de inibir a formação de granuloma e que, apesar de apresentar a maior média para o tempo de cicatrização (41 dias, 5 a 132 dias), este dado não foi estatisticamente significante.

Avaliou-se também todos os casos nos quais não se utilizou atropina, antibiótico ou anti-inflamatório, com o objetivo de analisar as úlceras somente tratadas com grupos de tratamentos que, segundo a literatura, pouco interferissem na cicatrização (acetilcisteína, vitamina $C$ e debridamento/cauterização) (PETROUTSOS et al., 1982; SAIKA et al., 1992; STANLEY; HARDMAN; JOHNSON, 1998; KASETSUWAN et al., 1999; GROSS, 2000; BENTLEY et al., 2001; ALDAVOOD et al., 2003; GUO et al., 2007). Entretanto, esta consideração não foi estatisticamente significante quanto ao tempo de cicatrização e a formação de granuloma.

Apesar do tempo de alteração ocular antes da primeira consulta e as características da lesão não terem influenciado estatisticamente no tempo de cicatrização, observou-se que os animais que apresentavam úlceras com granuloma 
apresentaram média de tempo de cicatrização menor do que os que apresentavam outros tipos de úlcera. Contudo, os proprietários destes cães não receberam alta de pronto, sendo recomendados a administrar corticosteróides tópicos, 4 vezes ao dia (dexametasona 0,05 ou 0,1\%), por pelo menos 20 dias. Com o objetivo de restabelecer a transparência corneal (GELATT; SAMUELSON, 1982; HENDRIX; WARD; BARNHILL, 2002; SLATTER, 2005a,b), esta recomendação prolongou o tratamento de forma equivalente àqueles que não cicatrizaram rapidamente, não parecendo esta ser uma vantagem sobre os outros cães, já que o objetivo do tratamento é, além da cicatrização, o retorno da transparência corneal.

Portanto, conhecer os diversos tipos de tratamento se mostra fundamental para o sucesso da resolução da doença, já que este deve ser específico, realizado de forma cautelosa e por tempo indeterminado, cuidando para que a lesão não progrida e promovendo o retorno da transparência corneal. 


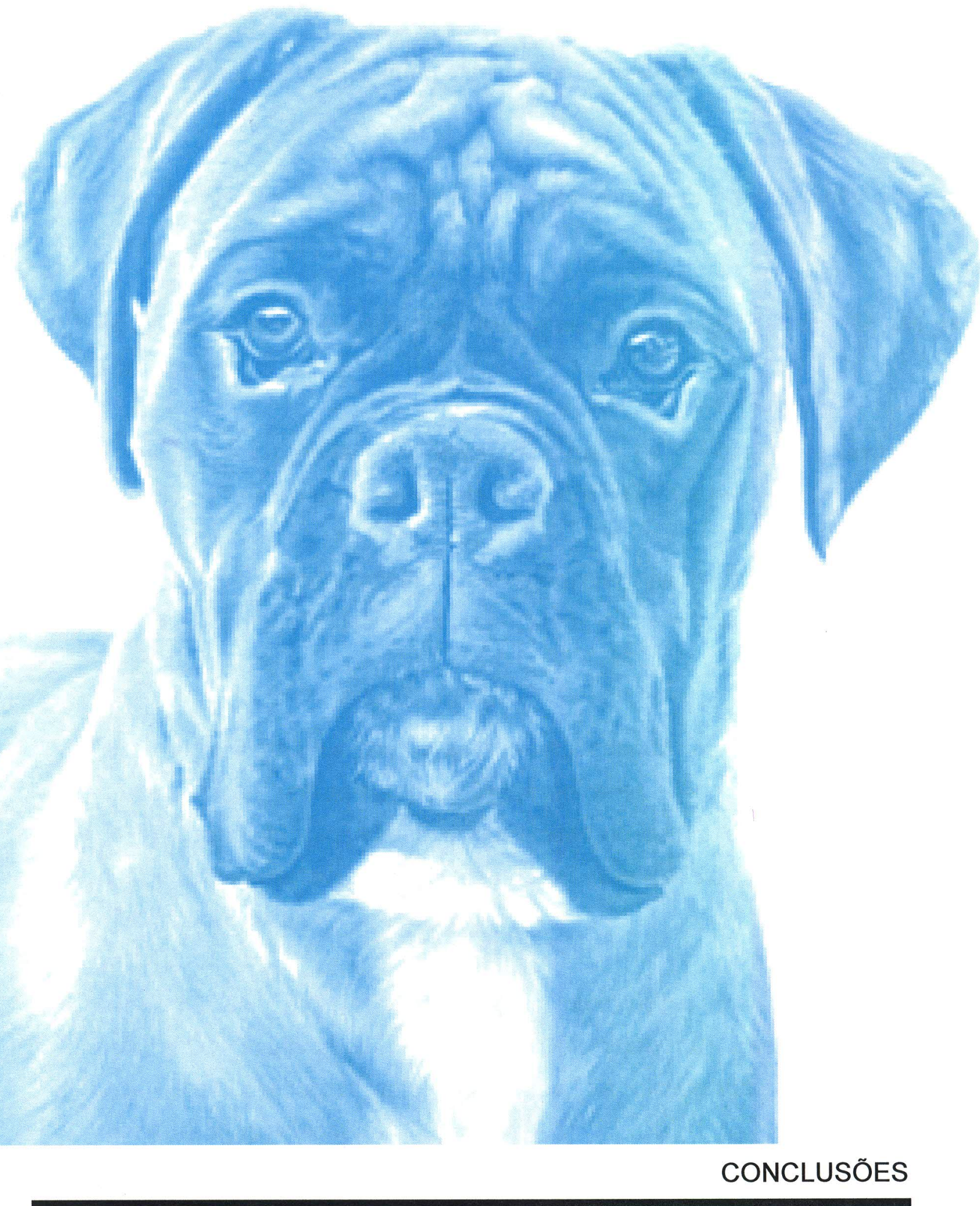




\section{CONCLUSÕES}

Com base nos resultados apresentados, podemos concluir que:

1. Cães da raça Boxer são predispostos a desenvolver úlcera indolente, distrofia corneal e catarata.

2. As úlceras indolentes foram mais frequentemente observadas em fêmeas de meia idade.

3. A maioria dos proprietários demoraram mais de 15 dias para levar seus animais ao Serviço de Oftalmologia do HOVET-FMVZ-USP.

4. Blefarospasmo, olho vermelho e secreção foram as alterações oculares mais frequentemente referidas pelos proprietários durante a anamnese da primeira consulta.

5. Úlceras transparentes com o epitélio não aderido, ou com algum grau de vascularização; unilaterais, mais frequentemente observadas no olho direito; de aparecimento espontâneo e localizadas no centro da córnea, foram as principais características das lesões observadas após o exame oftalmológico da primeira consulta.

6. Inibidores das proteinases foram as medicações mais frequentemente prescritas. Observou-se que sua administração não interferiu, de forma estatisticamente significante, no tempo de cicatrização corneal ou na formação de granuloma.

7. Vitamina $C$ (ácido ascórbico), foi a segunda medicação mais rotineiramente prescrita no HOVET-USP e, ocasionalmente prescrita antes da primeira 
consulta. Esta medicação, apesar de ter prolongado de maneira significante, o tempo de cicatrização corneal quando comparada aos cães que não a utilizaram, também reduziu, de maneira significante, a inflamação corneal, observada pela diminuição da presença de granuloma.

8. Debridamento/cauterização corneal foi $\circ$ terceiro tratamento mais frequentemente realizado. Observou-se que, além de não interferir na formação de granuloma, pode acelerar, significativamente, o processo de cicatrização.

9. A antibioticoterapia foi o quarto tipo de tratamento mais utilizado no Serviço de Oftalmologia (USP) e o mais frequentemente prescrito antes da primeira consulta. Apesar de não interferir no tempo de cicatrização corneal, sua utilização se relacionou diretamente, de forma estatisticamente significante, à presença de granuloma, o que pode estar provavelmente relacionado à toxicidade celular das preparações utilizadas.

10.Atropina $1 \%$ foi ocasionalmente prescrita. Observou-se que esta medicação não interfere no tempo de cicatrização, mas segundo análise estatística, predispôs à formação de granuloma, fato que pode estar relacionado à inflamação da superfície ocular decorrente da diminuição da produção do FLPC.

11.O uso de anti-inflamatórios tópicos e sistêmicos também foi ocasionalmente observado. Apesar de também não interferir no tempo de cicatrização, diminuiu, de maneira significante, a presença de granuloma nos cães em que foram administrados.

12. Não administrar atropina $1 \%$, antibióticos e anti-inflamatórios, não interfere no tempo de cicatrização, nem na formação de granuloma.

13.O tempo de alteração ocular antes da primeira consulta e as características das lesões não interferiram, de maneira relevante, no tempo de cicatrização corneal. 


\section{REFERÊNCIAS}

AITKEN, D. A.; BEIROUTY, Z. A.; LEE, W. R. Ultrastructural study of the corneal epithelium in the recurrent erosion syndrome. British Journal of Ophthalmology, v. 79, p. 282-289, 1995.

ALDAVOOD, S. J.; BEHYAR, R.; SARCHAHI, A. A.; RAD, M. A.; NOROOZIAN, I.; GHAMSARI, S. M.; SADEGHI-HASHJIN G. Effect of acetylcysteine on experimental corneal wounds in dogs. Ophthalmic Research, v. 35, p. 319-323, 2003.

BARROS, P. S. M.; SAFATLE, A. M. V.; SILVA, H. A. R.; BARROS, S. B. M. Ascorbic acid levels in plasma and aqueous humor of dogs with diabetic cataract. Veterinary Ophthalmology, v. 5, p. 283-301, 2002. Abstract n. 47.

BENTLEY, E.; ABRAMS, G. A.; COVITZ, D.; COOK, C. S.; FISCHER, C. A.; HACKER, D.; STUHR, C. M.; REID, T. W.; MURPHY, C. J. Morphology and immunohistochemistry of spontaneous chronic corneal epithelial defects (SCCED) in Dogs. Investigative Ophthalmology \& Visual Science, v. 42, n. 10, p. 2262-2269, 2001.

BENTLEY, E.; CAMPBELL, S.; WOO, H. M.; MURPHY, C. J. The effect of chronic corneal epithelial debridement on epithelial and stromal morphology in dogs. Investigative Ophthalmology \& Visual Science, v. 43, n. 7, p. 2136-2142, 2002.

BENTLEY, E. Spontaneous chronic corneal epithelial defects in dogs: a review. Journal of the American Animal Hospital Association, v. 41, p. 158-165, 2005.

BERMAN, N. Collagenase inhibitors: rationale for their use in treating corneal ulceration. International Ophthalmology Clinics, v. 15, n. 4, p. 49-66, 1975.

BILGIHAN, A.; BILGIHAN, K.; TOKLU, Y.; KONUK, O.; YIS, O.; HASANREISOĞLU, B. Ascorbic acid levels in human tears after photorefractive keratectomy, transepithelial photorefractive keratectomy, and laser in situ keratomileusis. Journal of Cataract \& Refractive Surgery, v. 27, n. 4, p. 585-588, 2001. 
BROOKS, D. E.; OLLIVIER, F. J.; SCHULTZ, G. S.; ANDREW, S. E.; GELATT, K. N.; LASSALINE, M. E.; KALLBERG, M. E. Duration of in vitro inhibitory activity of equine serum against equine tear film matrix metalloproteinase. Veterinary

Ophthalmology, v. 5, p. 283-301, 2002. Abstract n. 23.

BROOKS, D. E.; OLLIVIER, F. J.; LASSALINE, M. E.; KALLBERG, M. E.; SCHULTZ, G. S.; GELATT, K. N. MMP production by microbial isolates from equine corneal ulcers. Veterinary Ophthalmology, v. 6, p. 351-366, 2003. Abstract n. 17.

BRUBAKER, R. F.; BOURNE, W. M.; BACHMAN, L. A.; MCLAREN, J. W. Ascorbic Acid Content of Human Corneal Epithelium. Ophthalmology \& Visual Science, v. 41, n. 7, p. 1681-1683, 2000.

BURNS, F. R.; STACK, M. S.; GRAY, R. D.; PARERSON, C. A. Inhibition of Purified Collogenose from Alkali-Burned Rabbit Corneas. Investigative Ophthalmology \& Visual Science, v. 30, n. 7, p. 1569-1575, 1989.

CAMPBELL, S.; MURPHY, C. Clinical characterization of spontaneous, chronic, nonseptic corneal epithelial defects in dogs. Investigative Ophthalmology \& Visual Science, v. 40, n. 4, p. 337, 1999. Abstract n. 1786.

COLLIN, H. B.; GRABSCH, B. E. The effect of ophthalmic preservatives on the healing rate of the rabbit corneal epithelium after keratectomy. American journal of optometry and physiological optics, v. 59, n. 3, p. 215-22, 1982.

COUTURE, S.; CARRIER, M.; DOUCET, M.; MOREAU, M. Topical effect of cyclosporine A, acetylcysteine, ciprofloxacin, EDTA, doxycycline, polysulfated glycoaminoglycan, autoserum and artifical tears on matrix metalloproteinases 2 and 9 activity in the tear film of the normal dog. Veterinary Ophthalmology, v. 6, p. 351366, 2003. Abstract n. 65.

DAN, L.; SHI-LONG, Y.; MIAO-LI, L.; YONG-PING, L.; HONG-JIE, M.; YING, Z.; XIANG-GUI, W. Inhibitory effect of oral doxycycline on neovascularization in a rat corneal alkali burn model of angiogenesis. Current Eye Research, v. 33, n. 8, p. 653-660, 2008.

DONNENFELD, E. D.; HOLLAND, E. J.; DURRIE, D. S.; RAIZMAN, M. B. Doublemasked study of the effects of nepafenac $0.1 \%$ and ketorolac $0.4 \%$ on corneal epithelial wound healing and pain after photorefractive keratectomy. Advances in Therapy, v. 24, n. 4, p. 852-862, 2007. 
DURRIE, D. S.; KENNARD, M. G.; BOGHOSSIAN, A. J. Effects of nonsteroidal ophthalmic drops on epithelial healing and pain in patients undergoing bilateral photorefractive keratectomy (PRK). Advances in Therapy, v. 24, n. 6, p. 1278-1285, 2007.

DURSUN, D.; KIM, M. C.; SOLOMON, A.; PFLUGFELDER, S. C. Treatment of recalcitrant recurrent corneal erosions with inhibitors of matrix metalloproteinase-9, doxycycline and corticosteroids. American Journal of Ophthalmology, v. 132, p. 8-13, 2001.

FRAUNFELDER, F. T.; WRIGHT, P.; TRIPATHI, R. C. Corneal mucus plaques. American Journal of Ophthalmology, v. 83, n. 2, p. 191-197, 1977. Abstract.

GARRANA, M.; ZIESKE, J.; ASSOULINE, M.; GIPSON, I. K. Matrix metalloproteinases in epithelia from human recurrent corneal erosions. Investigative Opthalmology Vision Science, v. 40, p. 1266-1270, 1999.

GELATT, K. N. Exame Oftálmico e procedimentos diagnósticos. In: Oftalmologia Veterinária. 3 ed. Barueri, SP.: Manole, 2003a. cap. 1, p. 1-26. Manual de

Oftalmologia Veterinária. 3

GELATT, K. N. Doenças e cirurgia da córnea e esclera do cão. In: Manual de Oftalmologia Veterinária. 3 ed. Barueri, SP.: Manole, 2003b. cap. 7, p. 125-164.

GELATT K. N.; SAMUELSON, D. A. Recurrent corneal erosions and epithelial dystrophy in the boxer dog. Journal of the American Animal Hospital Association, v. 18, p. 453-460,1982.

GÖNÜL, B.; KAPLAN, B.; BILGIHAN, K.; BUDAK M. T. Effects of epidermal growth factor in artificial tear on vitamin $C$ levels of corneal wounded eye tissues. Eye (London), v. 15, n. 2, p. 213-216, 2001.

GREEN, K.; JOHNSON, R. E.; CHAPMAN, J. M.; NELSON, E.; CHEEKS, L. Preservative effects on the healing rate of rabbit corneal epithelium. Lens and Eye Toxicity Research, v. 6, n. 1-2, p. 37-41, 1989. Abstract.

GROSS, R. L. The effect of ascorbate on wound healing. International Ophthalmology Clinics, v. 40, n. 4, p. 51-57, 2000. 
GUO, X.; HUTCHEON, A. E. K.; MELOTTI, S. A.; ZIESKE, J. D.; TRINKAUSRANDALL, V.; RUBERTI, J. W. Morphologic characterization of organized extracellular matrix deposition by ascorbic acid-stimulated human corneal fibroblasts. Investigative Ophthalmology \& Visual Science, v. 48, p. 4050-4060, 2007.

HENDRIX, D. V.; WARD, D. A.; BARNHILL, M. A. Effects of antibiotics on morphologic characteristics and migration of canine corneal epithelial cells in tissue culture. American Journal of Veterinary Research, v. 62, p. 1664-1669, 2001.

HENDRIX, D. V.; WARD, D. A.; BARNHILL, M. A. Effects of anti-inflammatory drugs and preservatives on morphologic characteristics and migration of canine corneal epithelial cells in tissue culture. Veterinary Ophthalmology, v. 5, n. 2, p. 127-135, 2002.

HEYWORTH, P.; MORLET, N.; RAYNER, S.; HYKIN, P.; DART, J. Natural history of recurrent erosion syndrome-a 4 year review of 117 patients. British Journal of Ophthalmology, v. 82, p. 26-28, 1998.

HOLLINGSWORTH, S. R.; CANTON, D. D.; BUYUKMIHCI, N. C.; FARVER, T. B. Effect of topically administered atropine on tear production in dogs. Journal of the American Veterinary Medical Association, v. 200, n. 10, p. 1481-1484, 1992.

JENSEN, H.; ZEROUALA, C.; CARRIER, M.; SHORT, B. Comparison of ophthalmic gatifloxacin $0.3 \%$ and ciprofloxacin $0.3 \%$ in healing of corneal ulcers associated with pseudomonas aeruginosa-induced ulcerative keratitis in rabbits. Journal of Ocular Pharmacology and Therapeutics, v. 21, n. 1, p. 36-42, 2005.

JIANG, J.; WU, M.; SHEN, T. The toxic effect of different concentrations of povidone iodine on the rabbit's cornea. Cutaneous and Ocular Toxicology, v. 28, n. 3, p. 119-124, 2009.

KASETSUWAN, N.; WU, F. M.; HSIEH, F.; SANCHEZ, D.; MCDONNELL, P. J. Effect of topical ascorbic acid on free radical tissue damage and inflammatory cell influx in the cornea after excimer laser corneal surgery. Archives of Ophthalmology, v. 117 , n. 5, p. 649-52,1999. Abstract. 
KHODADOUST, A.; SILVERSTEIN, A.; KENYON, K.; DOWLING, J. Adhesion of regenerating corneal epithelium: the role of basement membrane. American Journal of Ophthalmology, v. 65, p. 339-348, 1968.

KIM, W.; HELENA, M.; MOHAN, R.; WILSON, S. Changes in corneal morphology associated with chronic epithelial injury. Investigative Ophthalmology \& Visual Science, v. 40, p. 35-42, 1999.

KIRSCHNER, S. E. Persistent corneal ulcers. What to do when ulcers won't heal. Veterinary Clinics of North America: Small Animal Practice, v. 20, n. 3, p. 627643, 1990.

KIRSCHNER, S. E.; NIYO, Y.; BETTS, D. M. Idiopathic persistent corneal erosions: clinical and pathological findings in 18 dogs. Journal of the American Animal Hospital Association, v. 25, p. 84-90, 1989.

LEDBETTER, E. C.; MUNGER, R. J.; RING, R. D. Efficacy of a topical antibioticchondroitin sulfate solution in the therapy of recurrent corneal erosions: a preliminary report. Veterinary Ophthalmology, v. 6, p. 343-350, 2003a. Abstract n. 29.

LEDBETTER, E. C.; MUNGER, R. J.; RING, R. D. Efficacy of topical antibioticchondroitin sulfate solutions in the therapy of canine recurrent corneal erosions. Veterinary Ophthalmology, n. 6, p. 351-366, 2003b. Abstract n. 21.

LOYA, N.; BASSAGE, S.; VYAS, S.; CERRO, M. del.; PARK, S. B.; AQUAVELLA, J. $V$. Topical diclofenac following excimer laser: effect on corneal sensitivity and wound healing in rabbits. Journal of Refractive Corneal Surgery, v. 10, n. 4, p. 423-427, 1994.

MAGRANE, W. G. Keratitis in dogs. Veterinary Scopes, v. 1, p. 2-10, 1956.

MARFURT, C. F.; MURPHY, C. J.; FLORCZAK, J. L. Morphology and neurochemistry of canine corneal innervation. Investigative Ophthalmology \& Visual Science, v. 42, n. 10, p. 2242-251, 2001.

MARINO, C.; PALADINO, G. M.; SCUDERI, A. C.; TROMBETTA, F.; MUGRIDGE, K.; ENEA, V. In vivo toxicity of netilmicin and ofloxacin on intact and mechanically damaged eyes of rabbit. Cornea, v. 24, n. 6, p. 710-716, 2005. 
MATHEWS, K. A.; PALEY, D. M.; FOSTER, R. A.; VALLIANT, A. E.; YOUNG, S. S. A comparison of ketorolac with flunixin, butorphanol, and oxymorphone in controlling postoperative pain in dogs. The Canadian Veterinary Journal, v. 37, n. 9, p. 557567, 1996.

MOREIRA, L. B.; LEE, R. F.; DE OLIVEIRA, C.; LABREE, L.; MCDONNELL, P. J. Effect of topical fluoroquinolones on corneal re-epithelialization after excimer laser keratectomy. Journal of Cataract \& Refractive Surgery, v. 23, n. 6, p. 845-848, 1997.

MORGAN, R. V.; ABRAMS, K. L. A comparison of six different therapies for persistent corneal erosions in dogs and cats. Veterinary Compendium of Ophthalmology, v. 4, p. 38-43, 1994.

MURPHY, C.; MARFURT, C.; MCDERMOTT, A.; BENTLEY, E.; ABRAMS, G. A.; REID, T. W.; CAMPBELL, S. Spontaneous chronic corneal epithelial defects in dogs (SCCED): clinical features, innervation, and effect of topical SP, with or without IGF1. Investigative Ophthalmology \& Visual Science, v. 42, p. 2252-2261, 2001.

NELSON, J. D.; SILVERMAN, V.; LIMA, P. H.; BECKMAN G. Corneal epithelial wound healing: a tissue culture assay on the effect of antibiotics. Current Eye Research, v. 9, n. 3, p. 277-285, 1990.

NISHIDA, T. Fibronectin: a new therapy for corneal trophic ulcer. Archives of Ophthalmology, v. 101, p. 1046-1048, 1983.

OLLIVIER, F. J.; BROOKS, D. E.; KALLBERG, M. E.; KOMAROMY, A. M.; LASSALINE, M. E.; CUTLER, T. J.; SAPP, H. L.; SCHULTZ, G. S. In vitro effect of EDTA, doxycycline, $n$ acetylcysteine, ilomostat, and a1-proteinase inhibitor on matrix metalloproteinase activity in the tear film of horses with ulcerative keratitis.

Veterinary Ophthalmology, v. 5, p. 283-301, 2002. Abstract n. 24.

OLLIVIER, F. J.; BROOKS, D. E.; KALLBERG, M. E.; ANDREW, S. E.; KOMAROMY, A. M.; LASSALINE, M. E.; BLALOCK, T. D.; SCHULTZ, G. S.; VAN SETTEN, G. Reduction in matrix metalloproteinase activity in the equine tear film during corneal healing. Veterinary Ophthalmology, v. 6, p. 343-350, 2003. Abstract n. 42. 
OYAMA, M. A.; REIKEN, S.; LEHNART, S. E.; CHITTUR, S. V.; MEURS, K. M.;

STERN, J.; MARKS, A. R. Arrhythmogenic right ventricular cardiomyopathy in Boxer dogs is associated with calstabin2 deficiency. Journal of Veterinary Cardiology, $v$. 10, n. 1, p. 1-10, 2008.

PERRY, H. D.; HODES, L. W.; SEEDOR, J. A.; DONNENFELD, E. D.; MCNAMARA, T. F.; GOLUB, L. M. Effect of doxycycline hyclate on corneal epithelial wound healing in the rabbit alkali-burn model. Preliminary observations. Cornea, v. 12, n. 5, p. 379382, 1993.

PETROUTSOS, G.; GUIMARAES, R.; GIRAUD, J. P.; RENARD, G.; POULIQUEN, $Y$. Effect of acetylcysteine (Mucomyst) on epithelial wound healing. Ophthalmic Research, v. 14, n. 4, p. 241-248, 1982.

PETROUTSOS, G.; GUIMARAES, R.; GIRAUD, J.; POULIQUEN, Y. Antibiotics and corneal epithelial wound healing. Archives of Ophthalmology, v. 101, p. 17751778, 1983.

PIRIE, A. Ascorbic acid content of cornea. Biochemical Journal, v. 40, p. 96-100, 1946.

RAINBOW, M. E.; OLLIVIER, F.; PICKETT, J. P.; HERRING, I. P.; BROOKS, D. E. Effects of systemic flunixin meglumine, topical oxytetracycline, and topical prednisolone on tear film proteinases in normal horses. Veterinary Ophthalmology, v. 6, p. 351-366, 2003. Abstract n. 37.

REIDY, J. J.; PAULUS, M. P.; GONA, S. Recurrent erosions of the cornea: epidemiology and treatment. Cornea, v. 19, p. 767-771, 2000.

REIM, M.; SEIDL, M.; BRUCKER, K. Accumulation of ascorbic acid in the corneal epithelium. Ophthalmic Research, v. 10, p. 135-139, 1978.

RINGVOLD, A.; ANDERSSEN, E.; KJØNNIKSEN, I. Ascorbate in the corneal epithelium of diurnal and nocturnal species. Investigative Ophthalmology \& Visual Science, v. 39, p. 2774-2777, 1998.

ROBERTS, S. R. Superficial indolent ulcer of the cornea in Boxer dogs. Journal of the Small Animal Practice, v. 6, p. 111-115, 1966. 
SAIKA, S.; UENOYAMA, K.; HIROI, K.; OOSHIMA, A. L-ascorbic acid 2-phosphate enhances the production of type I and type III collagen peptides in cultured rabbit keratocytes. Ophthalmic Research, v. 24, n. 2, p. 68-72, 1992.

SAIKA, S.; UENOYAMA, K.; HIROI, K.; TANIOKA, H.; TAKASE, K.; HIKITA, M. Ascorbic acid phosphate ester and wound healing in rabbit corneal alkali burns: epithelial basement membrane and stroma. Graefe's Archive for Clinical and Experimental Ophthalmology, v. 231, n. 4, p. 221-227, 1993.

SIMMONS, P. A.; CLOUGH, S. R.; TEAGLE, R. H.; JAANUS, S. D. Toxic effects of ophthalmic preservatives on cultured rabbit corneal epithelium. American journal of optometry and physiological optics, v. 65, n. 11, p. 867-73, 1988. Abstract.

SLATTER, D. Farmacologia ocular e Terapêutica. In: Fundamentos de Oftalmologia Veterinária. 3 ed. São Paulo: Roca, 2005a, cap. 3, p. 37-76.

SLATTER, D. Córnea e Esclera. In: Fundamentos de Oftalmologia Veterinária. 3 ed. São Paulo: Roca, 2005b, cap. 11, p. 283-338.

STANLEY, R. G.; HARDMAN, C.; JOHNSON, B. W. Results of grid keratotomy, superficial keratectomy and debridement for the management of persistent corneal erosions in 92 dogs. Veterinary Ophthalmology, v. 1, p. 233-238, 1998.

STERN, G. A.; SCHEMMER, G. B.; FARBER, R. D.; GOROVOY, M. S. Effect of Topical Antibiotic Solutions on Corneal Epithelial Wound Healing. Archives of Ophthalmology, v. 101, p. 644-647, 1983.

STOJANOVIC, A.; RINGVOLD, A.; NITTER, T. Ascorbate prophylaxis for corneal haze after photorefractive keratectomy. Journal of Refractive Surgery, v. 19, n. 3, p. 338-343, 2003.

TEIXEIRA, A. L.; MAIA, F. B. N.; ALVARENGA, L. S.; YU, M. C. Z.; HÖFLING-LIMA, A. L.; BARROS, P. S. M. Aerobic conjunctival flora of healthy dogs in Sao Paulo. Veterinary Ophthalmology, v. 6, p. 343-350, 2003. Abstract n. 30. 
THERMS, F.; MOLON-NOBLOT, S.; GROVE, J. Effects of acetylcysteine on rabbit conjunctival and corneal surfaces. Investigative Ophthalmology \& Visual Science, v. 32, p. 2958-2963, 1991.

WANG, L.; TSANG, H.; CORONEO, M. Treatment of recurrent corneal erosion syndrome using the combination of oral doxycycline and topical corticosteroid. Clinical and Experimental Ophthalmology, v. 36, p. 8-12, 2007.

WELLE, M. M.; BLEY, C. R.; HOWARD, J.; RÜFENACHT, S. Canine mast cell tumours: a review of the pathogenesis, clinical features, pathology and treatment. Veterinary Dermatology, v. 19, n. 6, p. 321-339, 2008.

WILLEFORD, K. O.; MILLER, W. W.; ABRAMS, K. L.; VAUGHN, B. M. Modulation of proteolytic activity associated with persistent corneal ulcers in dogs. Veterinary Ophthalmology, v. 1, n. 1, p. 5-8, 1998.

YORK, K. K.; MILLER, S.; GASTER, R. N.; BURSTEIN, N. L. Polyvinylpyrrolidone iodine: corneal toxicology and epithelial healing in a rabbit model. Journal of Ocular Pharmacology, v. 4, n. 4, p. 351-358, 1988. 
ANEXO A - Distribuição das 142 úlceras estudadas, com seus respectivos dias de cicatrização e segundo o tratamento ambulatorial preconizado

\begin{tabular}{|c|c|c|c|c|c|c|c|c|}
\hline Úlceras & Dia da alta & $\begin{array}{l}\text { Inib das } \\
\text { protein }\end{array}$ & VitC & $\begin{array}{l}\text { Debrid/ } \\
\text { cauter }\end{array}$ & Antibio & Antinfl & Atropina $1 \%$ & Sem \\
\hline 1 & 13 & $\operatorname{sim}$ & $\operatorname{sim}$ & $\operatorname{sim}$ & $\mathrm{n}$ & $\mathrm{n}$ & $\mathrm{n}$ & $\operatorname{sim}$ \\
\hline 2 & 20 & $\operatorname{sim}$ & $\operatorname{sim}$ & $\mathrm{n}$ & $\operatorname{sim}$ & $\mathrm{n}$ & $\mathrm{n}$ & $\mathrm{n}$ \\
\hline 3 & 32 & $\operatorname{sim}$ & $\operatorname{sim}$ & $\operatorname{sim}$ & $\operatorname{sim}$ & $\mathrm{n}$ & $\mathrm{n}$ & $\mathrm{n}$ \\
\hline 4 & 86 & $\mathrm{n}$ & $\operatorname{sim}$ & $\operatorname{sim}$ & $\mathrm{n}$ & $\mathrm{n}$ & $\mathrm{n}$ & $\mathrm{n}$ \\
\hline 5 & 5 & $\mathrm{n}$ & $\mathrm{n}$ & $\operatorname{sim}$ & $\operatorname{sim}$ & $\operatorname{sim}$ & $\mathrm{n}$ & $\mathrm{n}$ \\
\hline 6 & 21 & $\operatorname{sim}$ & $\operatorname{sim}$ & $\operatorname{sim}$ & $\operatorname{sim}$ & $n$ & $\mathrm{n}$ & $\mathrm{n}$ \\
\hline 7 & 19 & $\operatorname{sim}$ & $n$ & $\mathrm{n}$ & $\mathrm{n}$ & $\mathrm{n}$ & $\operatorname{sim}$ & $n$ \\
\hline 8 & 25 & $\operatorname{sim}$ & $\mathrm{n}$ & $\mathrm{n}$ & $\operatorname{sim}$ & $\mathrm{n}$ & $\mathrm{n}$ & $n$ \\
\hline 9 & 8 & $\operatorname{sim}$ & $\operatorname{sim}$ & $\operatorname{sim}$ & $\operatorname{sim}$ & $\operatorname{sim}$ & $\mathrm{n}$ & $n$ \\
\hline 10 & 36 & $\operatorname{sim}$ & $\operatorname{sim}$ & $\operatorname{sim}$ & $\operatorname{sim}$ & $\mathrm{n}$ & $\mathrm{n}$ & $n$ \\
\hline 11 & 21 & $\mathrm{n}$ & $\mathrm{n}$ & $\operatorname{sim}$ & $\operatorname{sim}$ & $\mathrm{n}$ & $\mathrm{n}$ & $\mathrm{n}$ \\
\hline 12 & 21 & $\operatorname{sim}$ & $\operatorname{sim}$ & $\operatorname{sim}$ & $\operatorname{sim}$ & $n$ & $\operatorname{sim}$ & $\mathrm{n}$ \\
\hline 13 & 49 & $\operatorname{sim}$ & $\mathrm{n}$ & $\operatorname{sim}$ & $\operatorname{sim}$ & $\operatorname{sim}$ & $\operatorname{sim}$ & $\mathrm{n}$ \\
\hline 14 & 15 & $\operatorname{sim}$ & $\mathrm{n}$ & $\operatorname{sim}$ & $\operatorname{sim}$ & $\mathrm{n}$ & $\operatorname{sim}$ & $\mathrm{n}$ \\
\hline 15 & 36 & $\operatorname{sim}$ & $\operatorname{sim}$ & $\operatorname{sim}$ & $\operatorname{sim}$ & $n$ & $\mathrm{n}$ & $\mathrm{n}$ \\
\hline 16 & 8 & $\operatorname{sim}$ & $\operatorname{sim}$ & $\operatorname{sim}$ & $\operatorname{sim}$ & $n$ & $\mathrm{n}$ & $\mathrm{n}$ \\
\hline 17 & 31 & $\operatorname{sim}$ & $\operatorname{sim}$ & $\operatorname{sim}$ & $\operatorname{sim}$ & $\mathrm{n}$ & $\mathrm{n}$ & $\mathrm{n}$ \\
\hline 18 & 29 & $\operatorname{sim}$ & $n$ & $\mathrm{n}$ & $\operatorname{sim}$ & $n$ & $n$ & $\mathrm{n}$ \\
\hline 19 & 42 & $\operatorname{sim}$ & $\operatorname{sim}$ & $n$ & $\operatorname{sim}$ & $\mathrm{n}$ & $\mathrm{n}$ & $n$ \\
\hline 20 & 42 & $\operatorname{sim}$ & $\operatorname{sim}$ & $\mathrm{n}$ & $\operatorname{sim}$ & $n$ & $\mathrm{n}$ & $\mathrm{n}$ \\
\hline 21 & 29 & $\operatorname{sim}$ & $\operatorname{sim}$ & $\operatorname{sim}$ & $\mathrm{n}$ & $\mathrm{n}$ & $\mathrm{n}$ & $\operatorname{sim}$ \\
\hline 22 & 45 & $\operatorname{sim}$ & $\operatorname{sim}$ & $\mathrm{n}$ & $\mathrm{n}$ & $n$ & $\mathrm{n}$ & $\operatorname{sim}$ \\
\hline 23 & 16 & $n$ & $n$ & $\operatorname{sim}$ & $\operatorname{sim}$ & $\operatorname{sim}$ & $n$ & $n$ \\
\hline 24 & 8 & $\operatorname{sim}$ & $n$ & $\operatorname{sim}$ & $\operatorname{sim}$ & $n$ & $\operatorname{sim}$ & $n$ \\
\hline 25 & 24 & $\operatorname{sim}$ & $\operatorname{sim}$ & $\operatorname{sim}$ & $\operatorname{sim}$ & $\mathrm{n}$ & $\mathrm{n}$ & $n$ \\
\hline 26 & 19 & $\operatorname{sim}$ & $\mathrm{n}$ & $\operatorname{sim}$ & $\operatorname{sim}$ & $n$ & $\mathrm{n}$ & $n$ \\
\hline 27 & 21 & $\operatorname{sim}$ & $\operatorname{sim}$ & $\operatorname{sim}$ & $\mathrm{n}$ & $\operatorname{sim}$ & $\operatorname{sim}$ & $\mathrm{n}$ \\
\hline 28 & 132 & $\operatorname{sim}$ & $\operatorname{sim}$ & $\mathrm{n}$ & $\operatorname{sim}$ & $\operatorname{sim}$ & $\operatorname{sim}$ & $\mathrm{n}$ \\
\hline 29 & 81 & $\operatorname{sim}$ & $\operatorname{sim}$ & $\mathrm{n}$ & $\operatorname{sim}$ & $\mathrm{n}$ & $\operatorname{sim}$ & $\mathrm{n}$ \\
\hline 30 & 14 & $\operatorname{sim}$ & $n$ & $\operatorname{sim}$ & $n$ & $\operatorname{sim}$ & $n$ & $\mathrm{n}$ \\
\hline 31 & 36 & $\operatorname{sim}$ & $\operatorname{sim}$ & $n$ & $\operatorname{sim}$ & $\mathrm{n}$ & $\operatorname{sim}$ & $\mathrm{n}$ \\
\hline 32 & 35 & $\operatorname{sim}$ & $\mathrm{n}$ & $\mathrm{n}$ & $\operatorname{sim}$ & $n$ & $\mathrm{n}$ & $\mathrm{n}$ \\
\hline 33 & 19 & $\operatorname{sim}$ & $\operatorname{sim}$ & $\operatorname{sim}$ & $\mathrm{n}$ & $n$ & $\mathrm{n}$ & $\operatorname{sim}$ \\
\hline 34 & 41 & $\operatorname{sim}$ & $\operatorname{sim}$ & $\operatorname{sim}$ & $\operatorname{sim}$ & $\mathrm{n}$ & $\mathrm{n}$ & $\mathrm{n}$ \\
\hline
\end{tabular}




\begin{tabular}{|c|c|c|c|c|c|c|c|c|}
\hline Úlceras & Dia da alta & $\begin{array}{l}\text { Inib das } \\
\text { protein }\end{array}$ & VitC & $\begin{array}{l}\text { Debrid/ } \\
\text { cauter }\end{array}$ & Antibio & Anti-in & Atropina $1 \%$ & Sem \\
\hline 37 & 19 & $\operatorname{sim}$ & $\mathrm{n}$ & $\mathrm{n}$ & sim & $\mathrm{n}$ & $\operatorname{sim}$ & $\mathrm{n}$ \\
\hline 38 & 20 & $\operatorname{sim}$ & $\operatorname{sim}$ & $\mathrm{n}$ & $\mathrm{n}$ & $\mathrm{n}$ & $\mathrm{n}$ & $\operatorname{sim}$ \\
\hline 39 & 15 & $\operatorname{sim}$ & $n$ & $\operatorname{sim}$ & $\operatorname{sim}$ & $\operatorname{sim}$ & $\mathrm{n}$ & $\mathrm{n}$ \\
\hline 40 & 42 & $\operatorname{sim}$ & $\operatorname{sim}$ & $\mathrm{n}$ & $\operatorname{sim}$ & $\mathrm{n}$ & $\mathrm{n}$ & $\mathrm{n}$ \\
\hline 41 & 33 & $\operatorname{sim}$ & $\operatorname{sim}$ & $\operatorname{sim}$ & $\operatorname{sim}$ & $\operatorname{sim}$ & $n$ & $\mathrm{n}$ \\
\hline 42 & 31 & $\operatorname{sim}$ & $\operatorname{sim}$ & $\mathrm{n}$ & $\operatorname{sim}$ & $\mathrm{n}$ & $\mathrm{n}$ & $\mathrm{n}$ \\
\hline 43 & 18 & $\operatorname{sim}$ & $\operatorname{sim}$ & $\operatorname{sim}$ & $\mathrm{n}$ & $n$ & $\mathrm{n}$ & $\operatorname{sim}$ \\
\hline 44 & 18 & $\mathrm{n}$ & $\operatorname{sim}$ & $\operatorname{sim}$ & $\operatorname{sim}$ & $\operatorname{sim}$ & $\mathrm{n}$ & $n$ \\
\hline 45 & 15 & $\operatorname{sim}$ & $\operatorname{sim}$ & $\operatorname{sim}$ & $n$ & $\mathrm{n}$ & $\mathrm{n}$ & $\operatorname{sim}$ \\
\hline 46 & 27 & $\operatorname{sim}$ & $\operatorname{sim}$ & $\operatorname{sim}$ & $\mathrm{n}$ & $\mathrm{n}$ & $\mathrm{n}$ & $\operatorname{sim}$ \\
\hline 47 & 42 & $\operatorname{sim}$ & $\operatorname{sim}$ & $\operatorname{sim}$ & $\operatorname{sim}$ & $\mathrm{n}$ & $\mathrm{n}$ & $\mathrm{n}$ \\
\hline 48 & 25 & $\operatorname{sim}$ & $\mathrm{n}$ & $\operatorname{sim}$ & $\operatorname{sim}$ & $\operatorname{sim}$ & $\mathrm{n}$ & $\mathrm{n}$ \\
\hline 49 & 24 & $\operatorname{sim}$ & $\operatorname{sim}$ & $\mathrm{n}$ & $\operatorname{sim}$ & $\mathrm{n}$ & $\mathrm{n}$ & $\mathrm{n}$ \\
\hline 50 & 36 & $\operatorname{sim}$ & $\operatorname{sim}$ & $\operatorname{sim}$ & $n$ & $n$ & $n$ & $\operatorname{sim}$ \\
\hline 51 & 28 & $\mathrm{n}$ & $\operatorname{sim}$ & $\mathrm{n}$ & $\mathrm{n}$ & $\mathrm{n}$ & $\mathrm{n}$ & $\operatorname{sim}$ \\
\hline 52 & 20 & $\operatorname{sim}$ & $\operatorname{sim}$ & $\operatorname{sim}$ & $\mathrm{n}$ & $\mathrm{n}$ & $\mathrm{n}$ & $\operatorname{sim}$ \\
\hline 53 & 25 & $\operatorname{sim}$ & $\operatorname{sim}$ & $\operatorname{sim}$ & $\operatorname{sim}$ & $\mathrm{n}$ & $\mathrm{n}$ & $\mathrm{n}$ \\
\hline 54 & 33 & $\operatorname{sim}$ & $\operatorname{sim}$ & $\operatorname{sim}$ & $\operatorname{sim}$ & $\mathrm{n}$ & $\mathrm{n}$ & $n$ \\
\hline 55 & 61 & $\operatorname{sim}$ & $\operatorname{sim}$ & $\operatorname{sim}$ & $\mathrm{n}$ & $n$ & $\mathrm{n}$ & $\operatorname{sim}$ \\
\hline 56 & 72 & $\operatorname{sim}$ & $\operatorname{sim}$ & $\mathrm{n}$ & $\mathrm{n}$ & $n$ & $\mathrm{n}$ & $\operatorname{sim}$ \\
\hline 57 & 20 & $\operatorname{sim}$ & $\operatorname{sim}$ & $n$ & $\mathrm{n}$ & $\mathrm{n}$ & $\mathrm{n}$ & $\operatorname{sim}$ \\
\hline 58 & 46 & $\operatorname{sim}$ & $\operatorname{sim}$ & $\operatorname{sim}$ & $n$ & $n$ & $n$ & $\operatorname{sim}$ \\
\hline 59 & 24 & $\operatorname{sim}$ & $\operatorname{sim}$ & $\mathrm{n}$ & $n$ & $n$ & $n$ & $\operatorname{sim}$ \\
\hline 60 & 13 & $\operatorname{sim}$ & $\operatorname{sim}$ & $\mathrm{n}$ & $n$ & $n$ & $\mathrm{n}$ & $\operatorname{sim}$ \\
\hline 61 & 21 & $\operatorname{sim}$ & $\operatorname{sim}$ & $\mathrm{n}$ & $\mathrm{n}$ & $\mathrm{n}$ & $\mathrm{n}$ & $\operatorname{sim}$ \\
\hline 62 & 15 & $\operatorname{sim}$ & $\operatorname{sim}$ & $\operatorname{sim}$ & $\operatorname{sim}$ & $n$ & $\mathrm{n}$ & $n$ \\
\hline 63 & 41 & $\operatorname{sim}$ & $\operatorname{sim}$ & $\operatorname{sim}$ & $\mathrm{n}$ & $n$ & $\mathrm{n}$ & $\operatorname{sim}$ \\
\hline 64 & 52 & $\mathrm{n}$ & $\operatorname{sim}$ & $\mathrm{n}$ & $\operatorname{sim}$ & $\operatorname{sim}$ & $\mathrm{n}$ & $\mathrm{n}$ \\
\hline 65 & 66 & $\operatorname{sim}$ & $\operatorname{sim}$ & $\operatorname{sim}$ & $n$ & $n$ & $\mathrm{n}$ & $\operatorname{sim}$ \\
\hline 66 & 37 & $\operatorname{sim}$ & $\operatorname{sim}$ & $\operatorname{sim}$ & $n$ & $\mathrm{n}$ & $n$ & $\operatorname{sim}$ \\
\hline 67 & 20 & $\operatorname{sim}$ & $\operatorname{sim}$ & $\operatorname{sim}$ & $\mathrm{n}$ & $n$ & $\mathrm{n}$ & $\operatorname{sim}$ \\
\hline 68 & 44 & $\operatorname{sim}$ & $\operatorname{sim}$ & $\mathrm{n}$ & $\mathrm{n}$ & $\mathrm{n}$ & $\mathrm{n}$ & $\operatorname{sim}$ \\
\hline 69 & 18 & $\operatorname{sim}$ & $\operatorname{sim}$ & $\mathrm{n}$ & $n$ & $n$ & $n$ & $\operatorname{sim}$ \\
\hline 70 & 24 & $\operatorname{sim}$ & $\operatorname{sim}$ & $\operatorname{sim}$ & $\mathrm{n}$ & $n$ & $n$ & $\operatorname{sim}$ \\
\hline 71 & 25 & $\operatorname{sim}$ & $\operatorname{sim}$ & $\operatorname{sim}$ & $\operatorname{sim}$ & $\mathrm{n}$ & $n$ & $n$ \\
\hline 72 & 38 & $\mathrm{n}$ & $\operatorname{sim}$ & $\operatorname{sim}$ & $\mathrm{n}$ & $\mathrm{n}$ & $\mathrm{n}$ & $\operatorname{sim}$ \\
\hline 73 & 28 & $\mathrm{n}$ & $\operatorname{sim}$ & $\mathrm{n}$ & $\operatorname{sim}$ & $\mathrm{n}$ & $\operatorname{sim}$ & $\mathrm{n}$ \\
\hline 74 & 47 & $\operatorname{sim}$ & $\mathrm{n}$ & $\mathrm{n}$ & $\mathrm{n}$ & $\mathrm{n}$ & $\mathrm{n}$ & $\operatorname{sim}$ \\
\hline
\end{tabular}




\begin{tabular}{|c|c|c|c|c|c|c|c|c|}
\hline Úlceras & Dia da alta & $\begin{array}{l}\text { Inib das } \\
\text { protein }\end{array}$ & VitC & $\begin{array}{l}\text { Debrid/ } \\
\text { cauter }\end{array}$ & Antibio & Anti-in & Atropina $1 \%$ & Sem \\
\hline 76 & 28 & $\operatorname{sim}$ & $\operatorname{sim}$ & $\operatorname{sim}$ & $\operatorname{sim}$ & $\mathrm{n}$ & $\mathrm{n}$ & $\mathrm{n}$ \\
\hline 77 & 28 & $\operatorname{sim}$ & $\operatorname{sim}$ & $\operatorname{sim}$ & $\operatorname{sim}$ & $\mathrm{n}$ & $\mathrm{n}$ & $n$ \\
\hline 78 & 48 & $\operatorname{sim}$ & $\mathrm{n}$ & $\mathrm{n}$ & $\mathrm{n}$ & $\mathrm{n}$ & $\mathrm{n}$ & $\operatorname{sim}$ \\
\hline 79 & 48 & $\operatorname{sim}$ & $\mathrm{n}$ & $\mathrm{n}$ & $\mathrm{n}$ & $\mathrm{n}$ & $\mathrm{n}$ & $\operatorname{sim}$ \\
\hline 80 & 30 & $\operatorname{sim}$ & $\operatorname{sim}$ & $\operatorname{sim}$ & $\mathrm{n}$ & $\mathrm{n}$ & $\mathrm{n}$ & $\operatorname{sim}$ \\
\hline 81 & 19 & $\operatorname{sim}$ & $\operatorname{sim}$ & $\operatorname{sim}$ & $\operatorname{sim}$ & $\mathrm{n}$ & $\operatorname{sim}$ & $\mathrm{n}$ \\
\hline 82 & 13 & $\operatorname{sim}$ & $\operatorname{sim}$ & $\operatorname{sim}$ & $\mathrm{n}$ & $\mathrm{n}$ & $\mathrm{n}$ & $\operatorname{sim}$ \\
\hline 83 & 60 & $\operatorname{sim}$ & $\operatorname{sim}$ & $\mathrm{n}$ & $\mathrm{n}$ & $\mathrm{n}$ & $\mathrm{n}$ & $\operatorname{sim}$ \\
\hline 84 & 17 & $\operatorname{sim}$ & $\mathrm{n}$ & $\operatorname{sim}$ & $\operatorname{sim}$ & $\mathrm{n}$ & $\mathrm{n}$ & $\mathrm{n}$ \\
\hline 85 & 20 & $\operatorname{sim}$ & $\operatorname{sim}$ & $\operatorname{sim}$ & $\mathrm{n}$ & $\mathrm{n}$ & $\mathrm{n}$ & $\operatorname{sim}$ \\
\hline 86 & 27 & $\operatorname{sim}$ & $\operatorname{sim}$ & $\mathrm{n}$ & $\operatorname{sim}$ & $n$ & $\mathrm{n}$ & $n$ \\
\hline 87 & 69 & $\operatorname{sim}$ & $\operatorname{sim}$ & $n$ & $\operatorname{sim}$ & $\operatorname{sim}$ & $\operatorname{sim}$ & $n$ \\
\hline 88 & 75 & $\operatorname{sim}$ & $\operatorname{sim}$ & $\mathrm{n}$ & $\operatorname{sim}$ & $\operatorname{sim}$ & $\operatorname{sim}$ & $n$ \\
\hline 89 & 44 & $\operatorname{sim}$ & $\operatorname{sim}$ & $\operatorname{sim}$ & $\operatorname{sim}$ & $\mathrm{n}$ & $\mathrm{n}$ & $\mathrm{n}$ \\
\hline 90 & 9 & $\operatorname{sim}$ & $\mathrm{n}$ & $\operatorname{sim}$ & $\operatorname{sim}$ & $\mathrm{n}$ & $\mathrm{n}$ & $\mathrm{n}$ \\
\hline 91 & 32 & $\operatorname{sim}$ & $\mathrm{n}$ & $\operatorname{sim}$ & $\mathrm{n}$ & $\mathrm{n}$ & $\operatorname{sim}$ & $\mathrm{n}$ \\
\hline 92 & 34 & $\operatorname{sim}$ & $\operatorname{sim}$ & $\mathrm{n}$ & sim & $\mathrm{n}$ & $\mathrm{n}$ & $\mathrm{n}$ \\
\hline 93 & 14 & $\operatorname{sim}$ & $\mathrm{n}$ & $\operatorname{sim}$ & $\operatorname{sim}$ & $\mathrm{n}$ & $\operatorname{sim}$ & $\mathrm{n}$ \\
\hline 94 & 20 & $\operatorname{sim}$ & $\operatorname{sim}$ & $\operatorname{sim}$ & $\operatorname{sim}$ & $\mathrm{n}$ & $\mathrm{n}$ & $\mathrm{n}$ \\
\hline 95 & 18 & $\operatorname{sim}$ & $\operatorname{sim}$ & $\operatorname{sim}$ & $\mathrm{n}$ & $n$ & $\mathrm{n}$ & $\operatorname{sim}$ \\
\hline 96 & 14 & $\operatorname{sim}$ & $\operatorname{sim}$ & $\operatorname{sim}$ & $\mathrm{n}$ & $n$ & $\mathrm{n}$ & $\operatorname{sim}$ \\
\hline 97 & 23 & $\operatorname{sim}$ & $\operatorname{sim}$ & $\mathrm{n}$ & $\mathrm{n}$ & $n$ & $\mathrm{n}$ & $\operatorname{sim}$ \\
\hline 98 & 23 & $\operatorname{sim}$ & $\operatorname{sim}$ & $\mathrm{n}$ & $\mathrm{n}$ & $\mathrm{n}$ & $\mathrm{n}$ & $\operatorname{sim}$ \\
\hline 99 & 24 & $\operatorname{sim}$ & $\operatorname{sim}$ & $\operatorname{sim}$ & $\mathrm{n}$ & $n$ & $\mathrm{n}$ & $\operatorname{sim}$ \\
\hline 100 & 7 & $\operatorname{sim}$ & $\operatorname{sim}$ & $\mathrm{n}$ & $\operatorname{sim}$ & $\mathrm{n}$ & $\operatorname{sim}$ & $\mathrm{n}$ \\
\hline 101 & 50 & $\operatorname{sim}$ & $\mathrm{n}$ & $\operatorname{sim}$ & $\operatorname{sim}$ & $\operatorname{sim}$ & $\operatorname{sim}$ & $\mathrm{n}$ \\
\hline 102 & 75 & $\operatorname{sim}$ & $\operatorname{sim}$ & $\operatorname{sim}$ & $\operatorname{sim}$ & $n$ & $\mathrm{n}$ & $\mathrm{n}$ \\
\hline 103 & 8 & $\operatorname{sim}$ & $\mathrm{n}$ & $\operatorname{sim}$ & $\operatorname{sim}$ & $\mathrm{n}$ & $\operatorname{sim}$ & $\mathrm{n}$ \\
\hline 104 & 30 & $\operatorname{sim}$ & $\operatorname{sim}$ & $\mathrm{n}$ & $\operatorname{sim}$ & $\mathrm{n}$ & $\mathrm{n}$ & $\mathrm{n}$ \\
\hline 105 & 20 & $\operatorname{sim}$ & $\operatorname{sim}$ & $\mathrm{n}$ & $\mathrm{n}$ & $\mathrm{n}$ & $\mathrm{n}$ & $\operatorname{sim}$ \\
\hline 106 & 23 & $\operatorname{sim}$ & $\operatorname{sim}$ & $\operatorname{sim}$ & $\mathrm{n}$ & $n$ & $\mathrm{n}$ & $\operatorname{sim}$ \\
\hline 107 & 19 & $\operatorname{sim}$ & $\operatorname{sim}$ & $\operatorname{sim}$ & $\mathrm{n}$ & $\mathrm{n}$ & $\mathrm{n}$ & $\operatorname{sim}$ \\
\hline 108 & 20 & $\operatorname{sim}$ & $\operatorname{sim}$ & $\operatorname{sim}$ & $\mathrm{n}$ & $\mathrm{n}$ & $\mathrm{n}$ & $\operatorname{sim}$ \\
\hline 109 & 19 & $\operatorname{sim}$ & $n$ & $\operatorname{sim}$ & $\operatorname{sim}$ & $\mathrm{n}$ & $n$ & $n$ \\
\hline 110 & 22 & $\operatorname{sim}$ & $\mathrm{n}$ & $\operatorname{sim}$ & $\operatorname{sim}$ & $\operatorname{sim}$ & $n$ & $n$ \\
\hline 111 & 28 & $\operatorname{sim}$ & $\operatorname{sim}$ & $n$ & $\mathrm{n}$ & $\mathrm{n}$ & $\mathrm{n}$ & $\operatorname{sim}$ \\
\hline 112 & 15 & $\operatorname{sim}$ & $\operatorname{sim}$ & $\operatorname{sim}$ & $\mathrm{n}$ & $\operatorname{sim}$ & $\operatorname{sim}$ & $\mathrm{n}$ \\
\hline 113 & 14 & $\mathrm{n}$ & $\mathrm{n}$ & $\operatorname{sim}$ & $\operatorname{sim}$ & $\mathrm{n}$ & $\mathrm{n}$ & $\mathrm{n}$ \\
\hline
\end{tabular}




\begin{tabular}{|c|c|c|c|c|c|c|c|c|}
\hline Úlceras & Dia da alta & $\begin{array}{l}\text { Inib das } \\
\text { protein }\end{array}$ & VitC & $\begin{array}{l}\text { Debrid/ } \\
\text { cauter }\end{array}$ & Antibio & Anti-in & Atropina 1\% & Sem \\
\hline 115 & 7 & $\operatorname{sim}$ & $\operatorname{sim}$ & $\operatorname{sim}$ & $\mathrm{n}$ & $n$ & $\mathrm{n}$ & $\operatorname{sim}$ \\
\hline 116 & 20 & $\operatorname{sim}$ & $\operatorname{sim}$ & $\mathrm{n}$ & $\mathrm{n}$ & $\mathrm{n}$ & $\mathrm{n}$ & $\operatorname{sim}$ \\
\hline 117 & 46 & $\operatorname{sim}$ & $\operatorname{sim}$ & $\mathrm{n}$ & $\mathrm{n}$ & $\mathrm{n}$ & $\mathrm{n}$ & $\operatorname{sim}$ \\
\hline 118 & 22 & $\operatorname{sim}$ & $\operatorname{sim}$ & $\mathrm{n}$ & $\operatorname{sim}$ & $\mathrm{n}$ & $\mathrm{n}$ & $\mathrm{n}$ \\
\hline 119 & 36 & $\operatorname{sim}$ & $\operatorname{sim}$ & $\operatorname{sim}$ & $\mathrm{n}$ & $\mathrm{n}$ & $\mathrm{n}$ & $\operatorname{sim}$ \\
\hline 120 & 24 & $\operatorname{sim}$ & $\operatorname{sim}$ & $\mathrm{n}$ & $\mathrm{n}$ & $\mathrm{n}$ & $\mathrm{n}$ & $\operatorname{sim}$ \\
\hline 121 & 36 & $\operatorname{sim}$ & $\mathrm{n}$ & $\mathrm{n}$ & $\operatorname{sim}$ & $\mathrm{n}$ & $\mathrm{n}$ & $\mathrm{n}$ \\
\hline 122 & 30 & $\operatorname{sim}$ & $\operatorname{sim}$ & $\operatorname{sim}$ & $\mathrm{n}$ & $\mathrm{n}$ & $\mathrm{n}$ & $\operatorname{sim}$ \\
\hline 123 & 64 & $\operatorname{sim}$ & $\operatorname{sim}$ & $\operatorname{sim}$ & $\operatorname{sim}$ & $\mathrm{n}$ & $\mathrm{n}$ & $\mathrm{n}$ \\
\hline 124 & 29 & $\operatorname{sim}$ & $\operatorname{sim}$ & $\mathrm{n}$ & $\mathrm{n}$ & $\mathrm{n}$ & $\mathrm{n}$ & $\operatorname{sim}$ \\
\hline 125 & 7 & $\operatorname{sim}$ & $\operatorname{sim}$ & $\operatorname{sim}$ & $\mathrm{n}$ & $\mathrm{n}$ & $\mathrm{n}$ & $\operatorname{sim}$ \\
\hline 126 & 16 & $\operatorname{sim}$ & $\operatorname{sim}$ & $\operatorname{sim}$ & $\mathrm{n}$ & $\mathrm{n}$ & $\mathrm{n}$ & $\operatorname{sim}$ \\
\hline 127 & 28 & $\operatorname{sim}$ & $\operatorname{sim}$ & $\mathrm{n}$ & $\operatorname{sim}$ & $\mathrm{n}$ & $\operatorname{sim}$ & $n$ \\
\hline 128 & 20 & $\operatorname{sim}$ & $\operatorname{sim}$ & $\operatorname{sim}$ & $\operatorname{sim}$ & $n$ & $n$ & $n$ \\
\hline 129 & 55 & $\operatorname{sim}$ & $\operatorname{sim}$ & $\operatorname{sim}$ & $\operatorname{sim}$ & $n$ & $n$ & $\mathrm{n}$ \\
\hline 130 & 50 & $n$ & $n$ & $\operatorname{sim}$ & $n$ & $\operatorname{sim}$ & $n$ & $n$ \\
\hline 131 & 28 & $\operatorname{sim}$ & $\operatorname{sim}$ & $\operatorname{sim}$ & $\operatorname{sim}$ & $n$ & $n$ & $n$ \\
\hline 132 & 120 & $\operatorname{sim}$ & $\operatorname{sim}$ & $n$ & $\operatorname{sim}$ & $\operatorname{sim}$ & $\operatorname{sim}$ & $n$ \\
\hline 133 & 42 & $\operatorname{sim}$ & $\operatorname{sim}$ & $n$ & $\operatorname{sim}$ & $\operatorname{sim}$ & $n$ & $n$ \\
\hline 134 & 19 & $n$ & $\operatorname{sim}$ & $\operatorname{sim}$ & $\operatorname{sim}$ & $n$ & $n$ & $n$ \\
\hline 135 & 35 & $\operatorname{sim}$ & $\operatorname{sim}$ & $n$ & $\operatorname{sim}$ & $n$ & $\mathrm{n}$ & $\mathrm{n}$ \\
\hline 136 & 20 & $\operatorname{sim}$ & $\operatorname{sim}$ & $\operatorname{sim}$ & $\operatorname{sim}$ & $n$ & $n$ & $n$ \\
\hline 137 & 20 & $\operatorname{sim}$ & $\operatorname{sim}$ & $\operatorname{sim}$ & $\operatorname{sim}$ & $n$ & $n$ & $n$ \\
\hline 138 & 48 & $\operatorname{sim}$ & $\operatorname{sim}$ & $n$ & $\operatorname{sim}$ & $n$ & $\operatorname{sim}$ & $\mathrm{n}$ \\
\hline 139 & 48 & $\operatorname{sim}$ & $\operatorname{sim}$ & $n$ & $\operatorname{sim}$ & $n$ & $\operatorname{sim}$ & $\mathrm{n}$ \\
\hline 140 & 25 & $\operatorname{sim}$ & $n$ & $\operatorname{sim}$ & $\operatorname{sim}$ & $n$ & $n$ & $n$ \\
\hline 141 & 26 & $\operatorname{sim}$ & $\operatorname{sim}$ & $\mathrm{n}$ & $\mathrm{n}$ & $\mathrm{n}$ & $\mathrm{n}$ & $\operatorname{sim}$ \\
\hline 142 & 19 & $\operatorname{sim}$ & $\operatorname{sim}$ & $\operatorname{sim}$ & $\operatorname{sim}$ & $\mathrm{n}$ & $\mathrm{n}$ & $\mathrm{n}$ \\
\hline
\end{tabular}

